\title{
Transcriptional Regulation of human Plasminogen Activator Inhibitor-1 Gene Expression \\ by Insulin-like Growth Factor-1, Insulin and Upstream Stimulatory Factor-2
}

\author{
Dissertation \\ zur Erlangung des Doktorgrades \\ der Mathematisch-Naturwissenschaftlichen Fakultäten \\ der Georg-August-Universität zu Göttingen
}

vorgelegt von

Elitsa Yosifova Dimova

aus Sofia, Bulgarien

Göttingen 2005 
D 7

Referent:

Prof. Dr. D. Doenecke

Korreferent:

Prof. Dr. R. Hardeland

Tag der mündlichen Prüfung:

26.04.2005 
to my parents 
INDEX

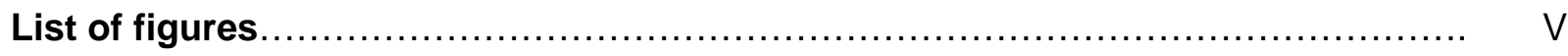

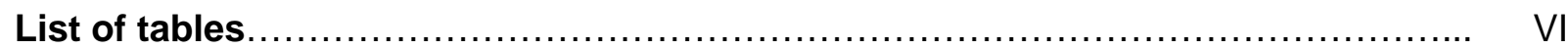

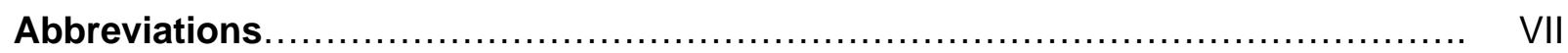

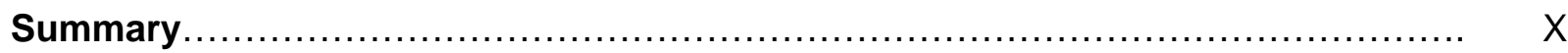

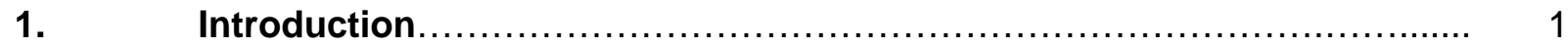

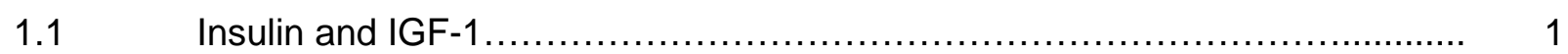

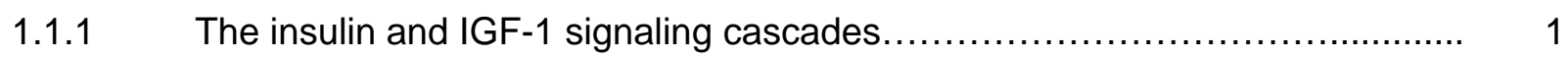

1.1.2 Regulation of gene transcription by insulin and IGF-1 $\ldots \ldots \ldots \ldots \ldots \ldots \ldots \ldots \ldots \ldots$

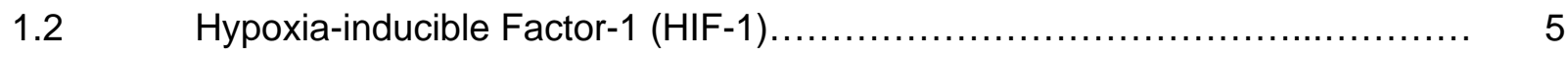

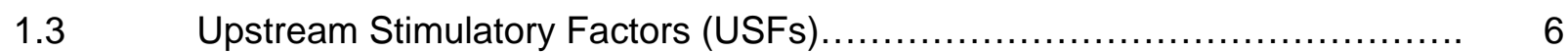

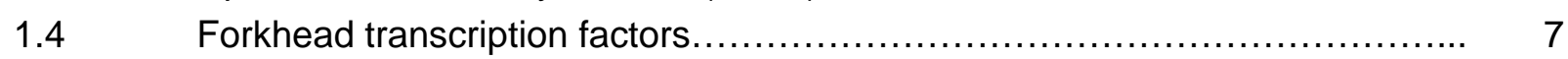

$1.5 \quad$ The fibrinolytic system and plasminogen activator inhibitor-1 (PAl-1) ........ 8

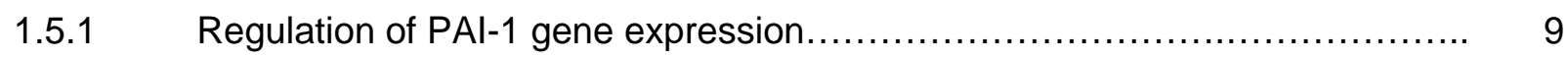

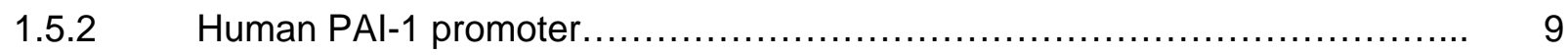

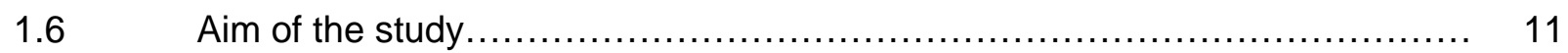

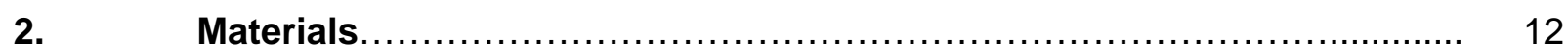

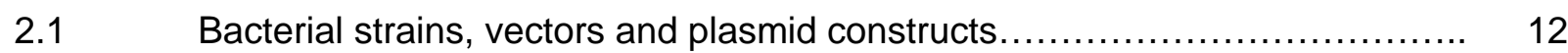

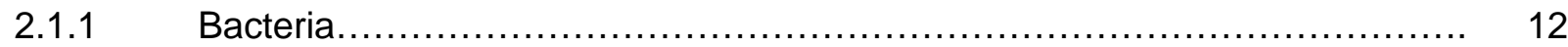

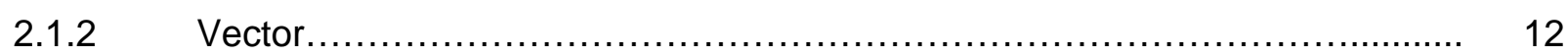

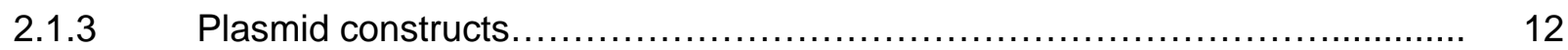

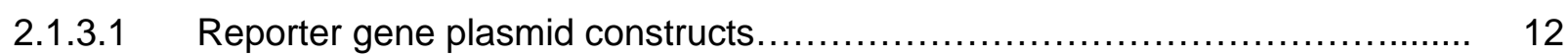

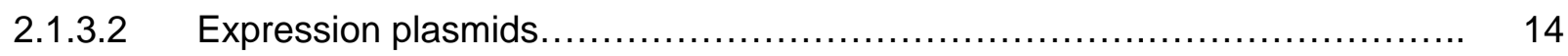

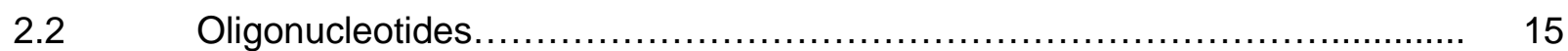

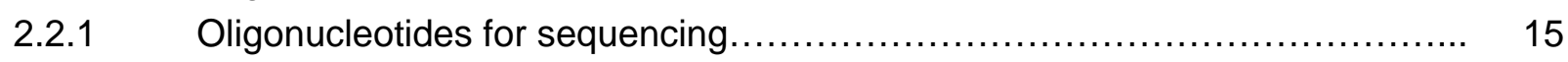

2.2.2 Oligonucleotides for Electrophoretic Mobility Shift Assay (EMSA)............. 15

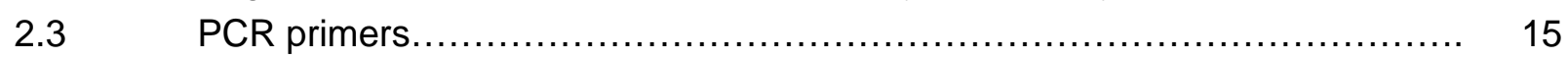

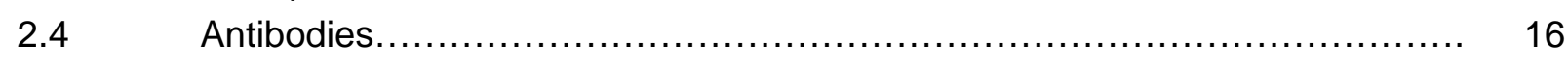

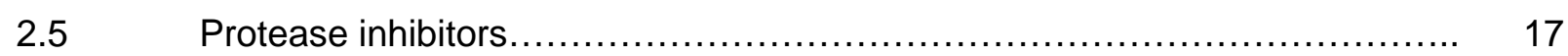

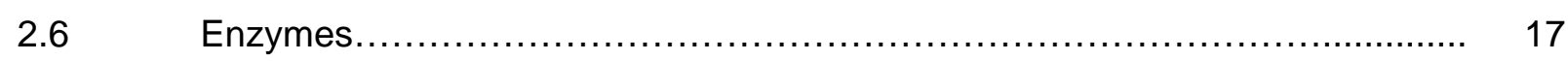

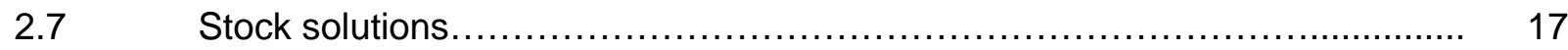

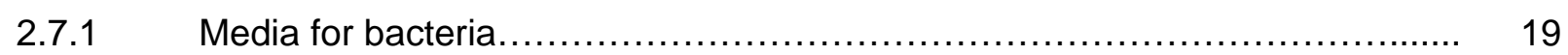

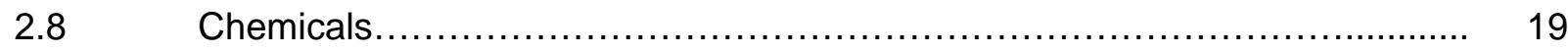

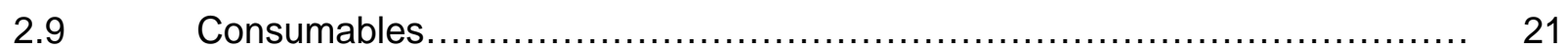

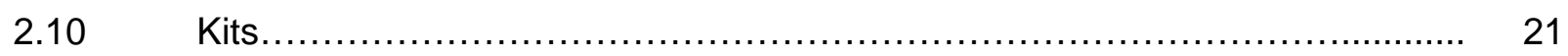

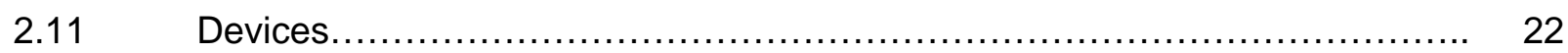

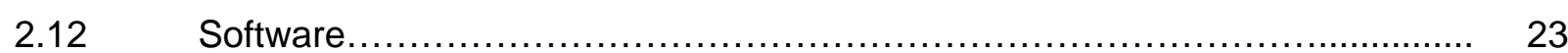




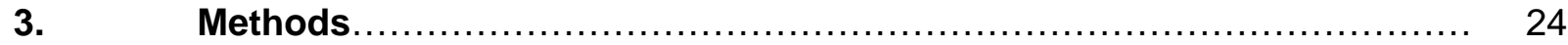

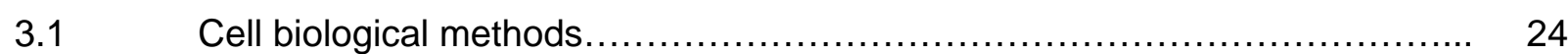

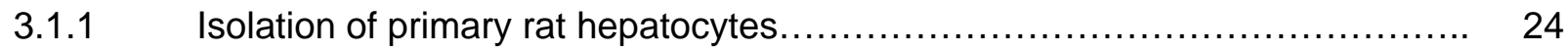

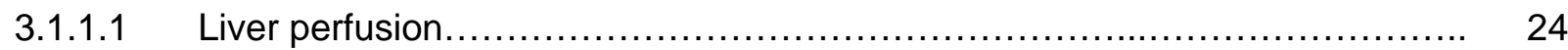

3.1.1.2 Preparation of hepatocyte suspension................................... 24

3.1.1.3 Mediums and solutions for hepatocyte preparation and culture.................. 25

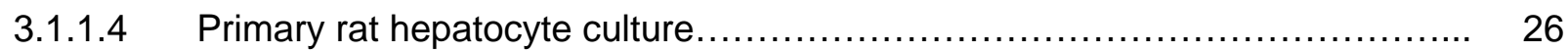

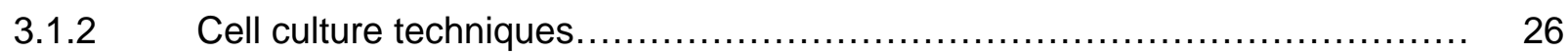

3.1.2.1 Culture of HepG2 and H4IIE cell lines.......................................... 26

3.1.3 Calcium phosphate transfection........................................... 26

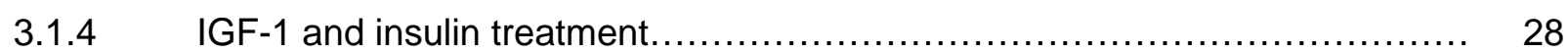

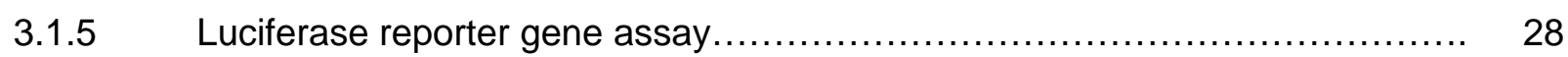

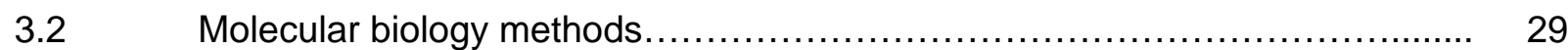

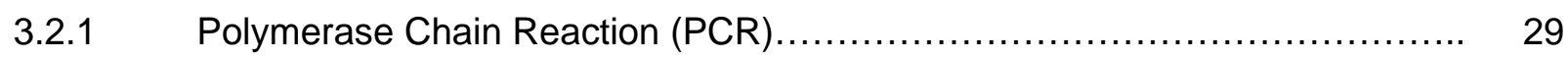

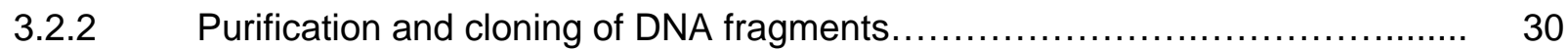

3.2.2.1 Fill-in of 3'-overhangs with Klenow fragment of DNA polymerase I.............. 30

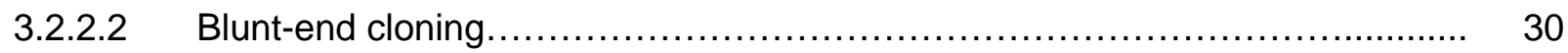

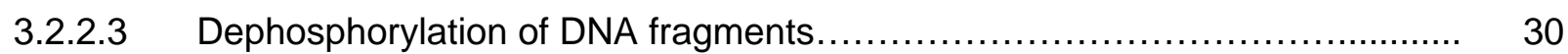

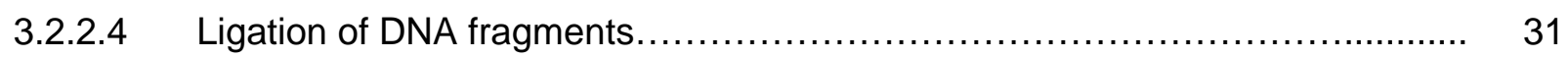

3.2.3 Preparation of competent Escherichia coli (E.coli) cells................................. 31

3.2.4 Heat-shock transformation of competent cells............................. 32

3.2.5 Transformation of competent cells by electroporation........................ 32

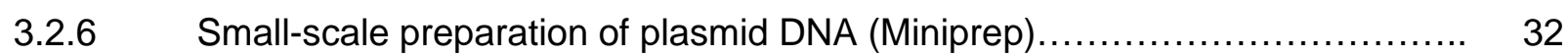

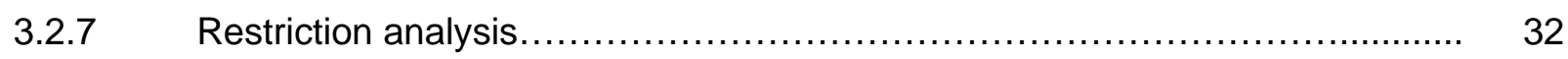

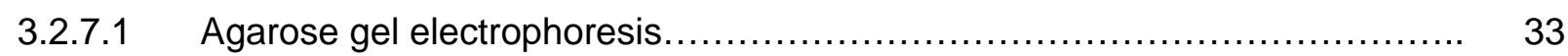

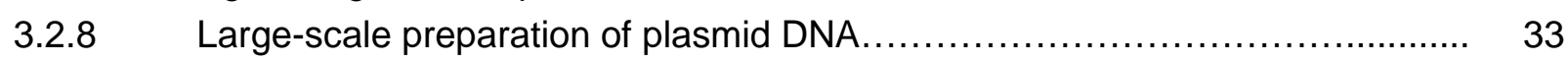

3.2.9 Estimation of nucleic acid concentration ....................................... 33

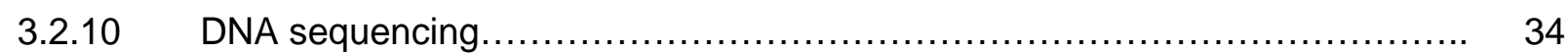

3.2.11 Preparation of digoxigenin-labeled RNA probes............................ 34

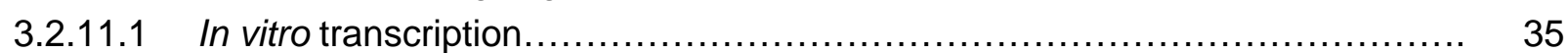

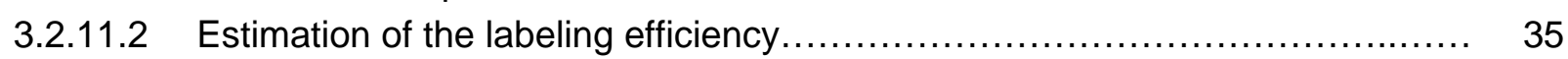

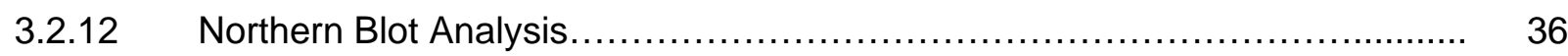

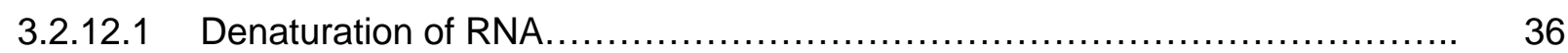

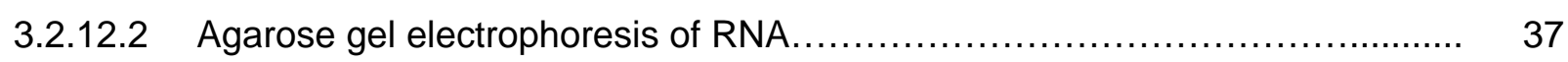

3.2.12.3 Visualization of RNA by ethidium bromide staining ............................. 37

3.2.12.4 Transfer of RNA onto nylon membranes...................................... 37

3.2.12.5 Hybridization of RNA blots with digoxigenin-labeled RNA probes................. 38

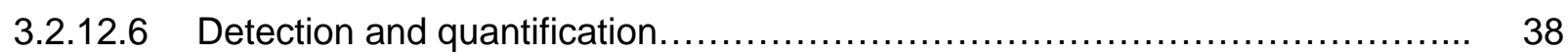

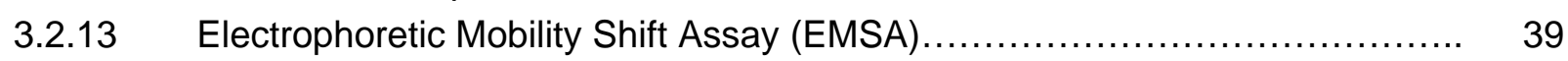

3.2.13.1 Preparation of probes for analysis of DNA-protein binding ..................... 39

3.2.13.2 Preparation of nuclear extracts from HepG2 cells............................. 41

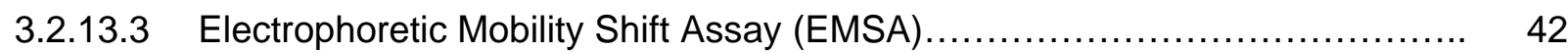

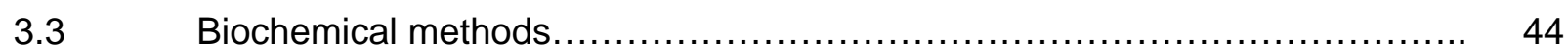

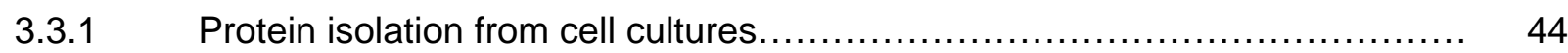




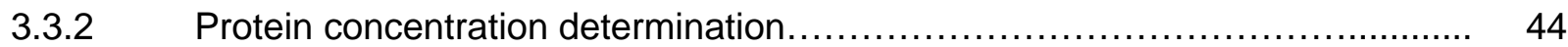

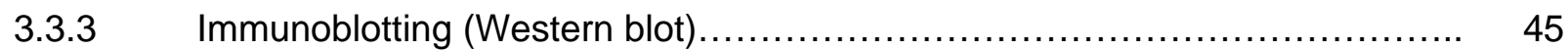

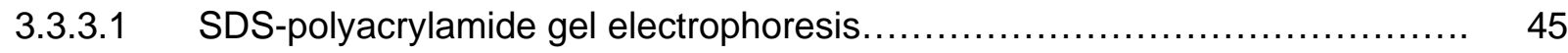

3.3.3.2 Semi-dry transfer of proteins onto a nitrocellulose membrane ................. 46

3.3.3.3 Immunodetection of proteins with specific antibodies....................... 47

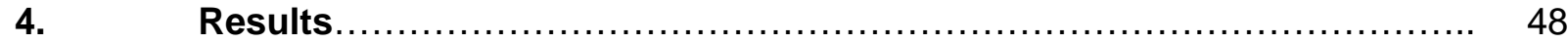

4.1 Induction of human PAI-1 gene expression by IGF-1 and insulin in HepG2

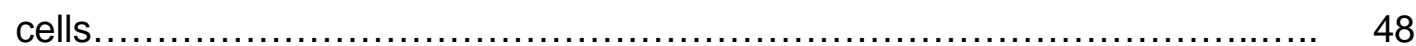

4.1.1 Induction of human PAI-1 mRNA and protein expression by IGF-1 and insulin under normoxia and hypoxia.

4.1.2 IGF-1 facilitates HIF-1 binding to the HRE and E-boxes of the human PAI-1 promoter.

4.1.3 Regulation of the human PAI-1 promoter Luc gene constructs in HepG2 cells

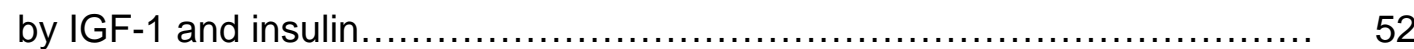

4.1.3.1 IGF-1-activated hPAl-1 promoter Luc gene expression in HepG2 cells........... 52

4.1.3.2 Insulin-activated hPAl-1 promoter Luc gene expression in HepG2 cells........ 52

4.1.3.3 Reduction of insulin-dependent PAI-1 promoter activity under normoxia by mutation of the possible FKHR binding site.

4.1.4 Reduction of the hypoxia-dependent human PAI-1 promoter activity by FKHR proteins in HepG2 cells

4.1.5 Effect of FKHR and FKHR AAA on insulin-dependent PAI-1 promoter activity

4.1.6 Modulation of PAI-1 and HIF-1 $\alpha$ mRNA and protein expression by FKHR and FKHR AAA under normoxia and hypoxia in HepG2 cells.

4.2 Signaling cascades involved in modulation of HIF-1 $\alpha$ protein levels by IGF-1 and insulin....

4.2.1 Time-course of HIF-1 $\alpha$ protein expression under hypoxia and after treatment with IGF-1 and insulin

4.2.2 ERK but not PKB mediates enhancement of HIF-1 $\alpha$ levels by IGF-1.......... 60

4.2.3 Involvement of the MAPK pathway in the enhancement of HIF-1 $\alpha$ levels by insulin

4.2.4 Involvement of the transcription factor USF-2 in insulin-dependent PAI-1 gene expression in HepG2 cells.

4.3 Regulation of the human PAI-1 gene expression by USF-2

4.3.1 Induction of human PAI-1 mRNA and protein expression by USF-2 under normoxia and hypoxia in HepG2 cells.

4.3.2 USF-2 activated human PAI-1 promoter Luc gene constructs in HepG2 cells..

4.3.3 Binding of USF to E-box sequences in the human PAI-1 promoter.....

4.4 Regulation of human and rat PAI-1 promoter Luc gene constructs by wild type and mutant USF-2 in different cell lines.

4.4.1 Regulation of human and rat PAI-1 promoter Luc gene constructs by wild type and mutant USF-2 in primary hepatocytes. 


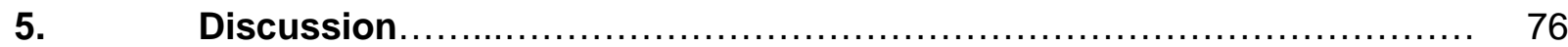

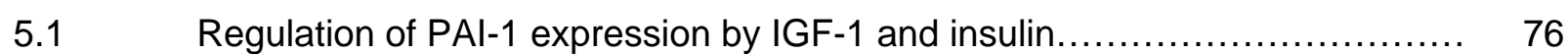

5.1.1 Transcriptional and post-transcriptional regulation of PAI-1 expression by

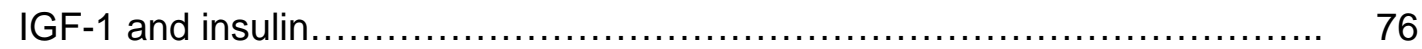

5.1.2 Enhancement of HIF-1 $\alpha$ and PAI-1 by IGF-1 and insulin.................... 77

5.1.2.1 Enhancement of HIF-1 $\alpha$ and PAI-1 by IGF-1 via ERK but not PKB ........... 78

5.1.2.2 Enhancement of HIF-1 $\alpha$ and PAI-1 by insulin via MAP kinase................ 79

5.2 Regulation of PAI-1 promoter activity by Forkhead transcription factor......... 80

$5.3 \quad$ Transcriptional regulation of PAI-1 by USF-2 .......................... 81

5.3.1 Involvement of USF-2 in transcriptional regulation of PAI-1 by insulin.......... 81

5.3.2 USF modulates PAI-1 expression via binding to E-box motifs................. 81

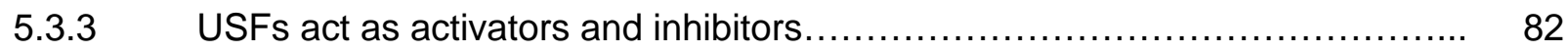

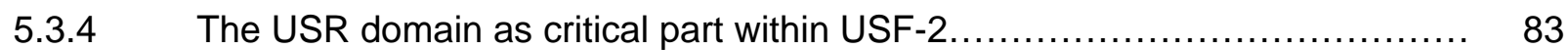

$5.4 \quad$ Regulation of human PAI-1 gene expression by IGF-1, insulin and USF-2 ..... 84

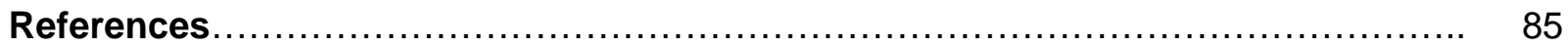

\section{Acknowledgments}

\section{Curriculum vitae}




\section{List of figures}

Figure 1 Insulin and IGF-1 signaling pathway

Figure 2 Structure of HIF-1 $\alpha$ and HIF-1 $\beta$ subunits

Figure 3 Structure of USFs

Figure 4 Structure of the pGL3 basic vector

Figure 5 Human PAI-1 luciferase promoter constructs

Figure 6 IGF-1-dependent increase of human PAI-1 mRNA and protein expression in HepG2 cells

Figure 7 Insulin-dependent increase of human PAI-1 mRNA and protein levels in HepG2 cells

Figure 8 Induction of HIF-1 binding to the HRE, E4 and E5 boxes of the human PAI-1 promoter

Figure 9 Induction of human PAI-1 promoter constructs by IGF-1 in HepG2 cells

Figure 10 Induction of human PAI-1 promoter constructs by insulin in HepG2 cells

Figure 11 Mutation within the putative FKHR binding site abolished induction of human PAI1 promoter activity by insulin under normoxia

Figure 12 Reduction of the hypoxia-mediated induction of the PAI-1 promoter by Forkhead transcription factor

Figure 13 Effect of FKHR and FKHR AAA on insulin-dependent PAI-1 promoter activity

Figure 14 Modulation of PAI-1 and HIF-1 $\alpha$ mRNA and protein levels by FKHR and FKHR AAA

Figure 15 Inhibition of the IGF-1-mediated HIF-1 $\alpha$ induction by the PI3-kinase inhibitor LY294002 and the MEK inhibitor U0126

Figure 16 Regulation of IGF-1-dependent HIF-1 $\alpha$ induction by dominant-negative PDK1, the PKB inhibitor TRB3 and dominant negative Raf

Figure 17 Modulation of the insulin-mediated HIF-1 $\alpha$ induction by the PI3-kinase inhibitor LY294002 and the MEK inhibitor U0126

Figure 18 Regulation of insulin-dependent HIF-1 $\alpha$ induction by dominant-negative PDK1, the PKB inhibitor TRB3 and dominant negative Raf

Figure 19 Induction of PAI-1 promoter activity by insulin and USF-2 in HepG2 cells

Figure 20 USF-dependent increase of human PAI-1 mRNA and protein levels in HepG2 cells

Figure 21 USF-activated human PAI-1 promoter constructs in HepG2 cells

Figure 22 Binding of USF to the E-boxes of the human PAI-1 promoter

Figure 23 Identification of the USF functional domain(s) responsible for the regulation of human and rat PAI-1 gene expression in HepG2 cells

Figure 24 Transcriptional activation of the human and rat PAI-1 promoter constructs by USF in the rat hepatoma cell line H4IIE

Figure 25 Inhibition of the human and rat PAI-1 promoter constructs by USF in primary rat hepatocytes

Figure 26 Model of human PAI-1 gene regulation by IGF-1, insulin and USF-2 under normoxia and hypoxia 


\section{List of tables}

Table 1 Comparison of consensus IRSs

Table 2 Transcriptional regulation of human PAI-1

Table 3 Expression constructs used in this work 
$\alpha$

AA

AC

Akt

Amp

Amp $^{r}$

AP1

approx.

APS

ARNT

ARPE-19

ATP

$\beta$-Gal

$\beta-M E$

BAECS

$\mathrm{bHLH}$

bp

BSA

bZIP

CDNA

CLIF

cpm

CREB

CSPD

C-terminus

DEPC

DIG

DMSO

DNA

DNase

dNTPs

dsDNA

DTT

E. coli

ECL+

EDTA

EMSA

EPAS

EPO

ERK

$\mathrm{EtBr}$

EtOH

FCS

FKHR
Antiserum

aminoacid(s)

Acetate

$\mathrm{PKB}$, homologue of $\mathrm{v}-\mathrm{Akt}$

Ampicillin

Ampicillin resistance

Activator protein 1

approximately

Ammonium persulfate

Arylhydrocarbon receptor-nuclear translocator protein

arising retinal pigment epithelia cell line-19

Adenosine triphosphate

$\beta$-galactosidase

$\beta$-mercaptoethanol

Bovine aortic endothelial cells

Basic helix-loop-helix

basepairs

Bovine serum albumin

basic region / leucine-zipper domain

complementary DNA

Cycle-like factor

counts per minute

cAMP-response element-binding protein

Dinatrium 3-(4-methoxyspiro \{1, 2-dioxetane-3, 2-(5' -chloro) tricyclo

[3.3.1.1 $1^{3,7}$ ] decan\}-4-yl)-phenylphosphate

Carboxyl-terminus

Diethylpyrocarbonate

Digoxigenin

Dimethylsulfoxide

Deoxyribonucleic acid

Deoxyribonuclease

Deoxynucleotide-5'-triphosphates

Double-stranded DNA

Dithiothreitol

Escherichia coli

Enhanced Chemiluminescence ${ }^{\mathrm{TM}}+$ kit

Ethylenediaminotetraacetate

Electrophoretic Mobility Shift Assay

Endothelial PAS domain protein

Erythropoietin

Extracellular signal-regulated kinase

Ethidium bromide

Ethanol

Fetal calf serum

Forkhead transcription factor 


\begin{tabular}{|c|c|}
\hline GH4 cells & Pituitary tumor cells \\
\hline GST & Glutathione S-transferase \\
\hline GTP & Guanosine-5'-triphosphate \\
\hline $\mathrm{HC}$ & Hepatocytes \\
\hline Hepes & N-[2-hydroxyethyl]-piperazine-N'-[2-ethanesulfonic acid] \\
\hline HIF-1 & Hypoxia-inducible factor-1 \\
\hline HRE & Hypoxia responsive element \\
\hline HRP & Horseradish peroxidase \\
\hline HUVEC & human umbilical vein endothelial cells \\
\hline IGF-1 & Insulin-like growth factor-1 \\
\hline IGFBP & Insulin-like growth factor binding protein \\
\hline Ins & Insulin \\
\hline Kan & Kanamycine \\
\hline $\mathrm{Kan}^{\mathrm{r}}$ & Kanamycine resistance \\
\hline IL-1 & Interleukin 1 \\
\hline lacZ & $\beta$-galactosidase gene \\
\hline LB & Luria-Bertani medium \\
\hline Luc & Luciferase \\
\hline LZ & Leucine zipper \\
\hline MAPK & Mitogen-activated protein kinase \\
\hline MCS & Multiple cloning site \\
\hline MOPS & 3-[N-morpholino]-propansulfonic acid \\
\hline mRNA & messenger ribonucleic acid \\
\hline MW & molecular weight \\
\hline NBRE & Nerve growth factor inducible-B protein response element \\
\hline$N F-\kappa B$ & Nuclear factor-kappa B \\
\hline N-terminus & Amino-terminus \\
\hline OD & Optical density \\
\hline $\mathrm{o} / \mathrm{n}$ & overnight \\
\hline PA & Plasminogen activator \\
\hline PAI & Plasminogen activator inhibitor \\
\hline PCR & Polymerase chain reaction \\
\hline PCV & Packed cell volume \\
\hline PDK & 3-phosphatidylnositide-dependent protein kinase \\
\hline PEG & Polyethyleneglycol \\
\hline PEPCK & Phosphoenolpyruvate kinase \\
\hline $\mathrm{PH}$ & Pleckstrin homology \\
\hline $\mathrm{PI}(3) \mathrm{K}$ & Phosphatidylinositol-3-kinase \\
\hline $\mathrm{PI}(4,5) \mathrm{P}_{2}$ & Phosphatidyl-inositol-4,5-biphosphate \\
\hline PKB & Protein kinase B \\
\hline PMSF & Phenylmethylsulfonylfluoride \\
\hline polyA & Polyadenylation signal \\
\hline poly-d(I-C) & Polydeoxyinosine-deoxycytosine \\
\hline PVDF & Polyvinylendifluoride \\
\hline PVP & Polyvinylpolypyrolidone \\
\hline
\end{tabular}




\begin{tabular}{|c|c|}
\hline RNA & Ribonucleic acid \\
\hline RNase A & Ribonuclease A \\
\hline ROS & Reactive oxygen species \\
\hline rpm & rotations per minute \\
\hline RT & Room temperature \\
\hline RTK & Receptor tyrosine kinase \\
\hline RT-PCR & Reverse transcription polymerase chain reaction \\
\hline SAP & Shrimp alkaline phosphatase \\
\hline SDS & Sodium dodecylsulfate \\
\hline SDS-PAGE & Denaturing SDS-polyacrylamide electrophoresis \\
\hline SEM & Standard error of the mean \\
\hline $\mathrm{SH} 2$ & Scr-homology-2 \\
\hline SRE & Smad recognition element \\
\hline Sos1 & Son of sevenless homolog 1 \\
\hline SSC & Standard saline citrate buffer \\
\hline ssDNA & Single-stranded DNA \\
\hline TAD & Transactivation domain \\
\hline TAE & Tris-acetate-EDTA buffer \\
\hline $\mathrm{T}_{\mathrm{ann}}$ & Annealing temperature \\
\hline Taq & Thermophylus aquaticus \\
\hline TBE & Tris-borate-EDTA buffer \\
\hline TEF3 & Translation elongation factor 3 \\
\hline TEMED & N,N,N',N'-tetramethylethylenediamine \\
\hline T4-PNK & T4 polynucleotide kinase \\
\hline Tris & Tris-(hydroxymethyl)-aminomethane \\
\hline TGF- $\beta$ & Tumor growth factor beta \\
\hline TNF- $\alpha$ & Tumor necrosis factor alpha \\
\hline$U$ & Unit (enzyme activity) \\
\hline USF & Upstream stimulatory factor \\
\hline USR & USF-specific region \\
\hline 5'-UTR & 5'-untranslated region \\
\hline UV & Ultraviolet light \\
\hline VEGF & Vascular endothelial growth factor \\
\hline VSMC & vascular smooth muscle cells \\
\hline VHL & Von Hippel-Lindau \\
\hline vol & volume \\
\hline$\%(v / v)$ & volume $\%$ (volume-per-volume) \\
\hline wt & Wild-type \\
\hline$\%(w / v)$ & Weight \% (weight-per-volume) \\
\hline ZIP & Zipper \\
\hline
\end{tabular}




\section{SUMMARY}

The plasminogen activator inhibitor type-1 (PAI-1) inhibits conversion of the proenzyme plasminogen to the active fibrin-degrading protease plasmin by binding and inactivating both tissue-type and urokinase-type plasminogen activators. In addition to its inhibitory effect on fibrinolysis, PAl-1 appears to be a multifunctional protein modulating proteolytic processes associated with pathophysiological conditions such as prethrombotic events, hemorrhage and thrombus formations which are positively correlated with increased PAI-1 plasma levels and hypoxic conditions. Furthermore, insulin-resistant states, associated with hyperinsulinemia, obesity, hypertension and diabetes type 2 are characterized by enhanced PAI-1 levels. Insulin and IGF-1 increase PAI-1 production in several experimental systems, but the molecular mechanisms underlying this effect have not been fully elucidated.

In this study, we investigated the transcriptional mechanisms and the signalling pathways that mediate IGF-1- and insulin-dependent induction of PAI-1 in human HepG2 hepatoma cells. Treatment of HepG2 cells with IGF-1 and insulin enhanced PAI-1 mRNA, protein expression and PAI-1 promoter-Luc reporter activity. We found that mutation of the hypoxia responsive element (HRE), a target for hypoxia-inducible factor-1 (HIF-1), completely abolished the insulindependent PAI-1 promoter activity and nearly abolished the induction by IGF-1. Mutation of E4 and E5 did not affect the IGF-1-dependent induction of PAI-1 promoter constructs under normoxia but abolished the effect of IGF-1 under hypoxia. In addition, E4 and E5 which seem to have a supportive role in the IGF-1- and the hypoxia-dependent, played no role in the insulindependent transcriptional regulation of the PAI-1 gene. We found that IGF-1-induced upregulation of PAI-1 expression was associated with activation of HIF-1 $\alpha$. IGF-1 enhanced HIF$1 \alpha$ protein levels and HIF-1 DNA-binding to HRE, and E-boxes E4 and E5 as shown by EMSAs. Inhibition of either phosphatidylinositol-3-kinase (PI(3)K) by LY294002 or extracellular signalregulated kinase $1 / 2(E R K 1 / 2)$ by $U 0126$ reduced HIF-1 $\alpha$ protein levels, while both inhibitors together completely abolished the IGF-1 effect on HIF-1 $\alpha$. Remarkably, transfection of HepG2 cells with a vector expressing dominant-negative Raf-1 inhibited the IGF-1 effect on HIF$1 \alpha$ while no effect was observed by using dominant-negative 3-phosphatidylnositide-dependent protein kinase 1 (PDK1), or the tribbles homolog TRB3 which inhibits Akt/PKB activation. Thus, IGF-1 activates human PAI-1 gene expression through activation of the PI(3)K and ERK1/2. The insulin-induced enhancement of HIF-1 $\alpha$ protein levels was inhibited by specific $\mathrm{PI}(3) \mathrm{K}$ inhibitors e.g. LY294002 under normoxia and only slightly reduced under hypoxia; thus the role of $\mathrm{PI}(3) \mathrm{K}$ in that process remained uncertain. Moreover, the overexpression of dominantnegative PDK1 as well as TRB3 reduced the basal HIF-1 $\alpha$ protein levels but did not influence 
the insulin-induced HIF-1 $\alpha$ protein levels. Thus, in the case of insulin, activation of PAI-1 expression occurred mainly via the MAPK pathway.

A member of the Forkhead transcription factor (FKHR) family was considered to mediate the insulin effects on PAI-1 transcription. Since the human PAI-1 promoter seems to contain a Forkhead-binding element-like sequence we investigated whether FHKR can influence PAI-1 mRNA, protein expression and PAI-1 promoter activity. Our results demonstrated that FKHR enhanced neither the PAI-1 mRNA and protein levels nor the basal and the insulin-dependent PAl-1 promoter activity.

We found in HepG2 cells that USF-2 induced human PAI-1 gene expression via HRE, E4 and E5. EMSAs showed that E4 and E 5 bound USFs and although the HRE contributed to the USF-dependent regulation of the human PAI-1 gene, it did not bind them. By contrast, USF-2 inhibited PAI-1 promoter activity in primary rat hepatocytes suggesting that PAI-1 expression depends on either the promoter context or the activity of USF which might be cell-type specific. To investigate this, human and rat PAI-1 promoter luciferase constructs were cotransfected in human HepG2 and rat HII4E cells as well as in primary rat hepatocytes together with expression vectors encoding wild-type USF-2 or USF-2 mutants lacking different domains. We found that the different effects of USF on PAI-1 expression depend on the cell-type rather than the promoter context and that the USR domain of USF accounts for the observed effects.

Together, we have shown that IGF-1, insulin and even hypoxia activate human PAI-1 expression through activation of the PI3-kinase and MAPK signaling cascade via the transcription factor HIF-1 binding to HRE indicating a molecular cross talk between these two pathways. We described a different USF-mediated regulation of the PAI-1 gene in hepatoma cells and primary rat hepatocytes showing a cell-type-dependent regulation and revealed the importance of the USR domain for the USF effects, implicating an interaction with a so far unknown cofactor. 


\section{INTRODUCTION}

Molecular oxygen is an essential component of the energy metabolism in all aerobic organisms. Due to its low redox potential it serves mainly as the final electron acceptor in the mitochondrial electron transfer chain, used by the cell for building up the necessary trans-membrane proton gradient to phosphorylate ADP to ATP. Under physiological conditions, the average oxygen tension in arterial blood is between 74 to $104 \mathrm{~mm} \mathrm{Hg}(104-146 \mu \mathrm{mol} / \mathrm{l})$ and in venous blood between 34 to $46 \mathrm{~mm} \mathrm{Hg}(48-64 \mu \mathrm{mol} / \mathrm{l})$. Even a slight reduction in oxygen concentration (hypoxia) elicits both acute and chronic responses. The acute responses often include changes in the activity of existing proteins while long-term responses entail changes in gene expression. In liver, within the smallest functional unit, the acinus, blood flows from the region around the hepatic artery and terminal portal vein (periportal zone) into the sinusoid towards the cells located in the region around the central vein (perivenous zone) (Jungermann \& Kietzmann, 1996; Jungermann et al., 2000). Due to cell metabolism within the sinusoid, oxygen, hormone and substrate gradients are established. The oxygen tension reaches $60-65 \mathrm{~mm} \mathrm{Hg}$ in the periportal area and about $30-35 \mathrm{~mm} \mathrm{Hg}$ in the perivenous zone and appeared that mainly the gradient in oxygen tension functions as a key regulator for zonated gene expression. Insulin is degraded from periportal to perivenous zones (Jungermann \& Kietzmann, 1996) whereas the insulin receptor is predominantly expressed in the perivenous zone (Krones et al., 2001). IGF-1, IGFBP-1 and 2 are also heterogeneously expressed in the liver acinus as the expression of IGF-1 and IGFBP-1 are clearly periportal and that of IGFBP-2 is perivenous (Hazel et al., 1998).

\subsection{Insulin and IGF-1}

\subsubsection{The insulin and IGF-1 signaling cascades}

The insulin and IGF-1 receptors belong to a family of receptor tyrosine kinases (RTK). These receptors are heterotetrameric proteins consisting of two extracellular $\alpha$ - and two transmembrane $\beta$-subunits (Van Obberghen et al., 1981). Binding of insulin/IGF-1 to the $\alpha$ subunit causes conformational changes in the receptor and thereby activation of the tyrosine kinase activity of the $\beta$-subunit. This, in turn, leads to autophosphorylation of tyrosine residues in several regions within the catalytic domain of the $\beta$-subunit which then mediates the tyrosine phosphorylation of the insulin receptor substrate (IRS) proteins (reviewed by White, 1996; Kellerer et al., 1999).

The phosphorylated tyrosines in IRS proteins act as "docking sites" for various signalling proteins containing SH2 (Src-homology-2) domains (Cheatham and Kahn, 1995; White, 1998). One of the proteins binding to IRS is the p85 regulatory subunit of phosphatidylinositol 3-kinase (PI(3)K), which together with the p110 catalytic subunit forms a heterodimer (Fig.1). The p85 
subunit of $\mathrm{PI}(3) \mathrm{K}$ binds to the IRS via its two $\mathrm{SH} 2$ domains. The $\mathrm{p} 110$ catalytic subunit possesses a phospholipid and a serine kinase activity. $\mathrm{PI}(3) \mathrm{K}$ catalyses the phosphorylation of phosphoinositides at the D3 position of the inositol ring generating phosphatidylinositol-3phosphates, especially $\mathrm{PI}(3,4,5) \mathrm{P}_{3}$ (Vanhaesebroeck et al., 1997). $\mathrm{PI}(3,4,5) \mathrm{P}_{3}$ provides an adaptor site for the pleckstrin homology domain $(\mathrm{PH})$ of phosphoinositide-dependent kinase 1 (PDK1) (Cohen et al., 1997, Toker \& Newton, 2000) and protein kinase B (PKB/Akt) (Alessi \& Cohen, 1998). This interaction recruits PDK1 and PKB to the membrane and allows PDK1 to phosphorylate PKB at Thr308 whereas so far unidentified PDK2 mediates the phosphorylation of PKB at Ser473 (Downward, 1998). PKB, in turn, seems to play a crucial role in many of the cellular effects triggered by insulin, glycogen synthase kinase-3 (GSK-3) (Cross et al., 1995, Lawlor \& Alessi, 2001), p70 ribosomal S6 kinase (p70S6 kinase) which is involved in protein synthesis (reviewed by Taha \& Klip, 1999), the proapoptotic BAD (bcl-2 antagonist of cell death) (Datta et al., 1999) as well as transcription factors such as Foxo1 (FKHR) (Brunet et al., 1999), CREB (Du \& Montminy, 1998) and HIF-1 (Kietzmann et al., 2003).

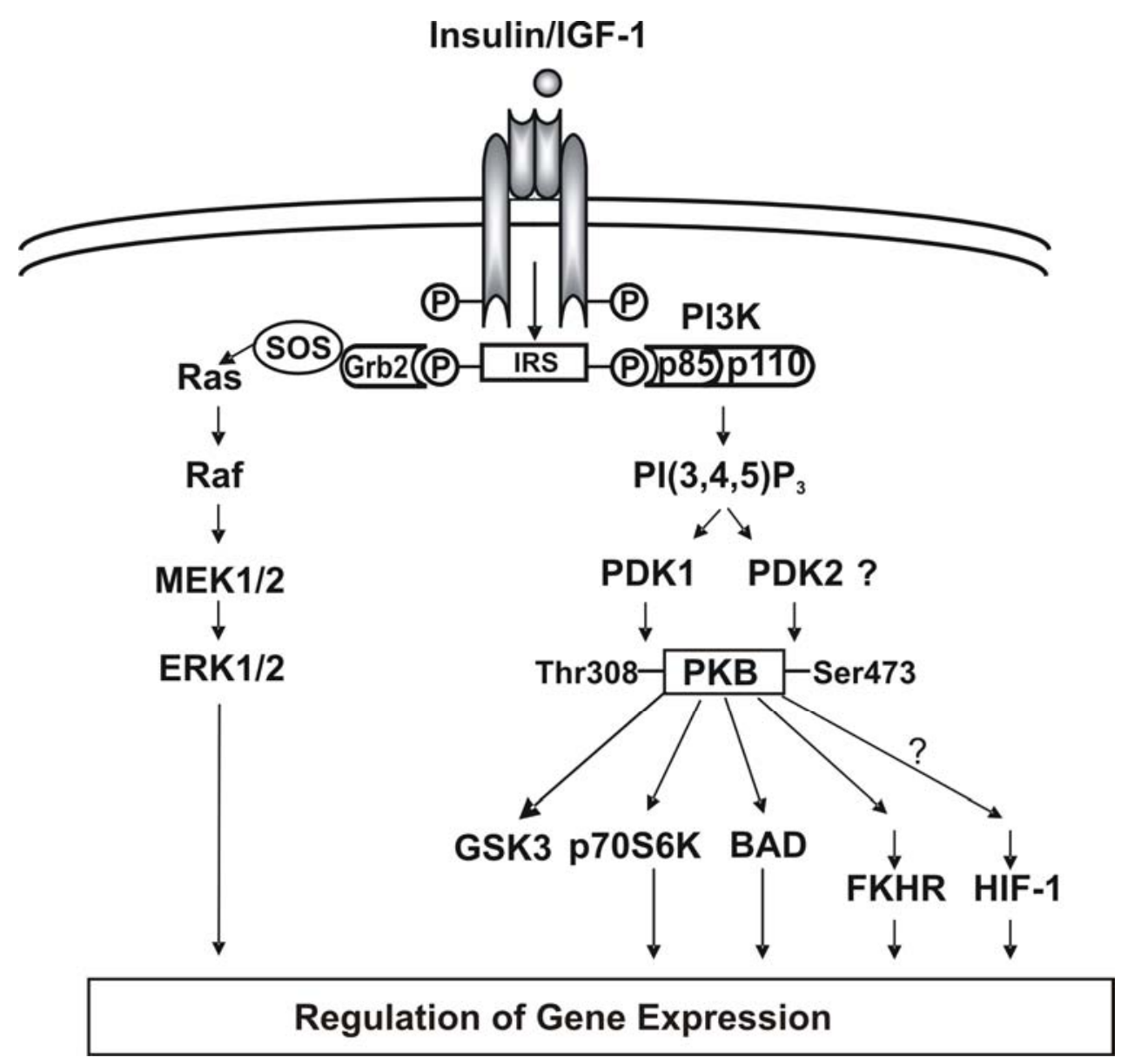

Figure 1. Insulin and IGF-1 signaling pathway (see text for details) 
In addition to the $\mathrm{PI}(3) \mathrm{K} / \mathrm{PKB}$ pathway, insulin and IGF-1 can act also through the Ras/ERKsignaling pathway (Fig. 1) since phosphorylated IRS proteins can also bind $\mathrm{SH} 2$ domains in several small adaptor molecules such as growth factor receptor-bound protein 2 (Grb2) (Skolnik et al., 1993a). Grb2 possesses also two SH3 domains, which bind and activate the guanine nucleotide-exchange protein Son of sevenless homolog 1 (Sos1) that in turn activates p21Ras by stimulating GDP/GTP exchange on Ras (Skolnik et al., 1993 a, b); Cheatham \& Kahn 1995). Activated p21Ras then recruits the Ser/Thr protein kinase Raf-1 to the plasma membrane via direct interaction with its N-terminal region (Pronk \& Bos, 1994). Raf-1 has been demonstrated to activate MEK-1 by phosphorylation on two serine residues (Ser217 and Ser221) (Dent et al, 1992). MEK-1 is dual-specificity protein kinase that activates mitogen-activated protein kinase (MAPK) or Erk 1/2 by phosphorylation at tyrosine (Tyr204) and threonine (Thr202) (Crews et al., 1992). MAP kinase/Erk phosphorylates many different proteins such as p90 ribosomal S6 kinase, phospholipase $A_{2}$, and transcription factors such as ternary complex factor p62 ${ }^{\mathrm{TCF}}$ or HIF-1 $\alpha$ (Fingar \& Birnbaum, 1994; Gille et al., 1992; Richard et al., 1999). Although the MAP kinase pathway is a well-characterized insulin and IGF-1 signaling pathway, it is remains open to what extend $\mathrm{PI}(3) \mathrm{K}$ and MAPK pathways undergo a crosstalk. This is possible since activated Ras can interact directly with PI(3)K (Rodriguez-Viciana et al., 1994). However, it is still unclear whether $\mathrm{PI}(3) \mathrm{K}$ acts upstream or downstream of Ras since both possibilities were proposed (Hu et al., 1995; Rodriguez-Viciana et al., 1996; Marte et al., 1997).

In addition to the kinase pathways, several protein tyrosine phosphatases (PTPases) have been shown to be involved in insulin signaling. An important role seems to play the cytoplasmic phosphatase PTP1B which can associate directly with the activated insulin receptor at multiple phosphotyrosine sites and the dephosphorylation by PTP1B may play a significant role in insulin receptor signal transduction (Seely et al., 1996). Lipid phosphatases such as SHIP2 can also temporarily control insulin action by dephosphorylating $\mathrm{PI}(3,4,5) \mathrm{P}_{3}$ (Kuhne et al., 1994; Vollenweider et al., 1999) which underlines the finding that loss of this enzyme leads to increased sensitivity to insulin (Clement et al., 2001).

\subsubsection{Regulation of gene transcription by insulin and IGF-1}

Regulation of gene transcription by insulin is an important aspect of its action. Insulin can regulate the transcription of a large number of genes either in a positive or in a negative manner (O'Brien \& Granner, 1996). It has long been suggested that the effects of insulin are mediated through a common insulin-responsive element (IRE) and a transcription factor that binds to IRE (Alexander-Bridges et al., 1992, O’Brien \& Granner 1991, O’Brien et al., 1990). However, up to now at least eight distinct IREs have been characterized (Table 1; O'Brien, Hornbuckle et al., 2001) suggesting that there is no single consensus IRE (Chapman et al., 1999; O'Brien \& Granner 2001). 
Various transcription factors have been suggested to mediate the insulin response, including cAMP-response element binding protein (CREB) (Klemm et al., 1998), members of the FoxO subfamily from Forkhead transcription factors family such as Foxo1 (previously known as FKHR, forkhead in rhabdomyosarcoma) (Durham et al., 1999; Vulin \& Stanley, 2003), Foxo3 (previously known as FKHRL1, forkhead in rhabdomyosarcoma like 1) (Brunet et al., 1999) and Foxo4 (previously known as AFX) (Kops et al., 1999) as well as GA binding protein (GABP) (Ouyang et al., 1996), Fra-2/Jun D (Chapman et al., 1999; Streeper et al., 1998), early growth response gene-1 (Egr-1) known also as nerve growth factor I-A, zif 268, or Krox 24 (Barroso \& Santisteban, 1999), hypoxia-inducible factor-1 $\alpha$ (HIF-1 $\alpha$ ) (Kietzmann et al., 2003), insulin response element-A binding protein (IRE-ABP) (Alexander-Bridges et al., 1992), nuclear factor1 (NF-1) (Ortiz et al., 1999), serum response factor (SRF) (Thompson et al., 1994) and upstream stimulatory factors (USFs) (Wang \& Sul, 1995, 1997).

Further, insulin-like growth factor 1 (IGF-1) has some structural homology with proinsulin and shares many signalling components and cellular responses with insulin (Blakesley et al., 1996). IGF-1 can exert acute short-term insulin-like effects on protein and carbohydrate metabolism and long-term growth factor-like effects on cell proliferation, differentiation as well as on apoptosis (review by Furstenberger et al., 2003). Unlike insulin, IGFs are present in most biological fluids as complexes with high affinity binding proteins, the insulin-like growth factor binding proteins (IGFBPs) which modulate binding of IGFs to the IGF receptor.

Table 1. Comparison of consensus IRSs

\begin{tabular}{|c|c|c|c|}
\hline IRE type & Genes & Consensus sequence & $\begin{array}{r}\text { Insulin } \\
\text { effect }\end{array}$ \\
\hline GAPDH IRE-A-like motif & GAPDH; Apo A-I & CCCGCCTC & Positive \\
\hline Serum RE & c-Fos: $\beta$-actin & $\mathrm{CC}(\mathrm{A} / \mathrm{T})_{6} \mathrm{GG}$ & Positive \\
\hline AP-1 motif & $\begin{array}{l}\text { Collagenase-1; } \\
\text { malic enzyme }\end{array}$ & TGA(G/C)TCA & Positive \\
\hline Ets motif & $\begin{array}{l}\text { Prolactin; } \\
\text { somatostatin }\end{array}$ & $(\mathrm{C} / \mathrm{A}) \mathrm{GGA}(\mathrm{A} / \mathrm{T})$ & Positive \\
\hline E-box motif & $\begin{array}{l}\text { Pyruvate kinase; } \\
\text { FAS, rPAI-1, }\end{array}$ & CANNTG & Positive \\
\hline SREBP motif & Glucokinase? & ATCACCCCAC & Positive \\
\hline TTF-2 motif & $\begin{array}{l}\text { Thyroglobulin; } \\
\text { thyroperoxidase }\end{array}$ & $C(T / A)(A / G) A(A / G)(C / A) A A A$ & Positive \\
\hline PEPCK-like motif & $\begin{array}{l}\text { PEPCK; IGFBP-1; } \\
\text { TAT; G6Pase, Apo CIII }\end{array}$ & $\mathrm{T}(\mathrm{G} / \mathrm{A}) \mathrm{TTT}(\mathrm{T} / \mathrm{G})(\mathrm{G} / \mathrm{T})$ & Negative \\
\hline
\end{tabular}


IGF-1 has been shown to increase the expression of various genes like c-fos (Damante et al., 1988), 81-crystallin (Alemany et al., 1990), osteonectin (Thiebaud et al.,1990), VEGF (Goad et al., 1996; Warren et al., 1996), uncoupling protein-3 (UCP-3) (Gustafsson et al., 2004), and PAI1 (Alessi et al., 1988; Kooistra et al., 1989; Anfosso et al., 1990; Schneider \& Sobel; 1991, Padayatty et al., 1993).

Moreover, IGF-1 has been reported to activate nuclear factor-kappa B (NF-kB) and to increase transcription of intercellular adhesion molecule-1 (Balaram et al., 1999) as well as to activate the transcription factor cAMP-response element-binding protein (CREB), which in turn induces the expression of the antiapoptotic factor bcl-2 (Mehrhof et al., 2001). It was also demonstrated that Sp1 was one of the proteins affected by IGF-1 (Jensen et al., 1995; Li et al., 2003) suggesting that transcriptional regulation by IGF-1 involves activation of Sp1.

\subsection{Hypoxia-inducible Factor-1 (HIF-1)}

Hypoxia-inducible factor- 1 is one of the most important proteins involved in the mammalian response to hypoxia and belongs to the basic helix-loop-helix (bHLH) PAS (Per-ARNT-Sim) transcription factors family (Fig. 2). HIF-1 is a dimer of HIF-1 $\alpha$ and HIF-1 $\beta$ also known as "arylhydrocarbon receptor-nuclear translocator", ARNT) and binds the hypoxia-responsive element (HRE) consensus sequence 5'-BACGTSSK-3' (B=G/C/T; $S=G / C ; K=G / T$ ) within the promoters of hypoxia-responsive genes (Kvietikova et al., 1995).

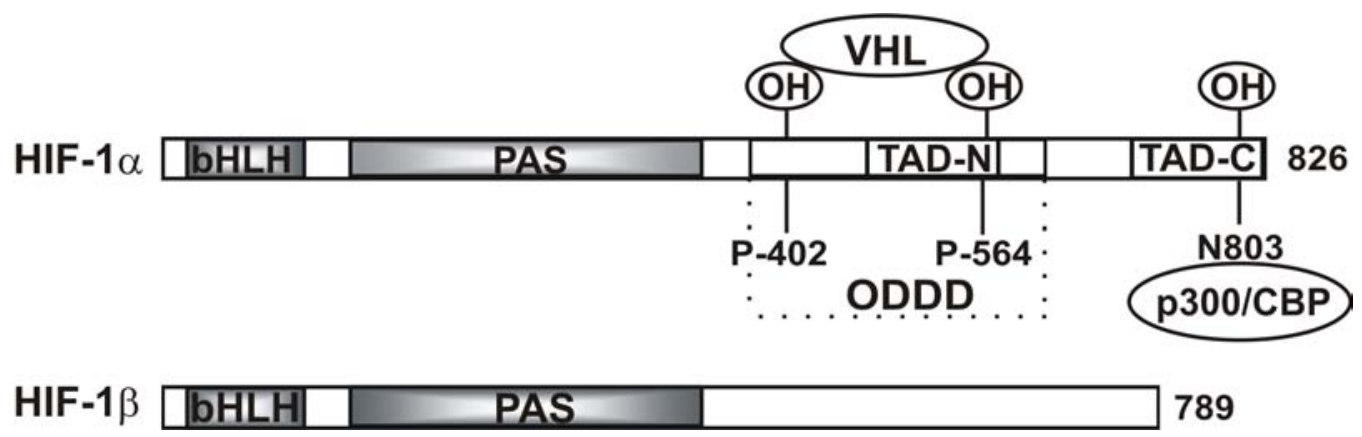

Figure 2. Structure of HIF-1 $\alpha$ and HIF-1 $\beta$ subunits. bHLH, basic helix-loop-helix domain mediates DNA binding and dimerization of the two subunits; PAS, Per-ARNT-Sim, domain also responsible for dimerization; ODDD, aa 401-603, oxygen-dependent degradation domain; under normoxia proline residues at 402 and 564 in ODDD are hydroxylated by proline hydroxylases (PHD 1-3) and recognized by VHL which targets the protein for proteasomal degradation; N-TAD, aa 481-603, N-terminal transactivation domain; C-TAD, aa 776-826, C-terminal transactivation domain; N803, asparagine 803 is critical for binding of p300/CBP which is lost if this residue becomes hydroxylated by FIH under normoxia. 
The expression and transcriptional activity of the HIF-1 $\alpha$ subunit is tightly regulated by the cellular oxygen concentration whereas the HIF-1 $\beta$ subunit is constitutively expressed (Wang et al., 1995). Besides HIF-1 $\alpha$, HIF-2 $\alpha$ and HIF-3 $\alpha$ as well as two other ARNT isoforms (ARNT2 and ARNT3) have been identified (Ema et al., 1997; Flamme et al., 1997; Tian et al., 1997; Gu et al., 1998). They may give rise to the formation of several HIF isoforms composed of different HIF $\alpha$-subunits and ARNT isoforms (reviewed by Wenger, 2002).

Although other HIF isoforms appear to exist, HIF-1 is considered to be the major regulator of physiologically important genes like erythropoietin, vascular endothelial growth factor and PAI-1 (Wang \& Semenza, 1993; Firth et al., 1994; Liu et al., 1995; Forsythe et al., 1996; Kietzmann et al., 1999). Oxygen sensitivity of the HIF-1 complex is conferred only by the HIF-1 $\alpha$ protein via regulation of its protein stability and coactivator recruitment. Both, regulation of protein stability and coactivator recruitment involve hydroxylation reactions carried out by specific prolyl and asparaginyl hydroxylases (Bruick \& McKnight, 2001; Lando et al., 2002). In addition to the $\mathrm{O}_{2}$ dependent hydroxylation reactions which enable binding of the von Hippel-Lindau (VHL) tumor suppressor protein and subsequent proteasomal degradation (Maxwell et al., 1999) it was found that HIF-1 $\alpha$ can be modified by redox factor-1, Ref-1 (Huang et al. 1996) and to interact with coactivators such as CBP/p300, TIE-2 and SRC-1 (Ema et al., 1999; Carrero et al., 2000).

\subsection{Upstream Stimulatory Factors (USFs)}

Upstream stimulatory factors (USFs) belong to the basic helix-loop-helix leucine zipper (bHLHZip) family of transcription factors characterized by a highly conserved C-terminal domain responsible for their dimerization and DNA binding (reviewed by Littlewood \& Evan, 1995) (Fig.3). USF was originally identified in HeLa cells by its ability to bind to the adenovirus major late promoter and to stimulate transcription through the canonical sequence 5 `CANNTG-3` $(\mathrm{N}=\mathrm{A} / \mathrm{G} / \mathrm{C} / \mathrm{T})$, referred to as an "E-box" motif (Sawadogo 1988; Murre et al., 1989). There are several forms of USF described (Sawadogo 1988; Gregor et al., 1990; Sirito et al., 1994; Viollet et al., 1996).

\section{USFs}

EXON 4 EXON 5 USR BR HLH LZ

DNA-binding and dimerization

Transactivation Nuclear localization
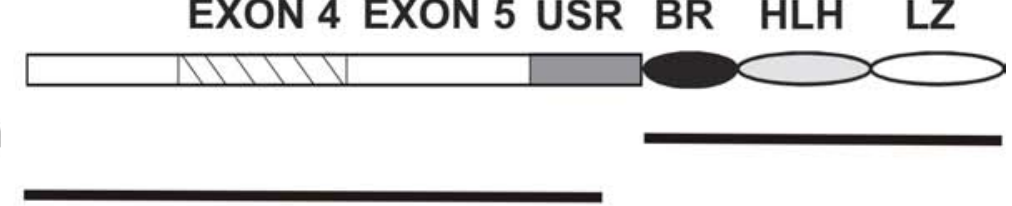

\section{Nuclear localization}

Figure 3. Structure of USFs. bHLH, basic helix-loop-helix domain; BR, basic region; LZ, leucine zipper; USR, USF-specific region; 
USF-1 (43 kDa) and USF-2 (44 kDa) have been shown to be encoded by distinct genes in human, rat and mouse (Lin et al., 1994; Henrion et al., 1995, Henrion et al., 1996; Aperlo et al., 1996) whereas USF-2a and USF-2b are isoforms of USF-2 generated by alternative splicing. In addition, isolation of a novel USF-2 isoform, USF-2c, from the human DU145 prostate cancer cell line was reported recently (Yan \& Sloane, 2004).

In liver and in most cell lines, USF-1/USF-2a heterodimers are predominant; USF-1 homodimers are less abundant, and USF-2 homodimers are usually quite scarce (Sirito et al., 1994, Violett et al., 1996; Sirito et al., 1998). Although, the exact biological roles of USFs and USF-2 isoforms are still not completely understood, they are thought to play crucial roles as transcriptional activators or repressors in the signal-induced and basal gene expression (Coulson et al., 2003).

Among the USF-regulated genes are those involved in cellular proliferation such as p53 (Reisman \& Rotter, 1993), cyclin B1 (Cogswell et al., 1995) and transforming growth factor $\beta 2$ (Scholtz et al., 1996) as well as glucose controlled genes such as fatty acid synthase (Wang \& Sul, 1995), L-type pyruvate kinase (Lefrancois-Martinez et al., 1995) and hormone sensitive lipase (Smih et al., 2002). USFs have been proposed also to be involved in insulin signalling to the fatty acid synthase gene (Wang \& Sul, 1995, 1997). An inhibitory role of USF was reported for the immunoglobulin heavy chain enhancer gene (Carter et al., 1997), the aortic preferentially expressed gene-1 (APEG-1) (Chen et al., 2001), the CYP1A1 gene (Takahashi et al., 1997) the CYP19 gene (Jiang \& Mendelson , 2003) and the PAI-1 gene (Samoylenko et al., 2001).

\subsection{Forkhead transcription factors}

The superfamily of Forkhead transcription factors consist of approximately 90 members and all members of the family show high sequence homology within their DNA-binding "winged-helix" domain to the fork head protein of Drosophila melanogaster (Weigel et al., 1989). The Forkhead transcription factor DAF-16 has been identified in Caenorhaditis elegans as an insulin-sensitive factor located downstream of the PI(3)K homolog AGF1 (O'Brien at al., 2001). In mammalian cells, the DAF-16 homolog Foxo1 (previously known as FHKR), Foxo3 (previously FKHRL1), and Foxo4 (previously AFX) represents the FoxO subfamily and have been found to be phosphorylated by PKB at three conserved residues namely Thr24, Ser256 and Ser319. In the nonphosphorylated form these FoxO transcription factors reside in the nucleus and interact with the insulin response sequences within the promoters of multiple target genes. Once bound to the target gene promoters, the FoxOs act as potent activator of transcription. When PKB is activated by insulin, the FoxO proteins are directly phosphorylated, which results in their nuclear export and cytoplasmic retention through binding to 14-3-3 proteins and subsequently in inhibition of target gene expression (Brunet et al., 1999; Kops et al., 1999; Rena et al., 1999; Biggs et al., 1999; Takaishi et al., 1999). 


\subsection{The fibrinolytic system and plasminogen activator inhibitor-1 (PAI-1)}

Fibrinolysis results in breakdown of the solid fibrin filaments that constitute the blood clot. For activation of the fibrinolytic system, plasminogen and plasminogen activators bind to the fibrin surface where plasminogen is cleaved into its active fibrin-degrading protease form, plasmin. Plasmin, then, cleaves the fibrin filaments forming fibrin degradation products. The plasminogen activators, tissue-type (tPA) and urokinase-type (UPA) are in turn regulated by plasminogen activator inhibitor-1 (PAI-1) (Lijnen \& Collen, 1988, review by Kohler \& Grant, 2000).

PAI-1 was first described in the early 1980`s as a rapid inhibitor of tPA (Chmielewska \& Wiman, 1983, Wiman et al., 1984). PAl-1 is a single chain $50 \mathrm{kDa}$ glycoprotein of 379 amino acids and belongs to the serine protease inhibitor (SERPIN) family. PAI-1 exists in an active, latent and inactive conformation (Nar et al, 2000) and can be secreted by platelets, vascular endothelial cells, vascular smooth muscle cells and several nonvascular cell types among them hepatocytes (Erickson et al., 1985; Reilly \& McFall, 1991; Busso et al., 1994).

Three other molecules with PAI activity are now known: PAI-2, PAI-3 (known also as protein C inhibitor) and the protease nexin-1 (PN-1) (Sitko et.al, 2001). Their functions in the regulation of the fibrinolytic system have not been yet clearly elucidated. In addition to PAI-1, there are other fibrinolytic inhibitors present such as $\alpha$-antiplasmin, which inhibits the non-bound plasmin and the thrombin activable fibrinolysis inhibitor (TAFI) which inhibits the fibrinolysis by removing $\mathrm{COOH}$-terminal lysine and arginine residues from fibrin (Wang et al., 1998). However, PAI-1 is considered to be the main regulator of fibrinolysis due to its high specificity and fast action.

In addition to its inhibitory effect in fibrinolysis (Loskutoff et al, 1989), PAI-1 appears to be a multifunctional protein modulating proteolityc processes associated with neovascularization, tissue remodelling and regeneration as well as inflammation (Agrenius et al., 1989) and fibrosis (Eddy and Giachelli, 1995). Impairment of the fibrinolytic system, caused primarily by an increase in the plasma levels of PAI-1 is followed by increase in fibrin formation and subsequent thrombin formation. Indeed, elevated plasma levels of PAI-1 are positively correlated with the risk to develop coronary artery disease (reviewed by Kohler \& Grand, 2000), deep vein thrombosis and atherosclerotic lesions leading to myocardial infarction (Hamsten et al., 1987). PAI-1 has also been implicated in both acute and chronic inflammatory lung disorders (reviewed by Binder et al., 2002) and several acute and chronic renal diseases such as glomerulosclerosis and renal interstitial fibrosis (reviewed by Eddy, 2002). Furthermore, insulin-resistant states, associated with hyperinsulinemia, obesity, hypertension and diabetes type 2 are characterized by enhanced PAI-1 levels (reviewed by Eddy, 2002). On the other hand, low PAI-1 levels or complete absences of PAI-1 in the blood stream are associated with bleeding diathesis (Dieval et al., 1991; Fay et al., 1992; Lee et al., 1993). In contrast to patients with PAI-1 deficiency, PAI1 deficiency in mice does not cause spontaneous or delayed bleeding, even after trauma (Carmeliet et al., 1993). 


\subsubsection{Regulation of PAI-1 gene expression}

PAI-1 is rapidly secreted from platelets, vascular endothelial cells (Erickson et al., 1985), vascular smooth muscle cells (Reilly \& McFal, 1991) and several nonvascular cell types, including hepatocytes (Heaton et al., 1989; Busso et al., 1994). Numerous factors including growth factors such as erythropoietin, IGF-1, EGF, fibroblast growth factor, TGF- $\alpha / \beta$, VEGF, PDGF, bEGF, TNF $\alpha$, IL-1 $\beta$ and TGF $\alpha$; coagulation factors such as thrombin; metabolites such as glucose, glucosamine, oxidized LDL; hormones such as insulin, aldosterone, angiotensin II, renin; environmental factors such as endothelial stretch, hypoxia and radiation have been reported to induce PAI-1 transcription (for detailed reference see Eddy, 2002). Although the list of reported PAI-1 agonists is impressive, the molecular mechanisms and the signaling pathways involved are largely unknown.

\subsubsection{Human PAI-1 promoter}

The human PAI-1 gene consists of nine exons and eight introns distributed over approximately $12.3 \mathrm{~kb}$ DNA. Two transcripts that are approximately 3.2 and $2.4 \mathrm{~kb}$ in length are generated from the single gene in humans by alternative splicing (Fattal \& Billadello, 1993). The sequenced 5'-flanking DNA (1520 bp) contains the essential eukaryotic cis-type proximal regulatory elements CCAAT and TATAA (Efstratiadis et al., 1980; Maniatis et al., 1987). The length of the PAI-1 5'-UTR was found to be 145 bp whereas the $3^{\prime}-$ UTR is about 1800 bp (Bosma et al., 1988). Comparison between human and rat PAl-1 genes revealed strict conservation of the intron-exon structure (Bosma et al., 1988, Bruzdzinski et al., 1990). In addition, two regions of the promoter showed a high degree of similarity: a 60 bp region between -90 and the TATA box, and the sequence located between -753 and -510 (Bruzdzinski et al., 1990). Although partially conserved, a number of differences between the rat and human promoter exist and might account for some different regulatory patterns between these genes.

Some of the transcription factors binding to the $5^{\prime}$-region of the human PAI-1 gene were identified (Table 2). 
Table 2. Transcriptional regulation of human PAI-1. AP1, Activator protein 1; BAECs, bovine aortic endothelial cells; BAH-ER3 cells; Bosc 23 cells,; CREB, CAMP-response element-binding protein; COS-1, African green monkey cells, HRE, hypoxia-responsive element; HUVEC, human umbilical vein endothelial cells; EPAS, endothelial PAS domain protein; IL-1, interleukin-1; MCF-7, human breast adenocarcinoma; NBRE, nerve growth factor inducible-B protein response element; NF-кB, nuclear factor-kappa $B$; PKA protein kinase $A$; PKB protein kinase $B ; R E$, responsive element; ROS, reactive oxygen species; SRE, Smad recognition element;TEF3, translation elongation factor 3; TF, transcription factor; TGF- $\beta$, tumor growth factor beta; TNF $\alpha$, tumor necrosis factor alpha, VMSC, vascular smooth muscle cells

\begin{tabular}{|c|c|c|c|c|c|}
\hline Position & RE & TF & $\begin{array}{c}\text { In response } \\
\text { to }\end{array}$ & Cell type & Reference \\
\hline$-15 k b$ & TNF $\alpha$ RE & $?$ & TNF- $\alpha$ & BAECS, HUVEC & Hou et al., 2004 \\
\hline$-795 /-531$ & TGF $\beta$ RE & $\begin{array}{l}\text { Smad3 } \\
\text { Smad4 } \\
\text { TEF3 }\end{array}$ & TNF $\beta$ & $\begin{array}{l}\text { HepG } 2 \text { cells } \\
\text { BAH-ER3 cells } \\
\text { Bosc } 23 \text { cells }\end{array}$ & $\begin{array}{l}\text { Hua et al., } \\
1996,1998\end{array}$ \\
\hline$-732 /-721$ & TGF $\beta$ RE & $\begin{array}{l}\text { Smad3 } \\
\text { Smad4 }\end{array}$ & TNF $\beta$ & $\begin{array}{l}\text { HepG3B cells } \\
\text { cos-1 cells }\end{array}$ & $\begin{array}{l}\text { Song et al., } \\
1998\end{array}$ \\
\hline$-678 /-673$ & NF-кB RE & $?$ & IL-1 & HepG2 cells & $\begin{array}{l}\text { Pessara Koch, } \\
1990\end{array}$ \\
\hline$-681 /-674$ & & CLOCK: & & & \\
\hline$-566 /-559$ & E-boxes & $\begin{array}{l}\text { BMAL1/2 } \\
\text { CLOCK: } \\
\text { BMAL1/2 }\end{array}$ & & HUVEC & $\begin{array}{l}\text { Schoenhard et } \\
\text { al., } 2003\end{array}$ \\
\hline $\begin{array}{l}-590 /-587 \\
-586 /-583 \\
-571 /-559\end{array}$ & $\begin{array}{l}\text { SRE1 } \\
\text { SRE2 } \\
\text { SRE3 }\end{array}$ & $\begin{array}{l}\text { Smad4 } \\
\text { Smad4 } \\
\text { Smad3 }\end{array}$ & TNF $\beta$ & $\begin{array}{l}\text { HepG2 cells } \\
\text { HepG3B }\end{array}$ & $\begin{array}{l}\text { Grinberg \& } \\
\text { Kerppola, } 2003\end{array}$ \\
\hline$-261 /-254$ & NBRE & Nur77 & TNF $\alpha$ & HUVEC & $\begin{array}{l}\text { Gruber et al., } \\
2003\end{array}$ \\
\hline$-194 /-187$ & HRE & HIF-1 & hypoxia & HepG2 cells & Fink et al., 2002 \\
\hline$-194 /-187$ & HRE & CREB & & $\begin{array}{l}\text { adenocarcinoma } \\
\text { A549 }\end{array}$ & Sato et al.,2004 \\
\hline $\begin{array}{c}-194 /-187 \\
-46 /-41\end{array}$ & HRE\&Sp1b & EPAS & & $\begin{array}{l}\text { adenocarcinoma } \\
\text { A549 }\end{array}$ & Sato et al.,2004 \\
\hline
\end{tabular}




\begin{tabular}{|c|c|c|c|c|c|}
\hline $\begin{array}{c}-777 /-741 \\
-157 /-128 \\
-93 /-62\end{array}$ & IRE & ? & insulin & HepG2 cells & $\begin{array}{l}\text { Banfi et al., } \\
2001\end{array}$ \\
\hline$-76 /-71$ & Sp1a RE & Sp1 & $\begin{array}{c}\text { glucose } \\
\text { angiotensinll } \\
\text { ROS }\end{array}$ & $\begin{array}{l}\text { VSMC } \\
\text { mesangial cells } \\
\text { BAEC }\end{array}$ & $\begin{array}{l}\text { Chen et al., } \\
\text { 1998; Motojima } \\
\text { et al., } 2000 \\
\text { Du et al., } 2000\end{array}$ \\
\hline \multirow[t]{5}{*}{$-59 /-52$} & $\begin{array}{c}\text { AP-1-like } \\
\text { RE }\end{array}$ & c-fos/junD & D-dimer & lung fibroblast & $\begin{array}{l}\text { Olman et al., } \\
1999\end{array}$ \\
\hline & & $\begin{array}{c}? \\
\text { c-jun }\end{array}$ & PKA,PKB & $\begin{array}{l}\text { MCF-7 } \\
\text { HepG2 }\end{array}$ & $\begin{array}{l}\text { Knudsen et } \\
\text { al.,1994; Arts et } \\
\text { al.,1999 }\end{array}$ \\
\hline & & AP1 & glucose & human VSMC & $\begin{array}{l}\text { Ahn et al.,2001; } \\
\text { Suzuki et al., } \\
2002\end{array}$ \\
\hline & & c-jun & $\begin{array}{l}\text { oxidative } \\
\text { stress }\end{array}$ & GH4 cells & $\begin{array}{l}\text { Vulin \& Stanley, } \\
2004\end{array}$ \\
\hline & & c-fos/c-jun & thymosin $\beta 4$ & endothelial cells & $\begin{array}{l}\text { Al-Nedawi et } \\
\text { al., } 2004\end{array}$ \\
\hline$-52 /-45$ & IRE & $?$ & insulin & GH4 cells & $\begin{array}{l}\text { Vulin \& Stanley, } \\
2002\end{array}$ \\
\hline$-46 /-41$ & Sp1b RE & Sp1 & $\begin{array}{c}\text { glucose } \\
\text { angiotensinll } \\
\text { ROS }\end{array}$ & $\begin{array}{l}\text { VSMC } \\
\text { mesangial cells } \\
\text { BAEC }\end{array}$ & $\begin{array}{l}\text { Chen et al. } \\
\text { 1998; Motojima } \\
\text { et al., } 2000 \\
\text { Du et al., } 2000\end{array}$ \\
\hline
\end{tabular}

\subsection{Aim of the study}

PAI-1 levels are linked to an increased risk of atherothrombosis and appear to be part of the insulin resistance syndrome. In addition to insulin, IGF-1 has also been shown to enhance PAI1 production in several experimental systems but the molecular mechanisms underlying these effects have not been fully elucidated. Since insulin and IGF-1 share critical signaling components it was the aim of the present study to identify the IGF-1 and insulin responsive elements within the human PAI-1 promoter and to investigate in vitro the signaling mechanisms mediating the IGF-1- and insulin-dependent induction of human PAI-1 gene expression. Further, the transcription factors HIF-1 and USF-2 were proposed to be mediators in the response to IGF-1 and insulin. Therefore it should be investigated whether HIF-1 and USF-2 are putative target transcription factors within the IGF-1 and insulin signaling pathway. 


\section{MATERIALS}

\subsection{Bacterial strains, vectors and plasmid constructs}

\subsubsection{Bacteria}

Two Escherichia coli bacterial strains-XL1-Blue (Bullock et al., 1987) and DH5a (Hanahan, 1983) were used as recipients of plasmids in various transformations.

\subsubsection{Vector}

\section{pGL3-basic vector}

The promoterless vector contains a 41 bp multiple cloning site (MCS, see Fig. 4) followed by the firefly luciferase gene (luc+, 1649 bp) and the SV40 late polyA signal (221 bp). Another upstream polyA signal (153 bp) is located directly before the multiple cloning site. The plasmid also contains an ampicillin resistance gene (ß-lactamase; Amp'; $857 \mathrm{bp}$ ) and two origins of replication, ColE1 ori and f1 ori (454 bp) (Fig. 4).

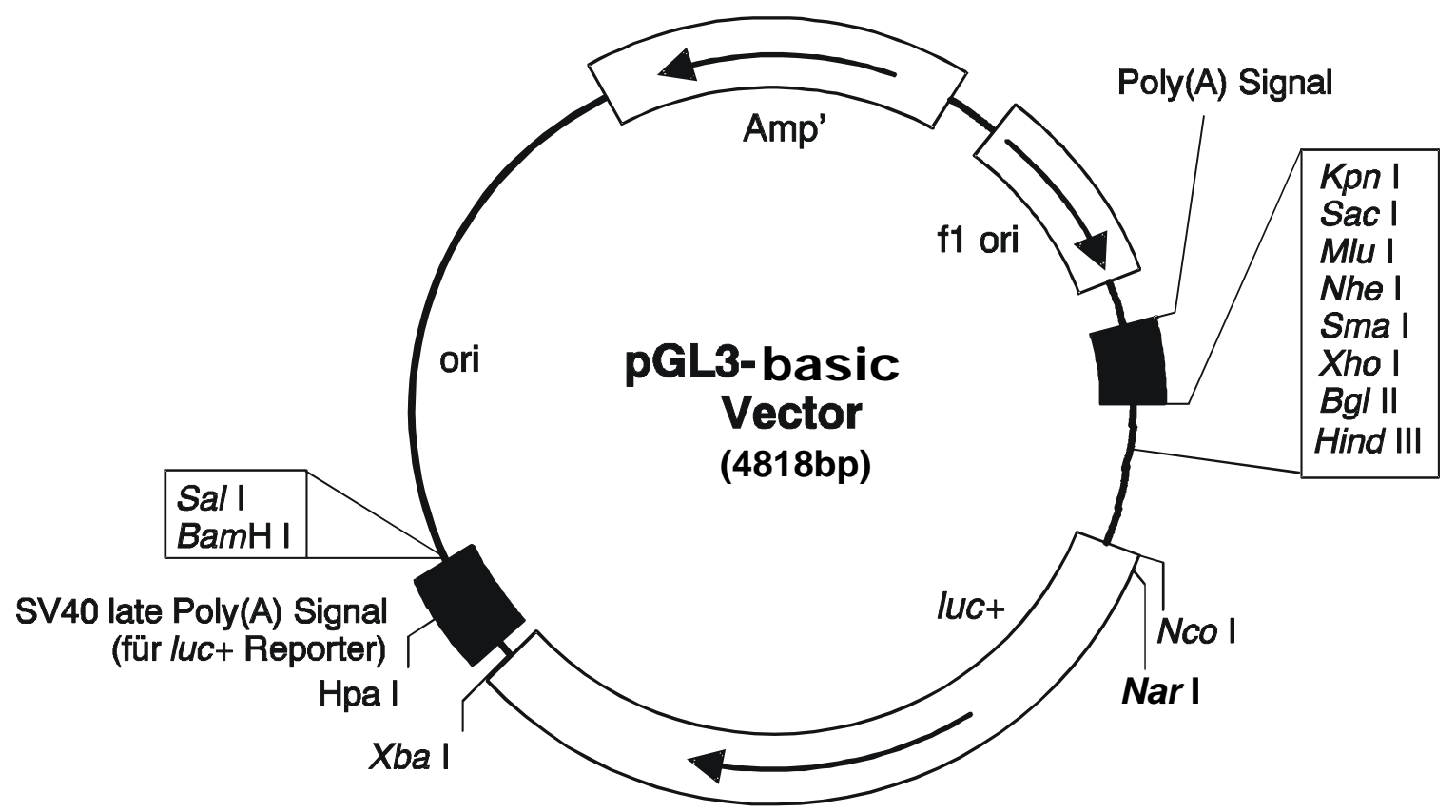

Figure 4. Structure of the pGL3 basic vector. luc+, cDNA encoding the modified firefly luciferase; $\mathrm{Amp}^{\mathrm{r}}$, gene conferring the ampicillin resistance in E.coli; f1 ori, origin of replication derived from filamentous phage; ori, origin of replication un E.coli. Arrows within luc+ and $\mathrm{Amp}^{r}$ gene indicate the direction of transcription; the arrow in the $\mathrm{f} 1$ ori indicates the direction of single-strand DNA synthesis.

\subsubsection{Plasmid constructs}

\subsubsection{Reporter gene plasmid constructs}

In the vector pGL3-basic (4818 bp) (Promega) the wild-type hPAl promoter as well as the hPAl promoter with different mutations was inserted in front of the Luc+ gene to create the pGI3hPAI- 
806/+19, pGI3hPAI-HREm, pGI3hPAI-M4, pGI3hPAI-M5, pGI3hPAI-M45, pGI3hPAI-HREmM45, pGI3hPAI-FKHRm and pGI3hPAI-HREmFKHRm constructs (Fig. 5). The constructs pGI3hPAl806/+19, pGI3hPAI-HREm, pGI3hPAI-M4, pGI3hPAI-M5, pGI3hPAI-M45, pGI3hPAI-HREmM45 were kind gifts from Dr. T. Fink and have been already described (Fink et al., 2002). The pGI3hPAI-FKHRm and pGI3hPAI-HREmFKHRm were created during the course of this work using the QuickChange XL site-directed mutagenesis kit (Stratagene) (Fig. 5).

\author{
pGI3hPAI-806/+19 \\ pGI3hPAI-HREm \\ pGI-hPAI-M4 \\ pGI3hPAI-M5
}

pGI3hPAI-M45

pGI3hPAI-HREmM45

pGI3hPAI-FKHRm

pGI3hPAI-HREmFKHRm
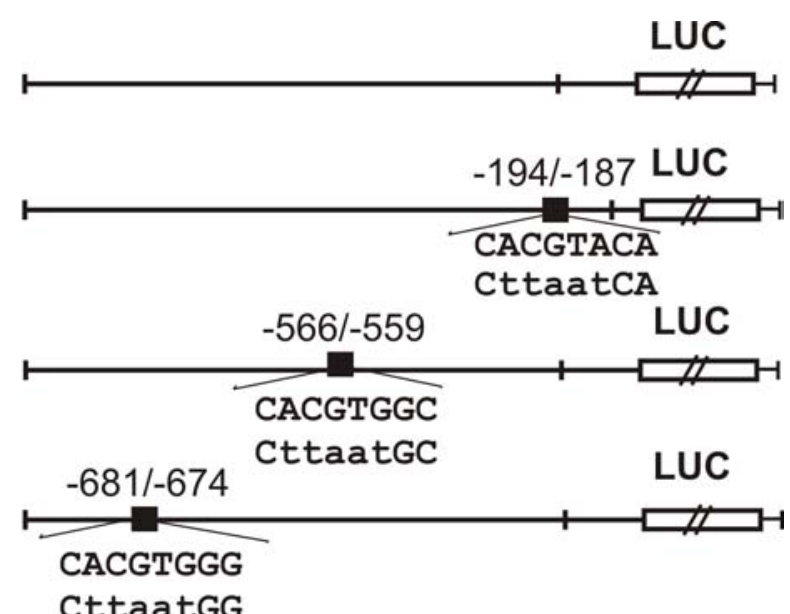

CttaatGG
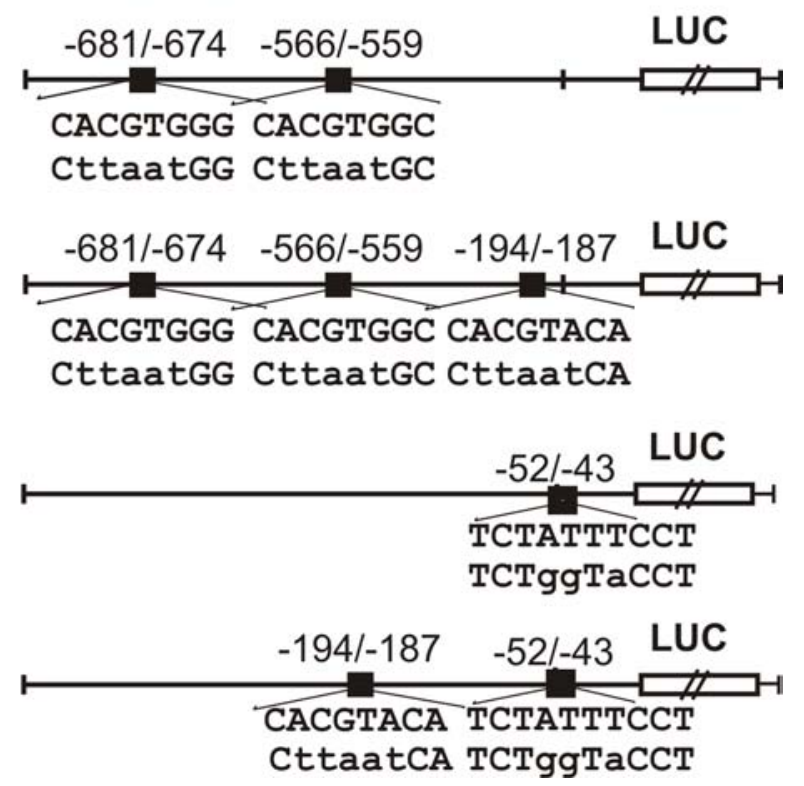

Figure 5. Human PAI-1 luciferase promoter constructs. The human PAI- 1 promoter $(-806 /+19$ according to the transcription start) was cloned into the pGI3-basic vector. The wild-type sequences are shown on the upper strand; the mutations are indicated on the lower strand by lower case letters 


\subsubsection{Expression plasmids}

Expression constructs used in the present work are listed in Table 3.

Table 3. Expression constructs used in this work

\begin{tabular}{|c|c|c|}
\hline Plasmid & Description & Reference \\
\hline pCMV3-Myc PDK1 dn & $\begin{array}{l}\text { Myc-taged human full-length PDK1-cDNA } \\
\text { with exchange of Lys111 and Asp223 to Ala } \\
\text { under the control of the CMV promoter in } \\
\text { pCMV3 (Ampr } \text {, Invitrogen) }\end{array}$ & $\begin{array}{l}\text { Bertrand et al., } \\
1999\end{array}$ \\
\hline pcDNA3-FLAG-Raf-1 dn & $\begin{array}{l}\text { FLAG-taged Raf-1-cDNA with exchange of } \\
\text { Lys375 to Met under the control of the CMV } \\
\text { promoter in pcDNA3 (Ampr', Invitrogen) }\end{array}$ & Dent et al.,1995 \\
\hline pcDNA3-FLAG-TRB3 & $\begin{array}{l}\text { FLAG-taged human TRB3-cDNA under the } \\
\text { control of the CMV promoter in pcDNA3 } \\
\text { (Ampr }{ }^{r} \text {, Invitrogen) }\end{array}$ & Du et al., 2003 \\
\hline pcDNA3-FLAG-FKHR & $\begin{array}{l}\text { FLAG-taged full-length ORF of human FKHR } \\
\text { under the control of the CMV promoter in } \\
\text { pcDNA3 (Amp }{ }^{r} \text {, Invitrogen) }\end{array}$ & Tang et al., 1999 \\
\hline $\begin{array}{l}\text { pcDNA3-FLAG-FKHR } \\
\text { AAA }\end{array}$ & $\begin{array}{l}\text { FLAG-taged human FKHR-cDNA with a } \\
\text { mutation at Thr24, Ser256 and Ser319 to Ala } \\
\text { under the control of the CMV promoter in } \\
\text { pcDNA3 (Amp }{ }^{r} \text {, Invitrogen) }\end{array}$ & Tang et al., 1999 \\
\hline $\mathrm{pCR}^{\mathrm{TM}} 3-\mathrm{hUSF} 2 \mathrm{a}$ & $\begin{array}{l}\text { human USF-2a-cDNA under the control of the } \\
\text { CMV promoter in } \mathrm{pCR}^{\mathrm{TM}} 3\left(\mathrm{Amp}^{\mathrm{r}} \text {, Stratagene, }\right. \\
\text { La Jolla, CA })\end{array}$ & $\begin{array}{l}\text { Lefrancois- } \\
\text { Martinez et al., } \\
1995\end{array}$ \\
\hline $\mathrm{pCR}^{\mathrm{TM}} 3-\mathrm{hUSF} 2 \Delta \mathrm{TDU} 2$ & $\begin{array}{l}\text { human USF-2a-cDNA with a deletion of the } \\
\text { codons for AA residues } 1 \text { to } 198 \\
\text { (corresponding to the transactivation domain) } \\
\text { under the control of the CMV promoter in } \\
\mathrm{pCR}^{\mathrm{TM}} 3 \text { (Amp }{ }^{\mathrm{r}} \text { Stratagene, La Jolla, CA) }\end{array}$ & $\begin{array}{l}\text { Lefrancois- } \\
\text { Martinez et al., } \\
1995\end{array}$ \\
\hline pSV-USF2 $\Delta \mathrm{E} 5$ & $\begin{array}{l}\text { mouse USF-2a-CDNA with a deletion of the } \\
\text { codons for AA residues } 144 \text { to } 188 \\
\text { (corresponding to the part of the } \\
\text { transactivation domain encoded by exon } 5 \text { ) } \\
\text { under the control of the early SV } 40 \text { promoter } \\
\text { in pSG5 (Ampr, Stratagene) }\end{array}$ & $\begin{array}{l}\text { Qyang et al., } \\
1999\end{array}$ \\
\hline pSV-USF2 $\Delta$ USR & $\begin{array}{l}\text { mouse USF-2a-cDNA with a deletion of the } \\
\text { codons for AA residues } 208 \text { to } 230 \\
\text { (correspond to USF-specific region (USR)) } \\
\text { under the control of the early SV40 promoter } \\
\text { in pSG5 (Ampr }{ }^{r} \text { Stratagene) }\end{array}$ & $\begin{array}{l}\text { Luo \& Sawadogo, } \\
\text { 1996a }\end{array}$ \\
\hline
\end{tabular}




\subsection{Oligonucleotides}

Synthetic oligonucleotides were obtained at HPLC-purified grade from MWG (Göttingen).

\subsubsection{Oligonucleotides for sequencing}

Oligonucleotide

GL2 primer

RV3 primer

M13 forward

M13 reverse

T7 primer

BGH primer
Sequence 5' $\rightarrow$ 3'

CTT TAT GTT TTT GGC GTC TTC C

CTA GCA AAA TAG GCT GTC CC

TGT AAA ACG ACG GCC AG

ACA GCT ATG ACC ATG ATT

TAA TAC GAC TCA CTA TAG GG

TAG AAG GCA CAG TCG AGG

2.2.2 Oligonucleotides for Electrophoretic Mobility Shift Assay (EMSA)

$\begin{array}{ll}\begin{array}{l}\text { Oligonucleotide } \\ \text { hPAl-1-HRE-s }\end{array} & \text { TCT TAC ACA CGT ACA CAC A } \\ \text { hPAl-1-HRE-as } & \text { TGT GTG TAC GTG TGT AAG T } \\ \text { hPAl-1-HREm-s } & \text { TCT TAC ACt taa tCA CAC A } \\ \text { hPAl-1-E4-s } & \text { ACA ATC ACG TGG CTG GCT } \\ \text { hPAl-1-E4-as } & \text { AGC CAG CCA CGT GAT TGT } \\ \text { hPAl-1-M4-s } & \text { ACA ATC tta atG CTG GCT } \\ \text { hPAl-1-E5-s } & \text { AGT CTG GAC ACG TGG GGA } \\ \text { hPAl-1-E5-as } & \text { TCC CCA CGT GTG CAG ACT } \\ \text { hPAl-1-M5-s } & \text { ATG CTG GAC tta atG GGA }\end{array}$

Position

$-199 /-181$

$-571 /-552$

$-689 /-670$

\subsection{PCR primers}

\section{Primer}

hPAI-1 -438 F

hPAl-1- 438 R

hPAI-1-70/-31 F

hPAI-1-70/-31 R

$$
\text { Sequence } 5^{\prime} \rightarrow 3^{\prime}
$$

GGT TAT CTT TGG TAC CTC CAC AGT G

GGT CCT GGA TCC AAA CAC A

GGG TGG AAC ATG AGT TCA TCT GGT ACC

TGC CCA CAT CTG G

CCA GAT GTG GGC AGG TAC CAG ATG AAC

TCA TGT TCC AGC C
Tann $\left[{ }^{\circ} \mathrm{C}\right]$

63

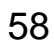

$>75$

$>75$ 


\subsection{Antibodies}

\begin{tabular}{|c|c|c|c|c|}
\hline Antibody & Properties & Epitope & Dilution & Manufacturer \\
\hline$\alpha-\mathrm{HIF}-1 \alpha$ & $\begin{array}{l}\text { mouse monoclonal, } \\
\text { peroxidase conjugate }\end{array}$ & $\begin{array}{l}\text { AA } 432-528 \text { of human } \\
\text { HIF-1 }\end{array}$ & $1: 2000$ & $\begin{array}{l}\text { Novus Biological } \\
\text { Transduction Lab } \\
\text { (Littleton, USA) }\end{array}$ \\
\hline$\alpha-H A-t a g$ & $\begin{array}{l}\text { mouse monoclonal, } \\
\text { peroxidase conjugate }\end{array}$ & $\begin{array}{l}\text { AA 98-108 of the } \\
\text { influenza hemaglutinin } \\
\text { (HA) protein }\end{array}$ & $1: 500$ & Santa Cruz (Heidelberg) \\
\hline$\alpha p E R K 1 / 2$ & $\begin{array}{l}\text { rabbit polyclonal } \\
\text { peroxidase conjugate }\end{array}$ & $\begin{array}{l}\text { phospho-Thr202 and } \\
\text { phospho-Tyr204 and } \\
\text { residues around } \\
\text { Thr202\&Tyr204 }\end{array}$ & 1:1000 & $\begin{array}{l}\text { Cell Signaling, Biomol } \\
\text { (Hamburg) }\end{array}$ \\
\hline$\alpha$-Flag-tag & $\begin{array}{l}\text { mouse monoclonal, } \\
\text { peroxidase conjugate }\end{array}$ & $\begin{array}{l}\text { Flag-tag fused either } \\
\text { to } \mathrm{N} \text { or Met-N- or } \mathrm{C} \text { - } \\
\text { terminus }\end{array}$ & 1:1000 & Sigma (St.Louis, USA) \\
\hline $\begin{array}{l}\alpha-M y c-t a g \\
9 \mathrm{~B} 11\end{array}$ & $\begin{array}{l}\text { mouse monoclonal, } \\
\text { peroxidase conjugate }\end{array}$ & $\begin{array}{l}\text { Myc-tag fused either to } \\
\mathrm{N} \text { - or C-terminus }\end{array}$ & 1:1000 & $\begin{array}{l}\text { Cell Signaling, Biomol } \\
\text { (Hamburg) }\end{array}$ \\
\hline$\alpha-\mathrm{hPAl}-1$ & $\begin{array}{l}\text { mouse monoclonal, } \\
\text { peroxidase conjugate }\end{array}$ & AA $110-145$ of hPAl-1 & $1: 100$ & $\begin{array}{l}\text { American Diagnostica } \\
\text { Ins (Pfungstadt) }\end{array}$ \\
\hline$\alpha-\mathrm{rPAI}-1$ & $\begin{array}{l}\text { rabbit polyclonal, } \\
\text { peroxidase conjugate }\end{array}$ & rat PAI-1 & $1: 100$ & $\begin{array}{l}\text { American Diagnostica } \\
\text { Ins (Pfungstadt) }\end{array}$ \\
\hline$\alpha-p-P K B$ & $\begin{array}{l}\text { rabbit polyclonal, } \\
\text { peroxidase conjugate }\end{array}$ & $\begin{array}{l}\text { phospho-Thr308 and } \\
\text { residues around } \\
\text { Thr308 of mouse Akt }\end{array}$ & 1:1000 & $\begin{array}{l}\text { Cell Signaling, Biomol } \\
\text { (Hamburg) }\end{array}$ \\
\hline$\alpha-p-P K B$ & $\begin{array}{l}\text { rabbit polyclonal, } \\
\text { peroxidase conjugate }\end{array}$ & $\begin{array}{l}\text { phospho-Ser } 437 \text { and } \\
\text { residues around } \\
\text { Ser } 437 \text { of mouse Akt }\end{array}$ & 1:1000 & $\begin{array}{l}\text { Cell Signaling, Biomol } \\
\text { (Hamburg) }\end{array}$ \\
\hline$\alpha$-USF1 & $\begin{array}{l}\text { rabbit polyclonal, } \\
\text { peroxidase conjugate }\end{array}$ & $\begin{array}{l}\text { C-terminus of human } \\
\text { USF1 }\end{array}$ & $1: 200$ & Santa Cruz (Heidelberg) \\
\hline$\alpha$-USF1 & $\begin{array}{l}\text { rabbit polyclonal, } \\
\text { peroxidase conjugate }\end{array}$ & $\begin{array}{l}\text { N-terminus of human } \\
\text { USF1 }\end{array}$ & $1: 200$ & Santa Cruz (Heidelberg) \\
\hline$\alpha$-USF2 & $\begin{array}{l}\text { rabbit polyclonal, } \\
\text { peroxidase conjugate }\end{array}$ & $\begin{array}{l}\text { C-terminus of mouse } \\
\text { USF2 }\end{array}$ & $1: 200$ & Santa Cruz (Heidelberg) \\
\hline$\alpha$-USF2 & $\begin{array}{l}\text { rabbit polyclonal, } \\
\text { peroxidase conjugate }\end{array}$ & $\begin{array}{l}\text { N-terminus of mouse } \\
\text { USF2 }\end{array}$ & $1: 200$ & Santa Cruz (Heide \\
\hline
\end{tabular}




\subsection{Protease inhibitors}

\begin{tabular}{|c|c|c|c|c|c|c|}
\hline Inhibitor & $\begin{array}{r}\text { Stock solv } \\
\text { solv }\end{array}$ & tion and & $\begin{array}{r}\text { Wo } \\
\text { conce }\end{array}$ & $\begin{array}{l}\text { rking } \\
\text { ntration }\end{array}$ & Stability & Inhibitor of: \\
\hline Aprotinin & $10 \mathrm{mg} / \mathrm{ml}$ & $\mathrm{H}_{2} \mathrm{O}$ & 10 & $\mu \mathrm{g} / \mathrm{ml}$ & $\begin{array}{l}\text { stable at }-20^{\circ} \mathrm{C} \\
\text { for } 6 \text { months }\end{array}$ & $\begin{array}{l}\text { serine proteases } \\
\text { such as kallikrein, } \\
\text { plasmin, trypsin, } \\
\text { chymotrypsin }\end{array}$ \\
\hline Leupeptin & $1 \mathrm{mg} / \mathrm{ml}$ & $\mathrm{H}_{2} \mathrm{O}$ & 0.5 & $\mu \mathrm{g} / \mathrm{ml}$ & $\begin{array}{l}\text { stable at }-20^{\circ} \mathrm{C} \\
\text { for ca. } 3 \text { months }\end{array}$ & $\begin{array}{l}\text { trypsin-like and } \\
\text { cysteine proteases }\end{array}$ \\
\hline PepstatinA & $1 \mathrm{mg} / \mathrm{ml}$ & DMSO & 1 & $\mu \mathrm{g} / \mathrm{ml}$ & $\begin{array}{l}\text { stable at }-20^{\circ} \mathrm{C} \\
\text { for ca. } 1 \text { month }\end{array}$ & $\begin{array}{l}\text { acid proteases such } \\
\text { as pepsin, renin, } \\
\text { cathepsin D and } \\
\text { microbial proteases }\end{array}$ \\
\hline PMSF & $200 \mathrm{mM}$ & Isoprop & 200 & $\mu \mathrm{M}$ & $\begin{array}{l}\text { stable at RT for } \\
\text { ca. } 9 \text { months }\end{array}$ & $\begin{array}{l}\text { serine \& cysteine } \\
\text { protease (trypsin, } \\
\text { chymotrypsin,etc.) }\end{array}$ \\
\hline
\end{tabular}

\subsection{Enzymes}

Restriction endonucleases type II generate DNA fragments with 5' or 3' "sticky" overhangs or blunt ends after the digestion; the reactions were set in buffers optimized for the enzyme(s) and supplied by the manufacturer (TaKaRa and MBI Fermentas). Some of the other enzymes used are listed below:

\section{Enzyme}

Klenow fragment (DNA polymerase I large fragment) Shrimp alkaline phosphatase (SAP)

RNase A (DNase-free)

T4 DNA ligase

T4 polynucleotide kinase (T4-PNK)

Taq DNA polymerase

\section{Manufacturer}

MBI Fermentas (St.Leon-Rot)

Roche (Mannheim)

Qiagen (Hilden)

MBI Fermentas (St.Leon-Rot)

Amersham (Freiburg)

TaKaRa (Verviers,Belgium)

\subsection{Stock solutions}

The stock solutions were prepared in sterile deionized $\mathrm{H}_{2} \mathrm{O}$ at room temperature according to the 'Molecular Cloning' laboratory manual (Sambrook et al., 1989) unless mentioned otherwise. All solutions for RNA experiments were prepared with DEPC-treated $\mathrm{H}_{2} \mathrm{O}$ 
Stock solutions

Ammonium acetate

Ammonium persulfate (APS)

Ampicillin

Chloramphenicol

Penicillin G, sodium salt

Streptomycine sulfate

Tetracycline

Calcium chloride:

Dexamethasone
Concentration

$7,5 \mathrm{M}$

$10 \%(w / v)$

$50 \mathrm{mg} / \mathrm{ml}$ in $\mathrm{H}_{2} \mathrm{O}$, store at $-20^{\circ} \mathrm{C}$

$34 \mathrm{mg} / \mathrm{ml}$ in abs. EtOH, store at $-20^{\circ} \mathrm{C}$

$6.4 \mathrm{mg} / \mathrm{ml}$ in $0.9 \% \mathrm{NaCl}$, store at $-20^{\circ} \mathrm{C}$

$11.7 \mathrm{mg} / \mathrm{ml}$ in $0.9 \% \mathrm{NaCl}$, store at $-20^{\circ} \mathrm{C}$

$5 \mathrm{mg} / \mathrm{ml}$ in $70 \% \mathrm{EtOH}$, store at $-20^{\circ} \mathrm{C}$

Dexamethasone was first dissolved in $0.3 \mathrm{ml}$ of $\mathrm{EtOH}$ and then in $0.9 \% \mathrm{NaCl}$.

Dithiotreitol

$5 \mathrm{mM}$

in $\mathrm{NaAc}, \mathrm{pH} 5,2$, store at $-20^{\circ} \mathrm{C}$

EDTA

$500 \mathrm{mM}$

in $\mathrm{H}_{2} \mathrm{O}, \mathrm{pH} 8(\mathrm{NaOH})$, store at $\mathrm{RT}$

Ethidium bromide

$10 \mathrm{mg} / \mathrm{ml}$

$\mathrm{EtBr}$, store at $4^{\circ} \mathrm{C}$

Insulin

$10 \mu \mathrm{M}$

Insulin in $0.9 \% \mathrm{NaCl}$ solution

Insulin was dissolved at $\mathrm{pH} 2.5$, neutralized and then $10 \mathrm{mg} / \mathrm{l}$ BSA was added.

Glycerol

Lithium chloride

Magnesium chloride

Sodium acetate

$\mathrm{NaCl}$

$\mathrm{NaOH}$

SDS

$10 \times$ PBS buffer

$50 \times \mathrm{TAE}$

$\begin{array}{rl}140 & \mathrm{mM} \\ 25 & \mathrm{mM} \\ 81 & \mathrm{mM} \\ 15 & \mathrm{mM}\end{array}$

$\begin{array}{rll}10 \% & (\mathrm{v} / \mathrm{v}) & \text { filter-sterilized, store at } 4^{\circ} \mathrm{C} \\ 4 & \mathrm{M} & \mathrm{LiCl}, \text { store at RT } \\ 1 & \mathrm{M} & \mathrm{MgCl}_{2} \text {, store at RT } \\ 3 & \mathrm{M} & \mathrm{NaAc} \text { in } \mathrm{H}_{2} \mathrm{O}, \mathrm{pH}\left(\mathrm{CH}_{3} \mathrm{COOH}\right), \mathrm{RT} \\ 0,9 \% & (\mathrm{w} / \mathrm{v}) & \text { autoclave, store at RT } \\ 10 & \mathrm{M} & \text { store in plastic container at RT } \\ 1 \% & (\mathrm{w} / \mathrm{v}) & \text { SDS, store at RT }\end{array}$

$\mathrm{NaCl}$

$\mathrm{KCl}$

$\mathrm{Na}_{2} \mathrm{HPO}_{4}$

$\mathrm{KH}_{2} \mathrm{PO}_{4}$

$\mathrm{pH} 7.4(\mathrm{NaOH})$, store at RT

Tris

EDTA

Acetic acid

$\mathrm{pH}$ 8.5, autoclave, store at RT 
$10 \times$ TBE

$\begin{array}{rll}900 & \mathrm{mM} & \text { Tris } \\ 900 & \mathrm{mM} & \text { Boric acid } \\ 20 & \mathrm{mM} & \text { EDTA }\end{array}$

$\mathrm{pH}$ 8.0,autoclave, store at RT

$20 \times$ SSC

$\begin{array}{rll}2 & \mathrm{M} & \mathrm{NaCl} \\ 0.3 & \mathrm{M} & \text { Sodium citrate } \\ & & \mathrm{pH} 7.0, \text { autoclave, store at RT }\end{array}$

\subsubsection{Media for bacteria}

\section{Meduim}

LB (Luria Bertani):

\section{Concentration Substance}

$\begin{array}{rll}10 & \mathrm{~g} / \mathrm{l} & \text { Tryptone } \\ 5 & \mathrm{~g} / \mathrm{l} & \text { Yeast Extract } \\ 10 \mathrm{~g} / \mathrm{l} & \mathrm{NaCl}\end{array}$

$\mathrm{pH} 7.0(\mathrm{NaOH})$, autoclave, store at $4^{\circ} \mathrm{C}$

To prepare bacto agar, $1.5 \%(\mathrm{w} / \mathrm{v})$ agar and ampicillin $50 \mu \mathrm{g} / \mathrm{ml}$ were added to the LB medium.

SOC

$\begin{array}{rll}20 & \mathrm{~g} / \mathrm{l} & \text { Tryptone } \\ 5 & \mathrm{~g} / \mathrm{l} & \text { Yeast Extract } \\ 10 & \mathrm{mM} & \mathrm{NaCl} \\ 2.5 & \mathrm{mM} & \mathrm{KCl} \\ 10 & \mathrm{mM} & \mathrm{MgCl}_{2} \\ 10 & \mathrm{mM} & \mathrm{MgSO}_{4} \\ 20 & \mathrm{mM} & \text { Glucose }^{2}\end{array}$

\subsection{Chemicals}

\section{Substance}

$30 \%$ acrylamide: $\mathrm{N}, \mathrm{N}$-methylene-bisacrylamide (37.5:1)

$\gamma$ ATP $(3000 \mathrm{Ci} / \mathrm{mmol})$

Agar

Agarose

Ammonium persulfate (APS)

Ampicillin (Amp)

Antifoam A

Aprotinin

Bacitracin

Bacto agar

\section{Manufacturer}

Roth (Karlsruhe)

Amersham (Freiburg)

AppliChem (Darmstadt)

Invitrogen (Karlsruhe)

Serva (Heidelberg)

Serva (Heidelberg)

Sigma (Munich)

Bayer (Leverkusen)

Serva (Heidelberg)

Oxoid (Basingstoke, GB) 


\author{
Bacto trypton \\ Blocking reagent \\ Bovine serum albumin (BSA) \\ Bradford reagent \\ Bromphenolblue \\ Chloroform
}

Coomassie Brilliant Blue R-250

CDTA

CSPD

Diethylpyrocarbonate (DEPC)

Dimethylsulfoxide (DMSO)

Dithiothreitol (DTT)

dNTPs

Ethanol

Ethylenediaminotetraacetate (EDTA)

Ethidium bromide (EtBr)

Ficoll ${ }^{\circledR} 400$

Formaldehyde (37\%)

Glycerol

Glycine

Guanidine thiocyanate

Hepes

Insulin

Isopropanol

Leupeptin

Luciferase cell lysis reagent

$\beta$-mercaptoethanol ( $\beta$-ME)

Maleic acid

NP-40

$\mathrm{N}$-lauroylsarcosin

3-[N-morpholino]-propanesulfonic acid (MOPS)

Non-fat dried milk

Paraformaldehyde

Penicillin

Pepstatin A

Phenol

Phenylmethanesulfonyl fluoride (PMSF)
Oxoid (Basingstoke, GB)

Roche (Mannheim)

Serva (Heidelberg)

Serva (Heidelberg)

Serva (Heidelberg)

Merck (Darmstadt)

Merck (Darmstadt)

Sigma (Munich)

Roche (Mannheim)

Roth (Karlsruhe)

Sigma (Munich)

Sigma (Munich)

Roche (Mannheim)

Merck (Darmstadt)

AppliChem (Darmstadt)

Serva (Heidelberg)

Pharmacia (Ratingen (Breitscheid)

Merck (Darmstadt)

AppliChem (Darmstadt)

AppliChem (Darmstadt)

Fluka (Buchs, Switzerland)

Roth (Karlsruhe)

Sigma (Munich)

Merck (Darmstadt)

Roche (Mannheim)

Promega (Mannheim)

Serva (Heidelberg)

Sigma (Munich)

AppliChem (Darmstadt)

Sigma (Munich)

Biometra (Göttingen)

AppliChem (Darmstadt)

Serva (Heidelberg)

Serva (Heidelberg)

Roche (Mannheim)

Roth (Karlsruhe)

Sigma (Munich) 
Poly d (I-C)

Ponceau S

Sodium dodecyl sulfate (SDS)

TEMED

Tris(hydroxymethyl)aminomethane (Tris)

Triton X-100

Trypan Blue

Trypsin

Tween ${ }^{2} 20$

Urea

X-Gal

X-ray film developer LX24

$X$-ray film fixator AL4

All chemicals used were of p.a. quality.

\subsection{Consumables}

Product

3MM paper

Sterile filter Nalgene $0.2 \mu \mathrm{m}$

Braunules 2G14

Dialysis tubes VISKING type 8

Electroporation cuvettes

Hyperfilm MP

Nylon membranes Hybond-N+

PDVF membranes Immobilon ${ }^{\mathrm{TM}} \mathrm{P}$

Single-use plastic ware
Roche (Mannheim)

Serva (Heidelberg)

Serva (Heidelberg)

Roth (Karlsruhe)

Sigma (Munich)

Sigma (Munich)

Sigma (Munich)

Sigma (Munich)

Sigma (Munich)

Roth (Karlsruhe)

BioTech Grade

Kodak (Rochester, USA)

Kodak (Rochester, USA)

\section{Manufacturer}

Whatman Biometra (Göttingen)

Sartorius (Göttingen)

Braun (Kronberg)

Roth (Karlsruhe)

BioRad (Munich)

Amersham Pharmacia (Frankfurt)

Amersham Pharmacia (Frankfurt)

Millipore (Schwalbach)

Sarstedt (Nümbrecht), Eppendorf

(Hamburg), Greiner (Flacht), Biozym

(Hess. Oldendorf), Roth (Karlsruhe)

\subsection{Kits}

Kit

DIG-Nucleic-Acid Detection Kit

ECL-Kit

JETstar, Plasmid Purification System

Luciferase Assay Kit

Nucleotide Removal Kit

QIAEXII Gel Extraction Kit

\section{Manufacturer}

Roche (Mannheim)

Amersham (Freiburg)

Genomed (Löhne)

Berthold (Pforzheim)

Qiagen (Hilden)

Qiagen (Hilden) 
QuikChange XL Site-Directed Mutagenesis Kit Synthetic Oligonucleotides 5 '-end Labeling Kit

\subsection{Devices}

\section{Device}

Autoclave

Auto Lumat

Automatic pipettes

Automatic pipettes

Automatic DNA Sequencer

Cupboard Dryer

Electric power apparatus

Electroporator

Electroblotting instrument

Incubators with gas flow

control

Gel apparatus for EMSA gels

Gel dryer

Handheld radiation monitor

Heating blocks

Heating shaker

Heating stirrer

Hybridization ovens

Ice machine

Image analysis system

Image eraser

Incubator with shaking

Labofuge II

Magnetic mixer with warming

Microwave oven

Millipore apparatus

PCR thermocyclers

Peristaltic pump

$\mathrm{pH}$-meter

Phosphoimager

Photometer

\section{Model}

3870 ELV

LB 953

Varipette 4710

Pipetman P20,

P200, P1000

$373 \mathrm{~A}$

U 40

EPS 500/400

GenePulser II

Cytoperm 8080;

B $5060 \mathrm{EK} / \mathrm{O}_{2}$

Contamat

HB-130

Thermomixer 5436

RCT basic

OV 3

\section{3-25}

RCT B

KOR-6105

Milli-Q

GeneAmp 2400

Cyclo1

535 Multi Cal

Storm 860

$\lambda$ UV/VIS
Stratagene (Amsterdam)

Amersham (Freiburg)

\section{Manufacturer}

Tuttnauer (Breda)

Berthold (Pforzheim)

Eppendorf (Hamburg)

Abimed Analysen-Technik GmbH

(Langenfeld)

Applied Biosystems (Weiterstadt)

Memmert (Schwabach)

Pharmacia LKB GmbH (Freiburg)

BioRad (Munich)

Institute's workshop

Heraeus (Hanau)

Sigma (Munich)

Schütt Labortechnik (Göttingen)

Eberline (Erlangen)

Unitek (Sarstedt-Heisede)

Eppendorf (Hamburg)

IKA Labortechnik (Staufen)

Biometra (Göttingen)

Inco-Ziegra (Isernhagen)

SIS Computer-systems (Muenster)

Molecular Dynamics (Krefeld)

New Brunswick Scientific (Nuertingen)

Heraeus (Hanau)

Ika Labortechnik (Staufen)

Daewoo Electronics (Butzbach)

Millipore (Schwalbach)

Perkin-Elmer (Langen)

Roth (Karlsruhe)

Schütt Labortechnik (Göttingen)

Molecular Dynamics (Krefeld)

Perkin-Elmer (Langen) 


\begin{tabular}{|c|c|c|}
\hline \multirow[t]{3}{*}{ Power supplies } & E 323, E 835 & Consort \\
\hline & PS 305 & Invitrogen (Karlsruhe) \\
\hline & EC 105, EC 250-90 & E-C Apparatus Corp. \\
\hline RNA-/DNA-calculator & GeneQuant II & Pharmacia (Ratingen (Breitscheid) \\
\hline \multirow[t]{3}{*}{ Scales } & A $120 \mathrm{~S}, 2254, \mathrm{H}$ & Sartorius Analytic (Göttingen) \\
\hline & 120,2434 & \\
\hline & Spo 51, Sac 62 & ScalTec (Heiligenstadt) \\
\hline Shaker & ST 5 & M. Zipperer GmbH (Staufen) \\
\hline Sorvall high-speed centrifuges & RC5 and RC5 B & Du Pont Instruments \\
\hline Sterile benches & $\begin{array}{l}\text { Microflow Laminar, } \\
\text { TL 2472, HB } 2448\end{array}$ & Heraeus (Hanau) \\
\hline \multirow[t]{2}{*}{ Sterile pump } & DBP Nr. P & Schleicher \&Schüll (Dassel) \\
\hline & 24333991 & \\
\hline Table-top centrifuges & 5414 and 5415 C & Eppendorf (Hamburg) \\
\hline Table-top cooling centrifuges & $5403,5415 R$ & Eppendorf (Hamburg) \\
\hline Thermocycler & TC 4200 & Perkin Elmer (Langen) \\
\hline \multirow[t]{2}{*}{ Thermostats } & 450 LE; Typ R 10/2 & Meßgeräte-Werk Lauda \\
\hline & 5320 & Eppendorf-Netheler GmbH (Hamburg) \\
\hline Ultra-sound sonicator & $W-220 \mathrm{~F}$ & Schütt Labortechnik (Göttingen) \\
\hline Ultraviolet stratalinker & 1800 & Stratagene (Amsterdam) \\
\hline Vacuum evaporator & SpeedVac L 05 & WKF \\
\hline Vacuum gel dryer & Phero-Temp & Biotec-Fischer (Reiskirchen) \\
\hline Videodensitometer & & Biotec Fischer (Reiskirchen) \\
\hline Water bath & K2R; NB/S8 & Meßgeräte-Werk Lauda \\
\hline Water deionization system & Option 4,Maxima & ELGA (Ubstadt-Weiher) \\
\hline X-ray film cassettes & & Intas (Göttingen) \\
\hline
\end{tabular}

\subsection{Software}

Program

\section{Company / Organization}

Acrobat

BLAST

Adobe

$\mathrm{NCBI}$

CorelDraw

Corel

ImageQuant

Office

Molecular Dynamics

Microsoft

PhotoPaint

Corel

TINA

Raytest GmbH

DNA star

DNA star

Vector NTI

InforMax Inc. 


\section{METHODS}

\subsection{Cell biological methods}

All manipulations with eukaryotic cell cultures were performed under sterile hood conditions. All solutions were sterilized by autoclaving or filtration and were pre-warmed at $37^{\circ} \mathrm{C}$ in a water bath before use. All centrifugations of cell suspensions during transfection or propagating procedures were done for $2 \mathrm{~min}, 20 \times g$ at $4^{\circ} \mathrm{C}$.

\subsubsection{Isolation of primary rat hepatocytes}

The isolation of primary hepatocytes from rat liver was performed under sterile conditions by a collagenase perfusion according to the method of Berry \& Friend (1969).

\subsubsection{Liver perfusion}

1. Non-recirculative in situ pre-perfusion of the liver: After laparotomy, a braunule $(1.3 \times 45 \mathrm{~mm})$ was inserted in the vena portae, and the vena cava inferior was ligated above the diaphragma to close the whole body blood circulation. The vena cava inferior was then cut beneath the liver, cannulated with the braunule $(22 \times 50 \mathrm{~mm})$ and perfusion started with 150-200 ml pre-perfusion medium (Krebs-Ringer solution with EGTA) at a flow rate of $30 \mathrm{ml} / \mathrm{min}$ until the liver was free from blood.

2. Recirculative perfusion: the perfusion at a flow rate of $30 \mathrm{ml} / \mathrm{min}$ with collagenase perfusion medium was performed until consistency of the liver became soft, due to digestion of the connective tissue (about 7-11 min). During perfusion, the medium was recirculated through a plastic tube connected to the braunule inserted in the vena cava inferior.

Both pre-perfusion's and perfusion's mediums were pumped through an oxygenator, from which they were directed into the vena portae with a pressure of $10-15 \mathrm{~cm}$ of water.

\subsubsection{Preparation of hepatocyte suspension}

After perfusion, the liver was removed and transferred into a glass cup filled with culture medium M199. The Glisson's capsule i.e. the collagen tissue around the liver, was carefully removed and discarded. The obtained paste-like liver substance was further disrupted. Finally, connective tissue and remainders of the liver capsule as well as big cell aggregates were removed by filtration of the primary suspension through a nylon net (pore size $79 \mu \mathrm{m}$ ). Nonparenchymal cells and cell debris were removed by numerous selective sedimentations $(20 \times g$, $2 \mathrm{~min}$ ). After the last centrifugation, hepatocytes were resuspended in medium M199. $50 \mathrm{ml}$ of M199 were added per $1 \mathrm{~g}$ of wet weight of the sedimented cells to bring the density of the cell suspension up to about $10^{6} / 2.5 \mathrm{ml}$. 


\subsubsection{Mediums and solutions for hepatocytes preparation and culture}

Krebs-Ringer stock solution:

Final concentration

$\begin{array}{lr}\mathrm{NaCl} & 7 \mathrm{~g} / \mathrm{l} \\ \mathrm{KCl} & 0.4 \mathrm{~g} / \mathrm{l} \\ \mathrm{MgSO} 4 \times 7 \mathrm{H}_{2} \mathrm{O} & 0.3 \mathrm{~g} / \mathrm{l} \\ \mathrm{KH}_{2} \mathrm{PO}_{4} & 0.2 \mathrm{~g} / \mathrm{l} \\ \mathrm{NaHCO}_{3} & 2 \mathrm{~g} / \mathrm{l}\end{array}$

Equilibrated with carbogen and adjusted to $\mathrm{pH} 7.35$.

Pre-perfursion medium:

Final concentration

EGTA

$0.1 \mathrm{~g} / \mathrm{l}$

$0.25 \mathrm{mM}$

Dissolved in Krebs Ringer stock solution

Collagenase perfusion medium:

Final concentration

HEPES

$3 \mathrm{~g} / \mathrm{l}$

$15 \mathrm{mM}$

$\mathrm{CaCl}_{2} \times 2 \mathrm{H}_{2} \mathrm{O}$

$0.6 \mathrm{~g} / \mathrm{l}$

$4 \mathrm{mM}$

Collagenase

$0.5 \mathrm{~g} / \mathrm{l}$

Dissolved in Krebs Ringer stock solution

Before each preparation of hepatocytes, the collagenase was dissolved in perfusion medium, equilibrated with carbogen for $30 \mathrm{~min}$ and finally sterilized by filtration.

Wash medium:

Final concentration

HEPES/NaOH pH 7.4

$4.8 \mathrm{~g} / \mathrm{l}$

$20 \mathrm{mM}$

$\mathrm{NaCl}$

$7 \mathrm{~g} / \mathrm{l}$

$120 \mathrm{mM}$

$\mathrm{KCl}$

$0.4 \mathrm{~g} / \mathrm{l}$

$4.8 \mathrm{mM}$

$\mathrm{MgSO}_{4} \times 7 \mathrm{H}_{2} \mathrm{O}$

$0.3 \mathrm{~g} / \mathrm{l}$

$1.2 \mathrm{mM}$

$\mathrm{KH}_{2} \mathrm{PO}_{4}$

$0.2 \mathrm{~g} / \mathrm{l}$

$1.2 \mathrm{mM}$

Calf serum albumin

$4 \mathrm{~g} / \mathrm{l}$

$0.4 \%$

Medium M199:

Final concentration

Powder M199 with Earle`s

$9.8 \mathrm{~g} / \mathrm{l}$

salts without $\mathrm{NaHCO}_{3}$

Glucose $x \mathrm{H}_{2} \mathrm{O}$

$1.1 \mathrm{~g} / \mathrm{l}$

$5.5 \mathrm{mM}$

HEPES

$3.6 \mathrm{~g} / \mathrm{l}$

$15 \mathrm{mM}$

$\mathrm{NaHCO}_{3}$

$1.5 \mathrm{~g} / \mathrm{l}$

$18 \mathrm{mM}$

Calf serum albumin

$4 \mathrm{~g} / \mathrm{l}$

$0.4 \mathrm{mM}$ 
The M199 medium was prepared as follows: solution A was prepared by dissolving $1.5 \mathrm{~g}$ $\mathrm{NaHCO}_{3}$ in $550 \mathrm{ml} \mathrm{H}$ O and equilibrated with carbogen for 3-4 h. The $\mathrm{pH}$ was adjusted to 7.35. Solution B was prepared from powder medium, calf serum albumin and HEPES, all dissolved in $450 \mathrm{ml} \mathrm{H}_{2} \mathrm{O}$, and the $\mathrm{pH}$ was adjusted to 7.35. Then solutions $A$ and $B$ were mixed and again equilibrated with carbogen until a $\mathrm{pH}$ value of 7.35 was reached. Finally, the medium was sterilized by filtration.

\subsubsection{Primary rat hepatocyte culture}

Immediately after preparation, primary rat hepatocytes were plated onto $60 \mathrm{~mm}$ Petri-dishes in M199 medium supplemented with fetal calf serum (4 ml/100 ml suspension), $1 \%$ antibiotics (penicillin- streptomycine), $10^{-7} \mathrm{M}$ dexamethasone and $10^{-9} \mathrm{M}$ insulin as permissive hormones (see 2.7) and cultured in an atmosphere of $16 \% \mathrm{O}_{2}, 5 \% \mathrm{CO}_{2}$ and $97 \%$ humidity at $37^{\circ} \mathrm{C}$ in a cell culture incubator.

\subsubsection{Cell culture techniques}

\subsubsection{Culture of HepG2 and H4IIE cell lines}

HepG2 and H4IIE cell lines were maintained in Earle`s minimum essential medium (MEM, PAA Lab $\mathrm{GmbH}$ ) supplemented with 10\% (w/v) fetal bovine serum (Biochrom KG), 1\% non-essential amino acids (PAA) and 0,5\% (w/v) antibiotic, and grown on $175 \mathrm{~cm}^{2}$ cell-culture flasks in an atmosphere of $16 \% \mathrm{O}_{2}, 5 \% \mathrm{CO}_{2}$ and $97 \%$ humidity at $37^{\circ} \mathrm{C}$ in a cell culture incubator. Cells were grown to $80-90 \%$ confluence and then propagated as follows: Flasks were washed twice with 10-15 $\mathrm{ml} 1 \mathrm{x}$ PBS. Then $3 \mathrm{ml}$ of trypsin / EDTA (Sigma) was applied to detach the cells. After incubation for $5 \mathrm{~min}$ at $37^{\circ} \mathrm{C}$, flasks were shaken by hand and the reaction was stopped by adding 5-10 ml of culture medium with 10\% FBS which contained trypsin inhibitors. Then, cells were transferred to $50 \mathrm{ml}$ tubes (Blue Max, Falcon, Becton) and harvested by centrifugation. The pellet was resuspended in $5 \mathrm{ml}$ of culture medium, counted in a Neubauer chamber, resuspended in culture medium and seeded onto plates in a desired ratio (see below).

$\begin{array}{lcr}\text { Application } & \text { Cell number / vol. suspension plated } & \varnothing \text { of the culture } \\ \text { Transfection } & 1 \times 10^{6} / 1.5 \mathrm{ml} & 60 \mathrm{Mm} \\ \text { Protein isolation } & 2 \times 10^{6} / 3.0 \mathrm{ml} & 60 \mathrm{Mm} \\ \text { RNA isolation } & 3 \times 10^{6} / 9.0 \mathrm{ml} & 100 \mathrm{Mm}\end{array}$

\subsubsection{Calcium phosphate transfection}

For transfection of hepatocytes, HepG2 and H4IIE cells, the calcium phosphate precipitation method (Graham et al., 1973) with some modifications was used; the differences are mostly 
concerning the type of cells used and the time and duration of transfection (Parker \& Stark, 1979; Chen \& Okayama, 1987; Chen \& Okayama, 1988; Ginot et al., 1989; Pasco \& Fagan, 1989; Rippe et al., 1990). The principle of the method is that the DNA can be introduced into cells as a co-precipitate with calcium phosphate, which enters the cell by the process of endocytosis. The precipitate is obtained when the DNA/calcium chloride solution is mixed with a solution containing phosphate.

Transfection mixture for one dish $(60 \mathrm{~mm})$ :

Final concentration

Plasmid DNA

$\mathrm{H}_{2} \mathrm{O}$

$\mathrm{CaCl}_{2}(2.5 \mathrm{M})$

$2 \times$ Hepes
$2.5 \mu \mathrm{l}$

up to $67.5 \mu \mathrm{l}$

$7.5 \mu \mathrm{l}$

$75 \mu \mathrm{l}$
$10 \%$

$50 \%$

The cells from a culture flask (80-90\% confluence) were plated onto $60 \mathrm{~mm} \varnothing$ Petri-dishes at a density of approximately $4.5 \times 10^{5}$ cells $/ \mathrm{ml} 20-24 \mathrm{~h}$ before transfection to allow attachment of the cells under normal conditions $\left(16 \% \mathrm{O}_{2}, 5 \% \mathrm{CO}_{2}, 97 \%\right.$ humidity atmosphere, $\left.37^{\circ} \mathrm{C}\right)$. The transfection mixture was prepared in polystyrol tubes in order to prevent adhesion of DNA to the walls and then incubated for 5-20 min at RT to allow formation of the co-precipitate. After incubation, the mixture containing the co-precipitate was pipetted to $60 \mathrm{~mm} \varnothing$ plates $(150 \mu \mathrm{l}$ per plate). Cells were incubated with the DNA/calcium phosphate co-precipitate for $5-6 \mathrm{~h}$ in an atmosphere of $16 \% \mathrm{O}_{2}, 5 \% \mathrm{CO}_{2}$ and $97 \%$ humidity at $37^{\circ} \mathrm{C}$ and then the precipitate-containing medium was discarded. The cells then were grown for additional $24 \mathrm{~h}$ in fresh culture medium ( $2.5 \mathrm{ml}$ per plate) and then divided into groups which were cultured under normoxic $\left(16 \% \mathrm{O}_{2}\right)$ and hypoxic $\left(8 \% \mathrm{O}_{2}\right) \mathrm{pO}_{2}$ for the next $24 \mathrm{~h}$. In the case of hepatocytes, the transfection mixture was added immediately after plating of the cells. After $5 \mathrm{~h}$ transfection the medium was changed and the hepatocytes were further cultured in medium M199 with the same concentrations of hormones and antibiotics as mentioned above but without fetal calf serum. After $24 \mathrm{~h}$ the medium was changed again. A volume of $2.5 \mathrm{ml}$ medium per $60 \mathrm{~mm} \varnothing$ culture dish, $6 \mathrm{ml}$ per $100 \mathrm{~mm} \varnothing$ culture dish and $17 \mathrm{ml}$ per $150 \mathrm{~mm} \varnothing$ culture dish were added. Total DNA concentration was kept constant throughout all experiments by balancing it with empty vector.

2x Hepes:

$\begin{array}{lrrrr}\text { Hepes } & 1.2 & \mathrm{~g} / 100 \mathrm{ml} & 50 & \mathrm{mM} \\ \mathrm{NaCl} & 1.6 & \mathrm{~g} / 100 \mathrm{ml} & 280 & \mathrm{mM} \\ \mathrm{Na}_{2} \mathrm{HPO}_{4} & 0.3 & \mathrm{~g} / 100 \mathrm{ml} & 1.5 & \mathrm{mM}\end{array}$

The $\mathrm{pH}$ was adjusted to 7.05 with $5 \mathrm{~N} \mathrm{NaOH}$; the buffer was stored in $50 \mathrm{ml}$ aliquots at $-20^{\circ} \mathrm{C}$. 


\subsubsection{IGF-1 and insulin treatment}

The HepG2 cells were treated with IGF-1 or insulin. In a standard procedure, prior to addition of IGF-1 or insulin, cells were maintained for 16-18 $\mathrm{h}$ in serum-free medium. Human IGF-1 (Sigma) resuspended in $0.1 \mathrm{M}$ acetic acid was added to yield $100 \mathrm{nM}$ final concentrations in the samples. Acetic acid (0.1 M) was used in controls at a final concentration of $100 \mathrm{nM}$ to keep the $\mathrm{pH}$ constant. Insulin was applied in a final concentration of $500 \mathrm{nM}$. For luciferase assay, the cells were cultured under normoxia $\left(16 \% \mathrm{O}_{2}\right)$ or hypoxia $\left(8 \% \mathrm{O}_{2}\right)$ for the next $24 \mathrm{~h}$. For PAl-1 Western blot, cells were treated with insulin or IGF-1 in the same way. In case of Northern blots or EMSA analysis or HIF-1 $\alpha$ Western blots, the cells were treated with IGF-1 or insulin for about $4 \mathrm{~h}$ unless otherwise indicated. When necessary IGF-1 or insulin was applied in the time intervals as noted in the experiments. For inhibitory studies, the PI(3)-kinase inhibitor LY294002 and the MEK inhibitor U0126 were diluted in DMSO and used in a final concentration of $10 \mu \mathrm{M}$ for $30 \mathrm{~min}$.

\subsubsection{Luciferase reporter gene assay}

The detection of luciferase activity in cells, transfected with reporter vectors carrying the luciferase (Luc) gene from the North American firefly (Photinus pyralis) was performed with the Luciferase Assay Kit (Berthold, Pforzheim). The luciferase assay is based on enzyme-catalyzed chemiluminescence where the firefly luciferase enzyme catalyses oxidative decarboxylation of luciferin. This reaction is dependent on $\mathrm{Mg}^{2+}$ ions and ATP yielding photons as well as AMP, $\mathrm{CO}_{2}$ and oxyluciferine. The light emission measured at $562 \mathrm{~nm}$ depends on the concentration of the luciferase enzyme; therefore, it allows quantitative estimation of the expression level of the reporter gene.

For the purpose of the assay, the cells were washed twice with $2.5 \mathrm{ml} 1 \times$ PBS and $300 \mu$ lysis buffer was applied. The cells were shaked for approximately $30 \mathrm{~min}$, scraped, vortexed and centrifuged for $2 \mathrm{~min}$ at $16000 \times \mathrm{g}$ (14 $000 \mathrm{rpm}$ at a tabletop centrifuge Eppendorf, rotor $5415 \mathrm{C}$ ). Only in case of experiments with primary rat hepatocytes, the cell lysates after vortexing were frozen in liquid nitrogen for seconds, subsequently thawed at RT and centrifuged. $20 \mu \mathrm{l}$ of the supernatant were automatically mixed in the luminometer with $100 \mu \mathrm{l}$ luciferase assay reagent, prepared directly before use by mixing equal parts of solutions $A$ and $B$ (no information about their composition was provided by the supplier). The reaction was measured 10 times for $2 \mathrm{~s}$. The intensity of luminescence is constant for $20 \mathrm{~s}$ and then decreases with a half-life period of $5 \mathrm{~min}$. 
$\underline{5 x \text { Lysis buffer: }}$

Final concentration

$\begin{array}{lrllrl}\text { Tris } & 25 & \mathrm{ml} \text { of } & 1 \mathrm{M} & 125 & \mathrm{mM} \\ \text { CDTA } & 10 & \mathrm{ml} \text { of } & 200 \mathrm{mM} & 10 & \mathrm{mM} \\ \text { DTT } & 4 & \mathrm{ml} \text { of } & 500 \mathrm{mM} & 10 & \mathrm{mM} \\ \text { Glycerol } & 115 & \mathrm{ml} \text { of } & 85 \% & 50 \% & (\mathrm{v} / \mathrm{v}) \\ \text { TritonX-100 } & 10 & \mathrm{ml} \text { of } & 100 \% & 5 \% & (\mathrm{v} / \mathrm{v}) \\ \mathrm{H}_{2} \mathrm{O} & \text { up to } 200 & \mathrm{ml} & & & \end{array}$

\subsection{Molecular biology methods}

\subsubsection{Polymerase Chain Reaction (PCR)}

Polymerase Chain Reaction (Mullis \& Faloona, 1987) is an in vitro method for amplification of DNA fragments from a template DNA sequence. The reaction uses sequence-specific antiparallel oligonucleotides (primers) flanking the amplified region. The elongation of primers is catalyzed by a thermostable DNA polymerase (Taq), originally isolated from Thermophyllus aquaticus. At first, the two DNA strands of the template are exposed and separated by heat denaturation, thus allowing the recognition and the annealing of the primers to their complementary sequences in the 5'-regions of the amplified sequence. Next, the Taq polymerase catalyzes the elongation of the annealed primers by complementary polymerization of nucleotides to the free 3'-OH group. Each next cycle of denaturation, annealing and elongation (25-35 cycles are generally considered optimal) results in exponential accumulation of the primer-flanked DNA sequence.

A standard polymerase chain reaction mixture of $50 \mu$ usually contained:

Template plasmid DNA

$10 \times$ Taq buffer (with $1.5 \mathrm{mM} \mathrm{MgCl}_{2}$ )

$10 \mathrm{mM}$ (each) dNTPs

$10 \mathrm{pmol} / \mu \mathrm{l}$ primers

Taq polymerase

$\mathrm{H}_{2} \mathrm{O}$
$10 \mathrm{ng}$

$5 \mu \mathrm{l}$

$1 \mu l$

$2.5 \mu \mathrm{leach}$

$2.5 \mathrm{U}$

up to $50 \mu \mathrm{l}$

The amplification process was performed in programmable PCR thermocycler (Perkin Elmer) using the following parameters: 


$\begin{array}{crrrrr} & \text { Initial denaturation } & 4 & \min & 95^{\circ} \mathrm{C} & \\ & & & & & \\ & \text { Denaturation } & 1 & \min & 95^{\circ} \mathrm{C} & \\ 25-35 \mathrm{x} & \text { Annealing } & 30 & \sec & 50-60^{\circ} \mathrm{C} & \text { see Tann (2.3) } \\ & \text { Elongation } & 1 & \min / \mathrm{kb} & 72^{\circ} \mathrm{C} & \\ & & & & & \\ & \text { Final elongation } & 10 & \min & 72^{\circ} \mathrm{C}\end{array}$

$10 \mu \mathrm{l}$ of the reaction was used for tests on agarose gels (see 3.2.7.1)

\subsubsection{Purification and cloning of DNA fragments}

PCR products or restriction enzyme-digested fragments were purified from the reaction mixture by $\mathrm{NaAc} / \mathrm{EtOH}$ precipitation or separated on an agarose gel and the fragments of interest were purified using the QIAquick Gel Extraction Kit (Qiagen) following the instructions of the manufacturer. The purified DNA fragments were then modified and cloned into the cloning vector pGL3 using one of the following methods:

\subsubsection{Fill-in of 3'-overhangs with Klenow fragment of DNA polymerase I}

The Klenow fragment of DNA polymerase I from $E$. coli has a $5^{\prime} \rightarrow 3^{\prime}$ polymerase activity, i.e. it can incorporate nucleotides in 5' $\rightarrow 3$ ' direction on 3 '- termini templates, which can be used for integrating nucleotides in DNA fragments, converting sticky overhangs into blunt ends (filling-in) for cloning purposes. Reactions for filling-in were performed in an optimal buffer for the enzyme, supplied by the manufacturer as $10 \times(500 \mathrm{mM}$ Tris- $\mathrm{HCl}, \mathrm{pH} 8.0,50 \mathrm{mM} \mathrm{MgCl}, 10 \mathrm{mM}$ DTT$)$ using a mix of $0.125 \mathrm{mM}$ dNTPs at a final concentration of $2.5 \mu \mathrm{M}$; the reactions were incubated for $30 \mathrm{~min}$ at $37^{\circ} \mathrm{C}$ and stopped by heating them at $75^{\circ} \mathrm{C}$ for $10 \mathrm{~min}$.

\subsubsection{Blunt-end cloning}

In case of blunt end cloning, the PCR products were directly cloned in the dephosporylated pGL3 plasmid cloning vector (see 3.2.2.3). For this purpose, the PCR products were purified from the PCR mixture by $\mathrm{NaAc/EtOH}$ precipitation, resuspended and added into the ligation mixture.

\subsubsection{Dephosphorylation of DNA fragments}

To prevent the circularization of a plasmid vector in ligation reactions (e.g. when a plasmid was only linearized with a single restriction enzyme) a hydrolysis of the 5'-terminal phosphate 
residue (dephosphorylation) was performed using shrimp alkaline phosphatase (SAP) in $10 x$ SAP dephosphorylation buffer (Roche) for $1 \mathrm{~h}$ at $37^{\circ} \mathrm{C}$. The reaction was stopped by heating the sample at $65^{\circ} \mathrm{C}$ for $10 \mathrm{~min}$ and the DNA fragments were purified from agarose gel slices using QIAquick Gel Extraction Kit (Qiagen) and quantified against a $\lambda$-Hind -+III DNA ladder.

\subsubsection{Ligation of DNA fragments}

The T4-DNA ligase catalyzes the formation of a phosphodiesther bond between free 5'phosphate and 3'-OH groups of double-stranded DNA fragments, which results in the formation of recombinant DNA molecules. For the ligation of two fragments several conditions have to be fulfilled - the ends must be compatible (base complementation); at least one of the ends must be phosphorylated; ATP and optimal ligation buffer (supplied as $10 \mathrm{x}$ by MBI Fermentas) are necessary. For the insertion of double-stranded oligonucleotides generally up to $100: 1$ molar ratio of insert : vector was used, while larger DNA inserts were added to the ligation reaction in ratio 4-10: 1 (insert : vector). The ligations were performed with 1-2 units of T4-DNA ligase per $20 \mu \mathrm{l}$ reaction volume at $16^{\circ} \mathrm{C}$ in a thermomixer without shaking overnight. Then the ligation mixture was transformed into $E$. coli competent cells by electroporation (see 3.2.5).

\subsubsection{Preparation of competent Escherichia coli (E.coli) cells}

Naturally, bacterial cells have not the ability to accept "naked" DNA molecules from the environment, but with different treatments they can be artificially modified to become competent for transformation with external plasmids. This procedure is widely used in molecular biology, although the mechanisms via which this acquired competency works are still poorly understood. Briefly, a single colony of $E$. coli strain XL1-Blue was inoculated in $5 \mathrm{ml}$ LB medium (see 2.7.1) containing $5 \mu \mathrm{g} / \mu \mathrm{l}$ tetracycline and grown overnight at $37^{\circ} \mathrm{C}$ with moderate shaking. This $5 \mathrm{ml}$ pre-culture was used for inoculation of $500 \mathrm{ml}$ LB medium (i.e. 1:100 dilution) and the cells were grown with shaking $(250-300 \mathrm{rpm})$ to an $\mathrm{OD}_{550}$ of $0.4-0.5$ (3-5h). The bacterial cells were harvested by centrifugation at $1000 \times g$ for $15 \mathrm{~min}$ (2500 rpm, Beckman GSA rotor). The pellet was washed with $1 / 10$ volume $(5-10 \mathrm{ml})$ of ice-cold TSS buffer $(1 \%(\mathrm{w} / \mathrm{v}) \mathrm{NaCl}, 1 \%(\mathrm{w} / \mathrm{v})$ Tryptone, $0.5 \%$ (w/v) yeast extract, $30 \mathrm{mM} \mathrm{MgCl}$, 10\% (w/v) PEG 4000, 5\% (v/v) DMSO, pH 6.5 , sterile filtration). The cells were aliquoted into volumes of $100 \mu \mathrm{l}$, frozen in an ethanol/ $\mathrm{CO}_{2}$ bath and stored at $-80^{\circ} \mathrm{C}$.

In case of preparation of electro-competent cells, cells were grown to $\mathrm{OD}_{600}$ 0.6-0.8 and subsequently centrifuged for $15 \mathrm{~min}$ at $3500 \times \mathrm{g}$ (4800 rpm, Beckman GSA rotor). Two washing steps are performed with ice-cold $10 \%$ glycerol at $4000 \times g$ (5000 rpm, Beckman GSA) for 15 $\min$. The cells were aliquoted into volumes of $100 \mu \mathrm{l}$, immediately frozen in liquid $\mathrm{N}_{2}$ and stored at $-80^{\circ} \mathrm{C}$. The competence of the bacterial cells was tested by transformation with a plasmid carrying an ampicillin resistance gene. 


\subsubsection{Heat-shock transformation of competent cells}

A $100 \mu$ aliquot of competent cells was thawed on ice, 2-3 $\mu$ l of a ligation reaction or 0.5-1 ng of plasmid DNA were added carefully, the sample was stirred gently with the top of the pipette tip (without pipetting up and down) and incubated for $30 \mathrm{~min}$ on ice. After a heat-shock at $42^{\circ} \mathrm{C}$ for $1 \mathrm{~min}$, the cells were cooled on ice for $3 \mathrm{~min}$. Then, $500 \mu \mathrm{l}$ of SOC medium (see 2.7.1) were added and the sample was incubated for $30 \mathrm{~min}$ at $37^{\circ} \mathrm{C}$ on a roller. For selection of the transformed clones, the transformation mixture was plated on Petri dishes with solid LB medium and selective pressure (ampicillin) and incubated overnight at $37^{\circ} \mathrm{C}$.

\subsubsection{Transformation of competent cells by electroporation}

DNA is introduced into electrocompetent $E$. coli cells by exposing them to a short-high-voltage electrical discharge following the electroporator manufacturer (Bio-Rad)'s manual.

\subsubsection{Small-scale preparation of plasmid DNA (Miniprep)}

For analytical purposes, plasmid DNA was prepared by the TELT procedure (Medina-Acosta \& Cross, 1993). A single colony of E.coli strain XL1-blue was inoculated into $5 \mathrm{ml}$ of LB medium containing $40 \mu \mathrm{g} / \mathrm{ml}$ ampicillin and grown for $10-16 \mathrm{~h}$ at $37^{\circ} \mathrm{C}$ with good aeration. Then $3 \mathrm{ml}$ of the bacterial culture $(2 \times 1.5 \mathrm{ml}$ in an Eppendorf tube) were harvested by centrifugation at 3000 $x g$ (6000 rpm in a tabletop centrifuge Eppendorf, rotor 5415C) for $10 \mathrm{~min}$. The supernatant was removed, the bacterial pellet was resuspended completely in $150 \mu \mathrm{l}$ sterile TELT-solution (50 mM Tris, $62.2 \mathrm{mM}$ EDTA, $2.5 \mathrm{M} \mathrm{LiCl}, 0.4 \%(\mathrm{v} / \mathrm{v})$ Triton-X-100) and $3 \mu \mathrm{l}$ lysozyme $(50 \mathrm{mg} / \mathrm{ml}$ in $10 \mathrm{mM}$ Tris/ $\mathrm{HCl} \mathrm{pH} \mathrm{7.5,0.1} \mathrm{mM} \mathrm{EDTA)} \mathrm{was} \mathrm{added} \mathrm{for} \mathrm{efficient} \mathrm{lysis} \mathrm{of} \mathrm{the} \mathrm{cells.} \mathrm{The} \mathrm{solution}$ was well-mixed, heated for $2 \mathrm{~min}$ at $96^{\circ} \mathrm{C}$ and cooled on ice. The resulting bacterial lysate was cleared by centrifugation for $10 \mathrm{~min}$ at $16000 \times \mathrm{g}$ (14 $000 \mathrm{rpm}$ at a tabletop centrifuge Eppendorf, rotor 5415C) and the pellet containing proteins and genomic DNA was removed with a sterile toothpick. The plasmid DNA was precipitated from the supernatant with $100 \mu \mathrm{l}$ isopropanol $\left(10 \mathrm{~min}\right.$ at $\left.-20^{\circ} \mathrm{C}\right)$. After a centrifugation for $15 \mathrm{~min}$ at $16000 \times \mathrm{g}(14000 \mathrm{rpm}$ at a tabletop centrifuge Eppendorf, rotor $5415 \mathrm{C}$ ), the precipitated plasmid DNA was washed with 70 $\%(\mathrm{v} / \mathrm{v})$ ethanol, centrifuged again for $5 \mathrm{~min}$ and the DNA pellet was air-dried for 10-20 min. The plasmid DNA was dissolved in 20-30 $\mu \mathrm{H}_{2} \mathrm{O}$ and used further for restriction analysis (3-5 $\mu \mathrm{l}$ per digestion).

\subsubsection{Restriction analysis}

Restriction digestions of DNA were performed using type II restriction endonucleases, which leave fragments with 5', 3' "sticky" overhangs or blunt ends after digestion; the reactions were set in buffers optimized for the enzyme(s) and supplied by the manufacturer (TaKaRa and MBI Fermentas): 
The activity of the restriction enzymes is estimated in Units $(U)$, where $1 U$ stands for the amount of enzyme cutting completely at optimal conditions $1 \mu \mathrm{g}$ of $\lambda \mathrm{DNA}$ for $60 \mathrm{~min}$

$\begin{array}{llr}\text { Restriction mixture: } & \text { Plasmid DNA } & 3-5 \mu \mathrm{l} \\ & 10 \times \text { buffer (enzyme specific) } & 2 \mu \mathrm{l} \\ & \text { Restriction enzyme }(10 \mathrm{U} / \mu \mathrm{l}) & 0.5 \mu \mathrm{l} \\ & \mathrm{H}_{2} \mathrm{O} & \text { up to } 20 \mu \mathrm{l}\end{array}$

The restriction digestions were performed for $1-2$ hours at $37^{\circ} \mathrm{C}$, a temperature that is optimal for the most of the restriction enzymes. DNA fragments obtained from the restriction digestions were directly analyzed by agarose gel electrophoresis.

\subsubsection{Agarose gel electrophoresis}

DNA electrophoreses were performed in $1 \times$ TAE buffer (0.04 M Tris, $0.02 \mathrm{M} \mathrm{NaAc,} 1 \mathrm{mM}$ EDTA, pH 7.4) in a horizontal mini gel apparatus $(13 \times 8 \times 1 \mathrm{~cm})$. The concentration of the agarose gel varied depending on the size of tested DNA fragments $(1 \%(w / v)$ agarose in $1 \times$ TAE for fragments between $500 \mathrm{bp}$ and $10 \mathrm{~kb}, 1.5 \%$ gels for fragments between $200 \mathrm{bp}$ and $3 \mathrm{~kb}$ and $2 \%$ gels for fragments smaller than $500 \mathrm{bp}$ ).

The DNA samples were mixed with $1 / 10$ volume $10 \times$ DNA loading buffer (10\% Ficoll ${ }^{\circledR} 400$, $0.01 \%$ Orange $\mathrm{G}$, store at $-20^{\circ} \mathrm{C}$ ), loaded in the gel slots and subjected to an electrical current of $5 \mathrm{~V}$ per $\mathrm{cm}$ distance between the electrodes for 45-60 min according to the emigration of the Orange $\mathrm{G}$ dye. To visualize DNA, the gel was soaked for $10 \mathrm{~min}$ with ethidium bromide (1-1.5 $\mathrm{mg} / \mathrm{l}$ solution in $\mathrm{H}_{2} \mathrm{O}$ ) known to interact with nucleic acids strands and forming a complex that is fluorescent under UV light $(254 \mathrm{~nm})$; then the gel was washed with water to remove the background staining. The DNA fragment profiles were visualized under UV light and photographed. The estimation of the sizes and amount of the DNA fragments was done by comparison with a size standard marker (1kb DNA ladder, MBI Fermentas).

\subsubsection{Large-scale preparation of plasmid DNA}

For the preparation of larger amounts of high copy plasmid, DNA Jet Star Maxi-kit (Genomed) was used. The procedure was carried out according to the manufacturer's instructions (Genomed Plasmid Purification Handbook, 2000).

\subsubsection{Estimation of nucleic acid concentration}

The concentration of nucleic acids was determined using a spectrophotometer (GeneQuant, Pharmacia) by measuring the absorption at $260 \mathrm{~nm}$ of 100 -fold diluted samples in a quartz 
cuvette. An $\mathrm{OD}_{260}=1$ in a case of $1 \mathrm{~cm}$ cuvette corresponds to $50 \mu \mathrm{g} / \mathrm{ml}$ double-stranded DNA, $40 \mu \mathrm{g} / \mathrm{ml}$ RNA, $37 \mu \mathrm{g} / \mathrm{ml}$ single-stranded DNA and $30 \mu \mathrm{g} / \mathrm{ml}$ oligonucleotides (Sambrook et al., 1989).

The $A_{260} / A_{280}$ ratio is used to estimate the purity of the nucleic acid, since proteins absorb at 280 $\mathrm{nm}$ (due especially to the aromatic rings of tryptophan, tyrosine, histidine and phenylalanine amino acid residues that absorb at $280 \mathrm{~nm}$. DNA or RNA preparations, with ratio $\mathrm{OD}_{260} / \mathrm{OD}_{280}$ in the range of 1.8-2.0 were regarded as pure and protein-free (Sambrook et al. 1989).

Absorption at $230 \mathrm{~nm}$ reflects contamination of the sample by substances such as carbohydrates, peptides, phenols or aromatic compounds. In case of a pure sample, the ration $\mathrm{OD}_{260} / \mathrm{OD}_{230}$ should be approximately 2.2 .

\subsubsection{DNA sequencing}

Sequencing was performed by using the BigDye ${ }^{\mathrm{TM}}$ Terminator Enhanced Terminators Cycle Sequencing kit from Perkin-Elmer, based on the principle of the chain-termination method (Sanger et al., 1977). In this method, the reaction mixture besides deoxynucleotides contains also di-deoxynucleotides (terminators) whose incorporation in the newly-synthesized complementary chain leads to a premature interruption of its elongation. The four terminators are labeled with different fluorescent dyes and the terminated chains can be specifically detected by capillary electrophoresis on an ABI Model 373A Capillary Sequencer (Applied Biosystems) during which $40 \mathrm{~mW}$ argon lasers (488 nm and $514 \mathrm{~nm}$ ) stimulate the fluorescence of dye-labelled polynucleotides. Sequencing reactions were performed in a volume of $10 \mu \mathrm{l}$ (300-500 ng plasmid DNA, 10 pmol primer $(1 \mu \mathrm{l}), 3 \mu \mathrm{l}$ sequencing mix, $\mathrm{H}_{2} \mathrm{O}$ up to $10 \mu \mathrm{l}$ ). The samples were subjected to 25 cycles of: $30 \mathrm{sec}$ at $96^{\circ} \mathrm{C} ; 15 \mathrm{sec}$ at $55^{\circ} \mathrm{C} ; 4$ min at $60^{\circ} \mathrm{C}$ in a thermocycler. The products of the cycle-sequencing reaction were mixed with $90 \mu \mathrm{l} \mathrm{H}_{2} \mathrm{O}, 10 \mu \mathrm{l}$ $3 \mathrm{M} \mathrm{NaAc}, \mathrm{pH} 5.2$, and $250 \mu \mathrm{l} 95 \% \mathrm{EtOH}(\mathrm{v} / \mathrm{v})$ and centrifuged for $15 \mathrm{~min}$ at max speed in a tabletop centrifuge Eppendorf (14 $000 \mathrm{rpm}$ ). The pellet (usually not visible) was washed with $250 \mu \mathrm{l} 70 \%(\mathrm{v} / \mathrm{v}) \mathrm{EtOH}$, centrifuged for $5 \mathrm{~min}$ at $16000 \times \mathrm{g}$ (14 $000 \mathrm{rpm}$ at a tabletop centrifuge Eppendorf, rotor 5415C), dried in a speed-vacuum for $5 \mathrm{~min}$ and resuspended in $25 \mu \mathrm{l}$ water. After a denaturation for 2 min at $95^{\circ} \mathrm{C}$ and immediate cooling on ice, the sample was transferred into a special tube for sequencing and kept on ice until loading on an ABI-Prism ${ }^{\mathrm{TM}} 310$ capillary electrophoresis sequencing station (Perkin-Elmer) for analysis.

\subsubsection{Preparation of digoxigenin-labeled RNA probes}

For Northern blot analysis digoxigenine-labeled, single-stranded RNA probes were used. The RNA probes can be synthesized by an in vitro transcription catalyzed by SP6, T3 or T7 RNA polymerase. The plasmids containing the target gene sequence were linearized and then the RNA probes were synthesized with the DIG-RNA-Labeling Kit (Roche, Mannheim). The 
linearized plasmids allowed generation of transcripts of uniform length. One digoxigenin-11uridinine-monophosphate (DIG-UMP) residue is incorporated approximately per every 20-25 nucleotides.

For preparation of the digoxigenin-labeled antisense RNA probes for HIF-1 $\alpha, \mathrm{PAI}-1$ and $\beta$-Actin, the vectors pCRII-HIF1 $\alpha$, pBS-PAI-1 and pBS-Actin were linearized by BamH I, Xho I, and Xba I, respectively.

\subsubsection{In vitro transcription}

A sample in vitro transcription reaction usually includes:

Linearized plasmid

$11 \mu \mathrm{l}$

$10 \times$ transcription buffer

$2 \mu \mathrm{l}$

10 x labeling mix (ATP,CTP,GTP,UTP, DIG-UTP)

$2 \mu \mathrm{l}$

RNasin $(40 \mathrm{U} / \mu \mathrm{l})$

$1 \mu \mathrm{l}$

T7/T3 RNA polymerase $(20 \mathrm{U} / \mu \mathrm{l})$

$2 \mu \mathrm{l}$

DEPC- $\mathrm{H}_{2} \mathrm{O}$

$2 \mu \mathrm{l}$

The solution was incubated at $37^{\circ} \mathrm{C}$ for $1.5 \mathrm{~h}$. Then $0.5 \mu \mathrm{l}$ RNA polymerase was again added and the incubation was prolonged for another $1 \mathrm{~h}$. Synthesized digoxigenin-labeled RNA was precipitated with $2.5 \mu \mathrm{l} 4 \mathrm{M} \mathrm{LiCl}$ and $75 \mu \mathrm{l}$ absolute ethanol at $-20^{\circ} \mathrm{C}$ for at least $2 \mathrm{~h}$. The solution was centrifuged at $4^{\circ} \mathrm{C}, 12000 \times g(10000 \mathrm{rpm}$, SS-34 rotor) for $10 \mathrm{~min}$, the pellet washed with $80 \%$ ethanol and dried in a speed-vacuum. The pellet was dissolved in $100 \mu \mathrm{LEPC}-\mathrm{H}_{2} \mathrm{O}$ and stored at $-20^{\circ} \mathrm{C}$.

\subsubsection{Estimation of the labeling efficiency}

The labeling efficiency of the probe was estimated by comparison of the DIG-labeled probe with a DIG-labeled control DNA provided in the labeling kit. All steps were performed at RT. The transcript $(1 \mu \mathrm{l})$ as well as the digoxigenin-labeled control DNA (0.04-5ng) was spotted on a Hybond $(\mathrm{N}+)$ nylon membrane (Amersham). The nucleic acids were cross-linked to the membrane in an UV stratalinker (Stratagene) for 2 min and $1200 \mu \mathrm{J}$. Thereafter, the membrane was washed for $5 \mathrm{~min}$ in buffer 1 (see 3.2.12) and incubated with $1 \%$ blocking reagent (10\% blocking reagent diluted with buffer 1 ) for $20 \mathrm{~min}$. The membrane was then incubated for $20 \mathrm{~min}$ in $20 \mathrm{ml}$ of anti-digoxigenin antibody solution (1:10000 dilution in 1\% blocking reagent). The unbound antibody conjugate was removed by washing of the membrane twice in buffer 1 for 15 min. After 2 min equilibration in buffer 3 (described in 3.2.12), the color substrate solution containing $45 \mu \mathrm{l} \mathrm{NBT}$ and $35 \mu \mathrm{l}$ X-phosphate in $10 \mathrm{ml}$ of buffer 3 was added. The color spots 
started to appear within $3 \mathrm{~min}$. After about $10 \mathrm{~min}$ the reaction was stopped by washing the membrane in TE buffer.

\subsubsection{Northern Blot Analysis}

Northern blot analysis is used to quantify a target mRNA expression. The RNAs are separated on a denaturing formaldehyde agarose gel, transferred by capillary transfer to a nitrocellulose membrane and fixed by UV-cross-linking. The RNA of interest is identified by complementary hybridization with the specific probe.

All solutions used for the Northern blot were treated with DEPC $(1 \mathrm{ml} \mathrm{DEPC/1l})$ overnight and autoclaved. The electrophoresis and blot chambers, gel plates and combs before use were kept in $3 \% \mathrm{H}_{2} \mathrm{O}_{2}$ for at least $3 \mathrm{~h}$ to inactivate RNases.

\subsubsection{Denaturation of RNA}

The standard sample to be analyzed in a Northern blot contained 10-20 $\mu \mathrm{g}$ RNA and $16.5 \mu \mathrm{l}$ loading buffer. The sample was denaturated at $65^{\circ} \mathrm{C}$ for $20 \mathrm{~min}$ and subsequently cooled on ice for 2 min. After addition of $5 \mu$ sample buffer the RNA was loaded to the gel.

Loading buffer

Formamide

$14.3 \times$ MOPS

$37 \%(v / v)$ formaldehyde

The buffer was aliquoted and stored at $-20^{\circ} \mathrm{C}$.

MOPS $14.3 x$

MOPS

EDTA

$\mathrm{NaAc}$
$15 \mathrm{ml}$

$2.1 \mathrm{ml}$

$5.4 \mathrm{ml}$
Final concentration

$66.6(\mathrm{v} / \mathrm{v})$

$26.7 \mathrm{mM}$

$8.9 \%(\mathrm{v} / \mathrm{v})$

The $\mathrm{pH}$ was adjusted to 7.0 with $\mathrm{NaOH}$ and the solution was autoclaved.

Sample buffer

Glycerol

$0.5 \mathrm{M}$ EDTA

Bromphenolblue

DEPC- $\mathrm{H}_{2} \mathrm{O}$
$59.3 \mathrm{~g} / \mathrm{l}$

$5 \mathrm{~g} / \mathrm{l}$

$5.8 \mathrm{~g} / \mathrm{l}$
Final concentration

$286 \mathrm{mM}$

$1.3 \mathrm{mM}$

$7.1 \mathrm{mM}$

The buffer was aliquoted and stored at $-20^{\circ} \mathrm{C}$.

Final concentration

$\begin{array}{cc}5 & \mathrm{ml} \\ 20 & \mu \mathrm{l} \\ 10 & \mathrm{mg}\end{array}$

up to $10 \mathrm{ml}$

$$
\begin{array}{rl}
50 \% & (\mathrm{v} / \mathrm{v}) \\
1 & \mathrm{mM} \\
0.1 \% & (\mathrm{w} / \mathrm{v})
\end{array}
$$




\subsubsection{Agarose gel electrophoresis of RNA}

A $1.5 \%$ denaturing agarose gel was prepared as follows: $1.2 \mathrm{~g}$ agarose was dissolved by heating in $65 \mathrm{ml}$ DEPC- $\mathrm{H}_{2} \mathrm{O}$. Then $8 \mathrm{ml} 10 \times$ MOPS and $6.7 \mathrm{ml}$ formaldehyde was added. Formaldehyde was always added when the gel mixture was about $37^{\circ} \mathrm{C}$ in order to prevent its evaporation. After mixing, the gel was poured into the prepared gel plate and allowed to polymerize at RT for at least $1 \mathrm{~h}$. Then it was transferred into an electrophoresis chamber filled with 1 x MOPS buffer ( $700 \mathrm{ml})$. After loading the samples, the electrophoresis was performed at $100-120 \mathrm{~V}$ for about $2-2.5 \mathrm{~h}$.

\section{MOPS $10 x$}

MOPS

EDTA

$\mathrm{NaAc}$
$41.9 \mathrm{~g} / \mathrm{l}$

$4.1 \mathrm{~g} / \mathrm{l}$

$3.7 \mathrm{~g} / \mathrm{l}$
Final concentration

$$
200 \mathrm{mM}
$$

$50 \mathrm{mM}$

$10 \mathrm{mM}$

The $\mathrm{pH}$ was adjusted to 7.0 with $\mathrm{NaOH}$. The solution was autoclaved.

\subsubsection{Visualization of RNA with ethidium bromide staining}

After electrophoresis, the gel was washed by shaking in $150 \mathrm{ml}$ of a $1 \%$ glycine solution for 30 min. Then, a $5 \mu$ ethidium bromide solution (see 2.7) was added and the gel was further incubated for 5-10 min. Ethidium bromide forms a complex with RNA which is fluorescent under UV light; there are two predominant visible bands corresponding to the $28 \mathrm{~S}$ and $18 \mathrm{~S}$ ribosomal RNAs. The gel was photographed with a gel documentation station. Prior to blotting, the gel was washed for $20 \mathrm{~min}$ in $10 \times$ SSC (2.7).

\subsubsection{Transfer of RNA onto nylon membranes}

Total RNAs were transferred onto nylon membranes (Hybond $\mathrm{N}^{+}$, Amersham) by capillary blotting. In a plastic tray filled with $700 \mathrm{ml}$ of $10 \times$ SSC buffer a flat-surface plastic stand was fixed above the buffer level and covered (avoiding air bubbles) with the following: three layers 3MM paper stripes pre-wet in $10 \times$ SSC with their ends dipped in the buffer underneath; the RNA gel with the upper side downwards and surrounded by foil stripes to prevent drying-out of papers; the Hybond $\mathrm{N}^{+}$membrane; 3 layers of $3 \mathrm{MM}$ papers with the size of the gel and the membrane; approx. $10 \mathrm{~cm}$ thick layer of paper towels; a equally distributed weight of approx. 1 $\mathrm{kg}$. After at least 16 hours of blotting, the construction was dismantled. The covalent binding of the RNA molecules to the membrane surface was performed via cross-linking by UV radiation in an UV Stratalinker (Stratagene) for 2 min at $1200 \mu \mathrm{J}$. 


\subsubsection{Hybridization of RNA blots with digoxigenine-labeled RNA probes}

The membrane was placed in a hybridization glass tube and pre-hybridized in at least $6 \mathrm{ml}$ prehybridization solution at $65-68^{\circ} \mathrm{C}$ in a hybridization oven. After $30 \mathrm{~min}$ of incubation, the prehybridization solution was discarded and replaced with $6 \mathrm{ml}$ hybridization solution containing $100 \mathrm{ng} / \mathrm{ml}$ of digoxigenin-labeled antisense RNA probe.

The tube was rotated overnight at $65-68^{\circ} \mathrm{C}$ to allow hybridization of the labeled single-stranded probe with RNAs with complementary sequences. The solution containing the probe was collected and stored at $-20^{\circ} \mathrm{C}$ for multiple usages. The membrane was subjected to a series of washes: two times $\times 5$ min with $2 \times$ SSC / 0.1\% SDS and two times $\times 15$ min with $0.1 \times$ SSC / $0.1 \%$ SDS (see 2.7 ) for removing the unspecific-bound probe.

Pre- and hybridization solution

Deionized formamide

$10 \%$ blocking reagent

$20 \%$ SDS

$10 \% \mathrm{~N}$-lauroylsarcosine

$20 \times$ SSC
$12.5 \mathrm{ml}$

$6 \mathrm{ml}$

$25 \mu \mathrm{l}$

$250 \mu \mathrm{l}$

$6.25 \mathrm{ml}$
Final concentration

$\begin{array}{rl}50 \% & (\mathrm{v} / \mathrm{v}) \\ 2.5 \% & (\mathrm{w} / \mathrm{v}) \\ 0.02 \% & (\mathrm{w} / \mathrm{v}) \\ 0.1 \% & (\mathrm{w} / \mathrm{v}) \\ 5 & \mathrm{X}\end{array}$

The solution was stored at $4^{\circ} \mathrm{C}$.

\subsubsection{Detection and quantification}

The detection of the hybrids between the target RNA and the digoxigenin-labeled probe was performed using anti-digoxigenin antibodies conjugated to alkaline phosphatase (enzyme immunoassay). During the following dephosphorylation of dinatrium 3-(4-methoxyspiro $\{1,2-$ dioxetane-3, 2-(5'-chloro) tricyclo [3.3.1.1 $\left.{ }^{3,7}\right]$ decan\}-4-yl)-phenylphosphat (CSPD) by alkaline phosphatase a chemiluminescent unstable product was formed that produced light of $477 \mathrm{~nm}$. This light signal can be recorded on X-ray films. The quantification was done densitometrically. The detection was performed with the DIG Nucleic Acid Detection Kit (Roche) according to the manufacturer instructions. First, after hybridization and post hybridization washes the nylon membrane was equilibrated in $1 \times$ maleic acid buffer for $1 \mathrm{~min}$. To prevent nonspecific binding of the DIG antibody to the membrane it was shaked for $30 \mathrm{~min}$ in appropriate volume of $1 \%$ blocking reagent (10\% blocking reagent diluted to $1 \%$ with $1 \times$ maleic acid buffer). Then the nylon membrane was incubated for $30 \mathrm{~min}$ at RT in $50 \mathrm{ml}$ diluted antibody solution (antidigoxigenin Fab fragments conjugated to alkaline phosphatase, in $1 \%$ blocking reagent at a concentration of $75 \mathrm{mU} / \mathrm{ml}=1: 10000$ dilution $=5 \mu$ antibody solution in $50 \mathrm{ml} 1 \%$ blocking reagent). The unbound antibody conjugate was removed by washing in maleic acid buffer, containing $0.3 \%$ Tween - 2 x 15 min. After 1-2 min equilibration in buffer 3 the nylon membrane 
was wrapped in foil and incubated for 5 min with diluted CSPD solution (CSPD in buffer 3 at a concentration of $2,5 \mathrm{mM}=1: 1000=1 \mu \mathrm{l}$ CSPD in $1 \mathrm{ml}$ buffer 3 ). The liquid was completely removed by rolling the glass pipette on it and the membrane was dried for $10 \mathrm{~min}$ at $37^{\circ} \mathrm{C}$. Then the membrane was exposed to a Hyperfilm MP film (Amersham)) for 15, 30 or $90 \mathrm{~min}$ depending on strength of the signal.

For quantification of the RNA bands, TINA software (Raytest $\mathrm{GmbH}$ ) was used.

Final concentration

Buffer 1

Buffer 2

Buffer 3
Maleic acid-11.61 g/l

$\mathrm{NaCl}-8.78 \mathrm{~g} / \mathrm{l}$

$\mathrm{pH} 7.5$ with hard $\mathrm{NaOH}$

450 ml Buffer 1

$50 \mathrm{ml} 10$ x Blocking reagent

Tris-12.11 $\mathrm{g} / \mathrm{l}$

$\mathrm{NaCl}-5.84 \mathrm{~g} / 1 \mathrm{l}$

$\mathrm{MgCl}_{2}-10.17 \mathrm{~g} / \mathrm{l}$ after autoclaving

pH 9.5 with $\mathrm{HCl}$
$0.1 \mathrm{M}$

$0.15 \mathrm{M}$

$0.1 \mathrm{M}$

$0.1 \mathrm{M}$

$50 \mathrm{mM}$

\subsubsection{Electrophoretic Mobility Shift Assay (EMSA)}

Electrophoretic mobility shift assay (also known as "gel retardation assay" or "gelshift") provides a simple and rapid method for investigation of DNA-protein interactions. This method is widely used in studies of sequence-specific DNA binding proteins e.g. transcription factors. The gel shift assay is performed by incubating a purified protein or a mixture of proteins (nuclear or cell extracts, etc.) with a $\left[{ }^{32} \mathrm{P}\right]$ end-labelled DNA fragment containing a binding site(s) for the studied proteins. The eventual interaction complexes are analysed on non-denaturing polyacrylamide gels and visualized by autoradiography.

\subsubsection{Preparation of probes for analysis of DNA-protein binding}

To study the DNA-protein interactions with electrophoretic mobility gel shift assay synthetic oligonucleotides of $18-20$ bp were used. Before labelling with $\left[\gamma_{-}{ }^{32} \mathrm{P}\right]-\mathrm{ATP}$, a double-stranded probe was prepared by annealing of two complementary oligonucleotides. 
Annealing of two complementary oligodesoxynucleotides.

Final concentration

Oligodesoxynucleotide 1 (sense)

Oligodesoxynucleotide 2 (antisense)

$5 \mathrm{M} \mathrm{NaCl}$

$1 \mathrm{M}$ Tris, $\mathrm{pH} 7.8$

$\mathrm{H}_{2} \mathrm{O}$
$50 \mu \mathrm{g}$

$50 \mu \mathrm{g}$

$2 \mu l$

$4 \mu \mathrm{l}$

up to $100 \mu \mathrm{l}$
$0.5 \mu \mathrm{g} / \mu \mathrm{l}$

$0.5 \mu \mathrm{g} / \mu \mathrm{l}$

$100 \mu \mathrm{M}$

$40 \mu \mathrm{M}$

A 1 I Erlenmeyer flask with $800 \mathrm{ml}$ water was warmed up to $90^{\circ} \mathrm{C}$. The E-cup with the annealing mixture was transferred into the hot water and allowed to cool down at RT for at least 6h or overnight. The sample was stored at $-20^{\circ} \mathrm{C}$. To test whether the annealing was successful $1 \mu \mathrm{l}$ of the annealed DNA was loaded together with unannealed oligonucleotides on a $10 \%$ native acrylamide gel.

Native $10 \%$ acrylamide gel $(85 \mathrm{~mm} \times 90 \mathrm{~mm} \times 0,8 \mathrm{~mm})$ :

Acrylamide Rotiphorese ${ }^{\circledR G e l} 30$

$3,3 \mathrm{ml}$

$10 \times$ TBE

$1 \mathrm{ml}$

TEMED

$2 \mu \mathrm{l}$

APS-10\%

$70 \mu \mathrm{l}$

$\mathrm{H}_{2} \mathrm{O}$

up to $10 \mathrm{ml}$

Probes were mixed with $5 \mu \mathrm{l}$ DNA loading buffer and $4 \mu \mathrm{l} \mathrm{H}_{2} \mathrm{O}$ (total volume of $10 \mu \mathrm{l}$ ) and were loaded on the gel. The electrophoresis was performed in $1 \times$ TBE buffer for 30 min at $15 \mathrm{~mA}$. Then, the gel was incubated for $10 \mathrm{~min}$ in EtBr-containing solution $(1 \mu \mathrm{l} \mathrm{EtBr}$ in $10 \mathrm{ml} 1 \%$ glycine) and the DNA was visualized under UV light.

\section{$\underline{5}$ '-end labeling of DNA probes by T4 polynucleotide kinase}

Synthetic oligonucleotides lack phosphate groups at their 5' termini and therefore are easily radiolabeled by transferring the $\gamma^{32} \mathrm{P}$ from $\left[\gamma^{32} \mathrm{P}\right]$-ATP in a phosphorylation reaction catalysed by bacteriophage T4 polynucleotide kinase (T4-PNK). The radioactive labelling was performed by $\left[\gamma^{32}{ }^{32} \mathrm{P}\right]-\mathrm{ATP}$ with " 5 -labeling kit" (Amersham). 


\section{Final concentration}

Oligodesoxynucleotide $(10 \mathrm{pmol} / \mu \mathrm{l})$

$5 \mu \mathrm{l} \quad 50 \mathrm{pmol} / \mathrm{sample}$

$10 \times$ phosphorylation buffer

$1 \mu l \quad 1 x$

$\left[\gamma^{32} \mathrm{P}\right]-$ ATP

$5 \mu \mathrm{l} \quad 50 \mu \mathrm{Ci} /$ sample

T4-PNK (10 Units/ $\mu$ l)

$1 \mu \mathrm{l} \quad 10$ Units/sample

$\mathrm{H}_{2} \mathrm{O}$

up to $10 \mu \mathrm{l}$

The mixture was incubated at $37^{\circ} \mathrm{C}$ for $45 \mathrm{~min}$ and then at $70^{\circ} \mathrm{C}$ for $10 \mathrm{~min}$ to inactivate the T4 kinase. Unincorporated nucleotides and salts were removed using "Nucleotide Removal kit" (QIAGEN) following the instruction of the manufacturer. To test the labelling efficiency $1 \mu$ of the probe was measured in a liquid scintillation counter (PW 4700, Philips) Czerenkov counts $\left(1 \min \mathrm{H}^{3}\right)$.

\subsubsection{Preparation of nuclear extracts from HepG2 cells}

Nuclear protein extracts were prepared according to the method of Dignam et. al., (1983). All steps were performed at $4^{\circ} \mathrm{C}$ and pre-cooled buffers were used in order to prevent proteolytic degradation of the proteins. The cells were washed twice with $1 \times$ PBS and collected in approximately $600 \mu \mathrm{l}$ of ice-cold $1 \times$ PBS. The cells were harvested by centrifugation at $40 \times g$ (2000 rpm) for $2 \mathrm{~min}$ at $4^{\circ} \mathrm{C}$ and the pellet was resuspended in 5 PCV ("packed cell volume") of the hypotonic buffer A, containing 0,05-0,075\% Nonidet P-40. The cells were incubated for 10 min on ice and then the swollen cells were homogenized by vortexing (approximately 20-30s) or by 10-30 blows of a glass Teflon homogenizer. The cell homogenization was tested by microscopic examination after coloring the nuclei with Trypan Blue (1:1). Nuclei were separated from cell debris by centrifugation for $10 \mathrm{~min}$ at $700 \times \mathrm{g}\left(2300 \mathrm{rpm}\right.$ in a SS-34 rotor) at $4^{\circ} \mathrm{C}$. The nuclear pellet was mixed with 3 PCV of buffer A without NP-40 and again centrifuged for 20 min at $25300 \times g$ (14500 rpm in SS-34). The resulting pellet containing "crude" nuclei was resuspended in $3 \mathrm{PCV}$ of buffer $\mathrm{C}$ by 10-15 blows of the homogenizer. In order to extract nuclear proteins this solution was stirred in a magnet mixer for $30 \mathrm{~min}$ at $4^{\circ} \mathrm{C}$. Following centrifugation at $25300 \times g\left(14500 \mathrm{rpm}\right.$, SS-34) for $30 \mathrm{~min}$ at $4^{\circ} \mathrm{C}$ removed the debris; the supernatant was dialysed for maximum $4 \mathrm{~h}$ against 50 volumes of buffer $\mathrm{D}(\sim 200 \mathrm{ml})$. The dialysate was centrifuged at $25300 \times g(14500 \mathrm{rpm})$ for $30 \mathrm{~min}$ and the protein concentration in the supernatant was quantified by Bradford assay. The nuclear protein solution then was aliquoted and stored at $-70^{\circ} \mathrm{C}$. In some experiments, nuclear extracts were not subjected to dialysis but following the nuclear extraction, they were stored at $-70^{\circ} \mathrm{C}$ in buffer $\mathrm{C}$. 
Final concentration

\begin{tabular}{|c|c|c|}
\hline \multirow[t]{4}{*}{ Buffer A } & Hepes-KOH, pH 7.9 (200 mM) & $10 \mathrm{mM}$ \\
\hline & $\mathrm{MgCl}_{2} \times 6 \mathrm{H}_{2} \mathrm{O}$ & $1.5 \mathrm{mM}$ \\
\hline & $\mathrm{KCl}(1 \mathrm{M})$ & $10 \mathrm{mM}$ \\
\hline & DTT $(0,5 \mathrm{M})$ & $0.5 \mathrm{mM}$ \\
\hline \multirow[t]{6}{*}{ Buffer C } & Hepes-KOH, pH 7.9 (200 mM) & $20 \mathrm{mM}$ \\
\hline & $\mathrm{MgCl}_{2} \times 6 \mathrm{H}_{2} \mathrm{O}$ & $1,5 \mathrm{mM}$ \\
\hline & $\mathrm{NaCl}$ & $0,42 \mathrm{M}$ \\
\hline & DTT $(0,5 \mathrm{M})$ & $0,5 \mathrm{mM}$ \\
\hline & $\operatorname{EDTA}(0,2 \mathrm{M})$ & $0,2 \mathrm{mM}$ \\
\hline & Glycerol (50\%) & $20 \%(v / v)$ \\
\hline \multirow[t]{5}{*}{ Buffer D } & Hepes-KOH, pH 7.9 (200 mM) & $20 \mathrm{mM}$ \\
\hline & $\mathrm{KCl}(1 \mathrm{M})$ & $100 \mathrm{mM}$ \\
\hline & DTT $(0,5 \mathrm{M})$ & $0,5 \mathrm{mM}$ \\
\hline & $\operatorname{EDTA}(0,2 \mathrm{M})$ & $0,2 \mathrm{mM}$ \\
\hline & Glycerol (50\%) & $20 \%(v / v)$ \\
\hline
\end{tabular}

All buffers were supplemented with the following protease inhibitors immediately before the beginning of the nuclear isolation: phenylmethylsulfonyl fluoride (PMSF), aprotinin, leupeptin, pepstatin, protease inhibitor tablet (1 tablet/10 $\mathrm{ml}$, Roche) and fresh reducing agent (DTT) (see 2.7).

\subsubsection{Electrophoretic Mobility Shift Assay (EMSA)}

Gelshifts were performed in non-denaturing conditions to allow the binding and movement of complexes between the investigated transcription factors and labelled fragments from the human PAI-1 gene promoter; the components for the preparation of an non-denaturing gel are listed below:

Native acrylamide gel for EMSA:

Acrylamide Rotiphorese ${ }^{\circledR}$ Gel 30

$10 \mathrm{ml}$

$10 \times$ TBE

$5 \mathrm{ml}$

TEMED

$20 \mu \mathrm{l}$

APS (10\%)

$350 \mu \mathrm{l}$

$\mathrm{H}_{2} \mathrm{O}$

up to $50 \mathrm{ml}$ 
After polymerisation the gel was mounted in the electrophoresis chamber, bubbles between the glasses were removed, the pockets of the gel were cleaned and the gel was pre-run at $250 \mathrm{~V}$ for at least $30 \mathrm{~min}$ in $1 \times$ TBE.

\section{Binding reaction of the DNA probes with the nuclear extracts}

The protein samples were mixed with $5 \times$ Ratcliffe buffer and poly-dldC (a non-specific DNAmimicking polymer) in a total volume of $20 \mu \mathrm{l}$ (with or without $0,5 \mu \mathrm{g}-1 \mu \mathrm{g}$ antibodies) and incubated on ice for about 45 min for the elimination of the non-specific DNA-binding activity in the protein samples. Then radioactively labeled DNA probes were added and the binding reactions were further incubated for $45 \mathrm{~min}$ at $\mathrm{RT}$. After addition of $2 \mu \mathrm{l}$ of loading buffer ( $1 \mathrm{x}$ TBE, $60 \%$ glycerol and bromphenolblue) the samples were loaded to the gel. The gel was run for 3-4 hours at RT and $250 \mathrm{~V}$. Then the gel chamber was dismantled, the gel was wrapped in foil between two sheets of Whatman paper and dried under vacuum at $80^{\circ} \mathrm{C}$ for $45 \mathrm{~min}$. The dried gel was exposed for radiography in a Phosphoimager cassette overnight.

Binding mixture:

Buffer $\mathrm{C}$ or $\mathrm{D}$ with nuclear extracts

Ratcliffe buffer $5 x$

Poly $\mathrm{d}(\mathrm{I}-\mathrm{C}) 1 \mu \mathrm{g} / \mu \mathrm{l}$

DTT $50 \mathrm{mM}$

Antibodies (when nessesary)

DNA probe

$\mathrm{H}_{2} \mathrm{O}$

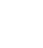

Final concentration

$\begin{array}{rrrr}\text { x } & \mu \mathrm{l} & 7-10 & \mu \mathrm{g} / \mathrm{sample} \\ 4 & \mu \mathrm{l} & & \\ 0.25-0.75 & \mu \mathrm{l} & 250-750 & \mathrm{ng} / \mathrm{sample} \\ 2 & \mu \mathrm{l} & 5 & \mathrm{mM} / \mathrm{sample} \\ 2 & \mu \mathrm{l} & 0.5-1 & \mu \mathrm{g} / \mathrm{sample} \\ 1-3 & \mu \mathrm{l} & 0.5-1.5 & \mathrm{ng} / \mathrm{sample}\end{array}$

Poly-d(I-C) was dissolved in sterile water in concentration $1 \mu \mathrm{g} / \mu \mathrm{l}$ (considering the fact that $\mathrm{OD}_{260}=1$ corresponds to $50 \mu \mathrm{g} / \mathrm{ml}$ dsDNA) and stored at $-20^{\circ} \mathrm{C}$.

\section{$5 \times$ Ratcliffe buffer:}

$\mathrm{KCl}$

$\mathrm{MgCl}_{2} \times 6 \mathrm{H}_{2} \mathrm{O}$

EDTA

Glycerol 
overnight to a europium-covered phosphoimager screen. Under X-ray irradiation, europium electrons are raised to higher energy levels and due to the laser beam of the scanner they return to their original energy levels thereby emitting energy in the form of light that is detected by a photomultiplier. The signal is further processed with the help of the ImageQuant software and displayed on the computer screen as black spots or bands, so the resulting picture is very similar to the picture obtained by autoradiography X-ray film exposure. This method of detection is much more sensitive than the classical autoradiography and shortens exposure time of the gel approx. to $1 / 10$ of the time needed to obtain an autoradiography on film.

\subsection{Biochemical methods}

\subsubsection{Protein isolation from cell cultures}

Cultured cells were washed twice with ice-cold 1 x PBS and scraped off the plate into $150 \mu \mathrm{l}$ lysis buffer. Then, the cells were thoroughly destroyed by ultrasonication on ice for $10 \mathrm{~min}$. After centrifugation at $10000 \times g(12000 \mathrm{rpm}, \mathrm{SS}-34$ rotor $)$ at $4^{\circ} \mathrm{C}$ for $20 \mathrm{~min}$, the supernatant was collected into a new tube. Protein concentration of the cell extract was measured using Bradford method.

Lysis buffer:

Tris- $\mathrm{HCl} \mathrm{pH} 8.0$ (1 M)

$\operatorname{EDTA}(0.5 \mathrm{M})$

$\mathrm{NaCl}(5 \mathrm{M})$

NP-40

$\mathrm{H}_{2} \mathrm{O}$

DTT
$12.5 \mathrm{ml}$

$2.5 \mathrm{ml}$

$7.5 \mathrm{ml}$

$1.25 \mathrm{ml}$

up to $100 \mathrm{ml}$

$100 \mu \mathrm{l}$
Final concentration

$$
\begin{aligned}
& 50 \mathrm{mM} \\
& 5 \mathrm{mM} \\
& 150 \mathrm{mM} \\
& 0.5 \%(\mathrm{v} / \mathrm{v}) \\
& 5 \mathrm{mM} \\
& 1 / 10 \mathrm{ml} \text { buffer }
\end{aligned}
$$

Protease inhibitors cocktail tablet (Roche)

The lysis buffer without DTT and protease inhibitors can be stored at $4^{\circ} \mathrm{C}$ for several mounts. DTT, PMSF and protease inhibitor cocktail tablet were added freshly before use.

\subsubsection{Protein concentration determination}

The concentrations of native protein extracts were measured by a colorimetric assay (Bradford, 1976) which is based on a spectral shift in the absorption maximum (from $465 \mathrm{~nm}$ to $596 \mathrm{~nm}$ ) of the Coomassie Brilliant Blue G-250 dye upon its binding to hydrophobic residues in the proteins. $2 \mu \mathrm{l}$ protein extracts and water up to $100 \mu \mathrm{l}$ was mixed with $1 \mathrm{ml}$ Bradford reagent (see bellow), 
incubated $5 \mathrm{~min}$ at RT and the optical density of the samples was measured at $578 \mathrm{~nm}$. A water dilution of pure Bradford reagent was used as a blank control. Protein concentrations were estimated with the help of a standard curve derived from different BSA protein amounts ( $2 \mu \mathrm{g}, 4$ $\mu \mathrm{g}, 6 \mu \mathrm{g}, 8 \mu \mathrm{g}, 16 \mu \mathrm{g})$ measured in the same experiment.

\begin{tabular}{ll} 
Bradford reagent & $100 \mathrm{mg}$ \\
\hline $95 \%$ Ethanol (v/v) & $50 \mathrm{ml}$ \\
$85 \%$ Phosphoric acid (v/v) & $100 \mathrm{ml}$ \\
$\mathrm{H}_{2} \mathrm{O}$ & up to $1 \mathrm{l}$
\end{tabular}

\subsubsection{Immunoblotting (Western blot)}

\subsubsection{SDS-polyacrylamide gel electrophoresis}

In analytical SDS gel electrophoresis of proteins, the strongly anionic detergent SDS is used in combination with heat treatment and a reducing agent (DTT) to dissociate the polypeptide chains of the proteins before they are loaded on the gel. The denatured polypeptides form complexes with SDS and become negatively charged. The amount of SDS bound is usually proportional to the molecular weight of the polypeptide and independent of its sequence, thus SDS-polypeptide complexes migrate in polyacrylamide gels in accordance with the size of the polypeptide. By using markers of known molecular weight, it is possible to estimate the molecular weight of the polypeptide chain(s). In most cases, SDS-polyacrylamide gel electrophoresis is carried out with a discontinuous buffer system in which the buffers in the reservoirs are of different $\mathrm{pH}$ and ionic strength from the buffers used to cast the gel. After migrating through a stacking gel of high porosity, the complexes are deposited in a very thin zone (or stack) on the surface of the resolving gel. The ability of discontinuous buffer systems to concentrate all of the complexes in the sample into a very small volume greatly increases the resolution of SDS-polyacrylamide gels (Laemmli, 1970).

In this study, a $4 \%$ "stacking" gel and a $10 \%$ or $7.5 \%$ "resolving" gel, respectively, were usually used. Before loading, the protein samples were mixed with loading buffer and denatured by incubation for $5-10 \mathrm{~min}$ at $95-100^{\circ} \mathrm{C}$ (boiling water bath) and immediately cooled on ice before loading on the gel. $20-30 \mu \mathrm{l}(100 \mu \mathrm{g})$ of samples were loaded per lane. Initially the electrophoresis was performed at $10 \mathrm{mV} / 59 \mathrm{~cm}^{2}$ gel until the samples reached the beginning of the resolving gel and then the gel was subjected to $20 \mathrm{~mA}$ until the bromphenolblue dye had run out of the gel. The size of the separated proteins was estimated in comparison to the Standard Protein Marker Mixture (Amerscham Biosciences) loaded on the same gel. 
SDS-PAGE gel preparation

Rotiphorese ${ }^{\circledR G e l} 30$

Resolving Buffer (1.875M Tris pH 8.8)

Stacking Buffer (0.6 M Tris pH 6.8)

Water

$10 \% \operatorname{SDS}(\mathrm{w} / \mathrm{v})$

$10 \%$ APS (w/v)

TEMED

$\underline{\text { Tank Buffer }(10 \mathrm{x})}$

Loading Buffer (4 x)

\begin{tabular}{|c|c|}
\hline Resolving Gel (10\%) & Stacking Gel (4\%) \\
\hline $2.33 \mathrm{ml}$ & $0.45 \mathrm{ml}$ \\
\hline $1.462 \mathrm{ml}$ & - \\
\hline- & $0.27 \mathrm{ml}$ \\
\hline $3,05 \mathrm{ml}$ & $1.9 \mathrm{ml}$ \\
\hline $69 \mu \mathrm{l}$ & $27 \mu l$ \\
\hline $34,5 \mu l$ & $20 \mu l$ \\
\hline $2,2 \mu l$ & $3 \mu l$ \\
\hline
\end{tabular}

Tris (pH 8.3)

$50 \mathrm{ml}$

Glycine

$384 \mathrm{ml}$

SDS

$0.1 \% \quad(w / v)$

Tris (pH 7.4)

$100 \mathrm{mM}$

Bromophenolblue

$0.05 \% \quad(w / v)$

SDS

$3 \% \quad(w / v)$

Glycerol

DDT (fresh)
$7,5 \% \quad(\mathrm{v} / \mathrm{v})$

$5 \% \quad(\mathrm{v} / \mathrm{v})$

\subsubsection{Semi-dry transfer of proteins onto a nitrocellulose membrane}

The transfer of proteins from the SDS-PAGE gel onto nitrocellulose (Protran B85, Schleicher \& Schuell) membranes was performed by a semi-dry blotting procedure (Towbin et al., 1979 with modifications) in an electric field between two graphite plates. The construction of the blotting "sandwich" $\left(18 \times 8 \mathrm{~cm}^{2}\right)$ from anode to cathode plate was as follows: a layer of Whatman paper, pre-soaked in transfer anode buffer 1 , then a second layer pre-soaked in anode buffer 2 , the nitrocellulose membrane pre-wet in $\mathrm{H}_{2} \mathrm{O}$ and in anode buffer 2 afterwards, the gel, pre-soaked in cathode buffer for $10 \mathrm{~min}$, two layers of pre-soaked in cathode buffer Whatman sheets. The bubbles between the sheets were removed by gentle rolling a glass pipette on top of the sandwich; the cathode plate was mounted and pressed with a weight of approx. $1 \mathrm{~kg}$ for better contact between all the layers. The transfer was performed with a constant electric current of 59 $\mathrm{mA}$ per gel for $1: 20 \mathrm{~h}\left(1.2 \mathrm{~mA} / \mathrm{cm}^{2}\right)$. The protein transfer was controlled by reversible staining with Ponceau S solution. 
Final concentration

\section{$\underline{\text { Anode Buffer } 1}$}

Anode Buffer 2

Cathode Buffer

$\underline{\text { Ponceau S }}$
Tris-36.4g/l, $\mathrm{pH} 11.3$ with 2M Borate

$\mathrm{MeOH} 200 \mathrm{ml} / \mathrm{l}$

Tris-6 g/l, pH 10.6

$\mathrm{MeOH} 200 \mathrm{ml} / \mathrm{l}$

Tris-3g/l, pH 9.0

$\mathrm{MeOH} 200 \mathrm{ml} / \mathrm{l}$

Ponceau S-2.5 g/l

glacial $\mathrm{CH}_{3} \mathrm{COOH} 150 \mathrm{ml} / \mathrm{l}$

$\mathrm{MeOH} 400 \mathrm{ml} / \mathrm{l}$
$300 \mathrm{mM}$

$20 \% \quad(v / v)$

$\begin{array}{rr}25 & \mathrm{mM} \\ 20 \% & (\mathrm{v} / \mathrm{v})\end{array}$

$25 \mathrm{mM}$

$20 \% \quad(v / v)$

$0,1 \% \quad(\mathrm{v} / \mathrm{v})$

$15 \% \quad(v / v)$

$40 \% \quad(v / v)$

\subsubsection{Immunodetection of proteins with specific antibodies}

The non-specific protein-binding capacity of the nitrocellulose membrane was saturated by $1 \mathrm{~h}$ incubation at room temperature in blocking buffer (1 x PBS, 0.1\% Tween 20,5\% (w/v) non-fat dried milk). The membrane then was incubated with appropriately diluted in the blocking buffer primary antibodies overnight at $4^{\circ} \mathrm{C}$ with gentle shaking. On the next day, the membrane was washed three times for 15 min each in 1 x PBS/T(1 x PBS, 0.1\% Tween 20) and then incubated with 1:5000 dilution of the horseradish peroxidase (HRP)-secondary antibody in blocking buffer for $1 \mathrm{~h}$ at RT on a shaker. Following three washes with $1 \times \mathrm{PBS} / \mathrm{T}$, the HRP-conjugated secondary antibody was detected using Enhanced Chemiluminescence Plus ${ }^{\mathrm{TM}}(\mathrm{ECL}+)$ Kit (Amersham). The membrane was incubated with the enzyme substrate for $5 \mathrm{~min}$ at room temperature and the chemiluminescence was detected by an exposition to an X-ray Hyperfilm MP (Amersham) for an optimal time range (from $15 \mathrm{sec}$ to several min) according to the strength of the signals. Protein expression was quantified using a densitometer. 


\section{RESULTS}

\subsection{Induction of human PAI-1 gene expression by IGF-1 and insulin in HepG2 cells}

\subsubsection{Induction of human PAI-1 mRNA and protein expression by IGF-1 and insulin under normoxia and hypoxia}

IGF-1 and insulin are known to induce the expression of genes containing hypoxia-responsive elements (HREs) in their promoters by stimulating the formation of the hypoxia-inducible factor (HIF-1) transcriptional complex (Zelzer et al., 1998). Since the human and the rat PAI-1 genes are induced by hypoxia via the promoter region containing HRE-2, a binding target for HIF-1 (Kietzmann et al., 1999; Fink et al., 2002) it should be examined whether IGF-1 and insulin can enhance PAI-1 mRNA expression and protein levels under normoxia or hypoxia in HepG2 cells. The expression of the human PAI-1 gene was detected at the mRNA level by Northern blot and on the protein level by Western blot. Prior to addition of IGF-1 or insulin, HepG2 cells were maintained for 16-18 $\mathrm{h}$ in serum-free medium and then treated with IGF-1 (100 nM) and acetic acid in the respective controls, or with insulin (500 nM). For RNA isolation and Northern blot detection cells were incubated for $4 \mathrm{~h}$ under normoxia or hypoxia, while for protein preparation and Western blotting cells were cultured for $24 \mathrm{~h}$ under the same conditions.

Northern blot experiments with HepG2 cells revealed two distinct PAI-1 mRNAs (3.2 kb and 2.4 kb) generated from the single gene in humans by alternative splicing (Fattal \& Billadello, 1993) which were summed for quantification. Hypoxia enhanced PAI-1 mRNA by about 2,5-fold (Fig. $6,7)$ in accordance with the data from a previous study (Kietzmann et al., 1999).

Treatment of cells with IGF-1 under normoxia induced PAI-1 mRNA by about 2-fold. When exposed to hypoxia and IGF-1, PAI-1 mRNA increased by about 3,5-fold. The IGF-1-mediated increase of PAI-1 mRNA was followed by an increase of PAI-1 protein levels. IGF-1 enhanced PAI-1 protein levels by about 4-fold under normoxia and by about 5-fold under hypoxia (Fig. 6). Insulin also induced the expression of PAI-1 mRNA in HepG2 cells. The admission of insulin caused an increase in PAI-1 mRNA by about 3-fold under normoxia and the exposure to hypoxia and insulin enhanced PAI-1 mRNA about 4-fold. The increase in PAI-1 protein levels by insulin was by about 1.7-fold under normoxia and by about 3-fold under hypoxia (Fig. 7).

\subsubsection{IGF-1 facilitates HIF-1 binding to the HRE and E-boxes of the human PAI-1 promoter}

To analyze whether the IGF-1 effects on PAI-1 gene expression are mediated by HRE and Eboxes 4 and 5 via binding of HIF-1, electrophoretic mobility shift assays (EMSA) were performed. Nuclear protein extracts were prepared from HepG2 cells cultured in the presence of IGF-1 under normoxia and hypoxia. When the HRE-spanning oligonucleotide was incubated with the nuclear extracts, three DNA-protein complexes were found. The formation of the fastest 
complex was enhanced when nuclear extracts from hypoxic cells or from normoxic cells treated with IGF-1 were used (Fig. 8). To investigate the presence of HIF-1 in these complexes, an antibody against HIF-1 $\alpha$ was included in the binding reaction. Addition of the antibody against HIF-1 $\alpha$, abolished the formation of the fastest complex but did not lead to the formation of the supershift (Fig. 8). When labeled oligonucleotides spanning E-box 4 and E-box 5 were incubated with HepG2 nuclear extracts, also three major DNA-protein complexes were detected (Fig. 8).

(A)

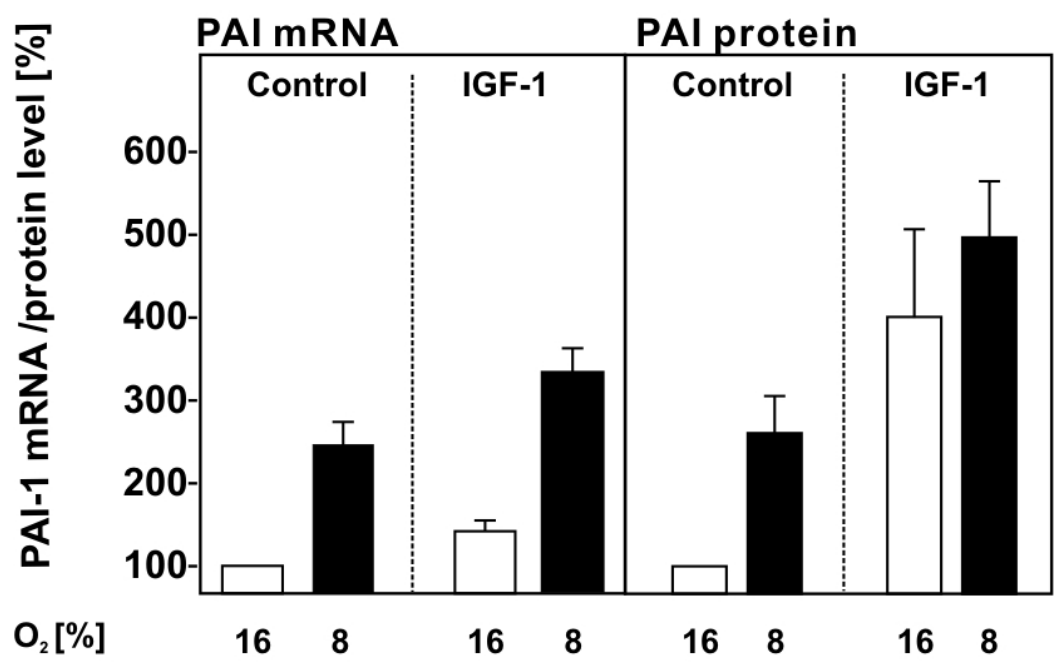

(B)

$\mathrm{O}_{2}[\%]$

PAI-1 mRNA

B-Actin mRNA

\section{Control IGF-1}
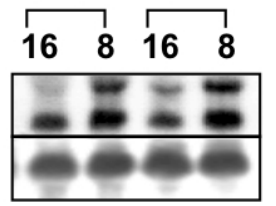

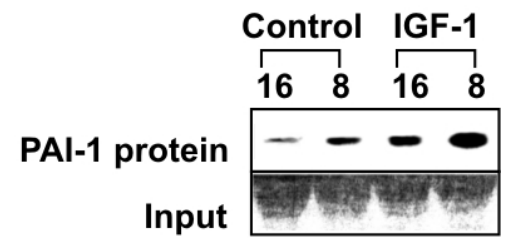

Figure 6. IGF-1-dependent increase of human PAI-1 mRNA and protein expression in HepG2 cells. HepG2 cells were cultured under normoxia $\left(16 \% \mathrm{O}_{2}\right)$ for $24 \mathrm{~h}$. At $24 \mathrm{~h}$ the medium was changed and the cells were further cultured under normoxic $\left(16 \% \mathrm{O}_{2}\right)$ or hypoxic $\left(8 \% \mathrm{O}_{2}\right)$ conditions in the presence of IGF-1. (A) The PAI-1 mRNA and protein levels were measured by Northern and Western blot, respectively. The PAI-1 mRNA and protein levels under normoxia $\left(16 \% \mathrm{O}_{2}\right)$ were set to $100 \%$. Values represent means \pm SEM of at least three independent experiments. (B) Representative Northern and Western blots. $20 \mu \mathrm{g}$ of total RNA isolated from cultured HepG2 cells were subjected to Northern blot analyses and hybridized with DIG-labeled PAI-1 and $\beta$-actin antisense RNA probes (see Materials and Methods). $100 \mu \mathrm{g}$ of protein from the HepG2 cell culture medium were subjected to Western blotting with an antibody against hPAI-1. Autoradiographic signals were detected by chemiluminescence and quantified by videodensitometry. 
Again, formation of the fastest complex was enhanced when nuclear extracts from hypoxia or IGF-1 treated cells were used. Addition of the HIF-1 $\alpha$ antibody prevented formation of this complex bound to E-box 4 and E-box 5, confirming that this complex contains HIF-1 $\alpha$ proteins. Moreover, mutation of the HRE, E4 and E5 eliminated binding of nuclear proteins, showing that the observed binding pattern is specific for these boxes. Thus, this data substantiated the idea that hypoxia and IGF-1 enhance HIF-1 binding to HRE, E4 and E5 within the human PAI-1 promoter.

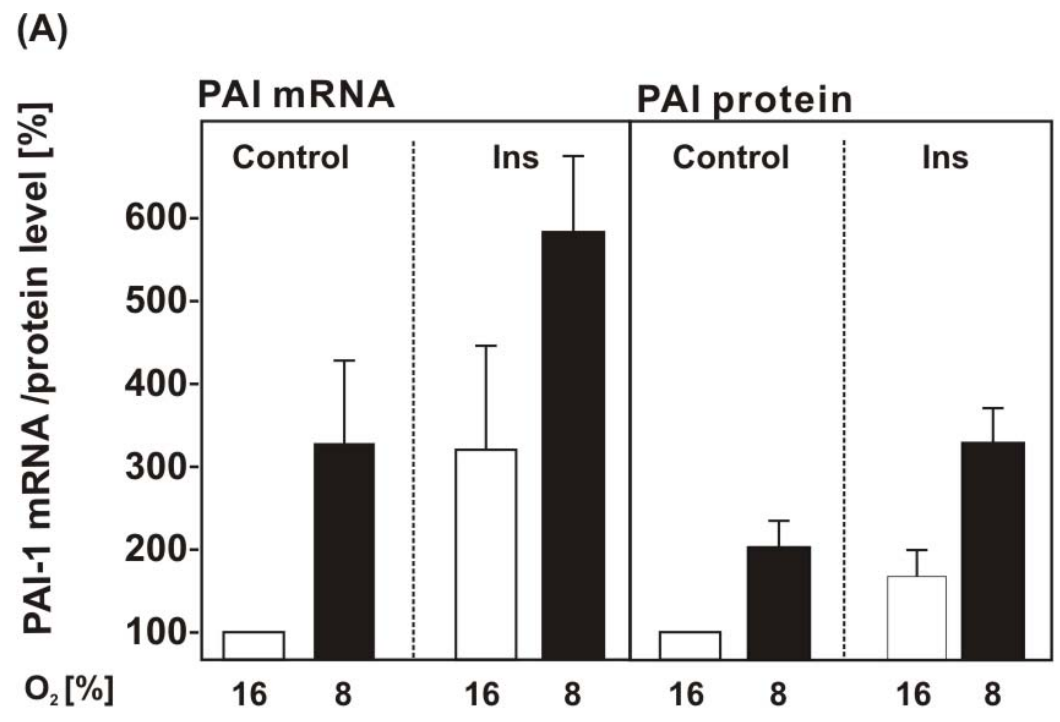

(B)

$\mathrm{O}_{2}[\%]$

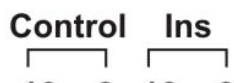

PAI-1 mRNA

B-Actin mRNA

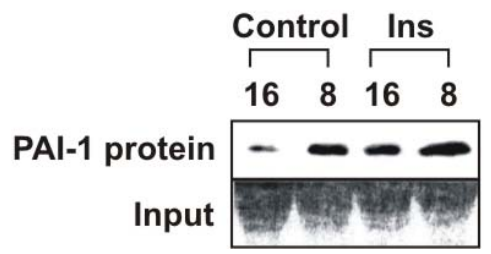

Figure 7. Insulin-dependent increase of human PAI-1 mRNA and protein levels in HepG2 cells. HepG2 cells were cultured under normoxia $\left(16 \% \mathrm{O}_{2}\right)$ for $24 \mathrm{~h}$. At $24 \mathrm{~h}$ the medium was changed and the cells were further cultured under normoxic $\left(16 \% \mathrm{O}_{2}\right)$ or hypoxic $\left(8 \% \mathrm{O}_{2}\right)$ conditions in the presence of insulin. (A) The PAI-1 mRNA and protein levels were measured by Northern and Western blot, respectively. The PAI-1 mRNA and protein levels under normoxia $\left(16 \% \mathrm{O}_{2}\right)$ were set to $100 \%$. Values represent means \pm SEM of at least three independent experiments. (B) Representative Northern and Western blots. $20 \mu \mathrm{g}$ of total RNA isolated from cultured HepG2 cells were subjected to Northern blot analyses and hybridized with DIG-labeled PAI-1 and $\beta$-actin antisense RNA probes. $100 \mu \mathrm{g}$ of protein from the HepG2 cell culture medium were subjected to Western blotting with an antibody against human PAI-1. Autoradiographic signals were detected by chemiluminescence and quantified by videodensitometry. 
(A)

$\begin{array}{lcc}\text { HIF-1 } & \text { consensus } & \text { BACGTSSK } \\ \text { HRE } & -199 /-181 & \text { TCTTACACACGTACACACA } \\ \text { E4 } & -571 /-552 & \text { ACAATCACGTGGCTGGCT } \\ \text { E5 } & -689 /-670 & \text { AGTCTGGACACGTGGGGA } \\ & & \\ \text { HREm } & -199 /-181 & \text { TCTTACACttaatCACACA } \\ \text { M4 } & -571 /-552 & \text { ACAATCttaatGCTGGCT } \\ \text { M5 } & -689 /-670 & \text { ATGCTGGACttaatGGGA }\end{array}$

(B)

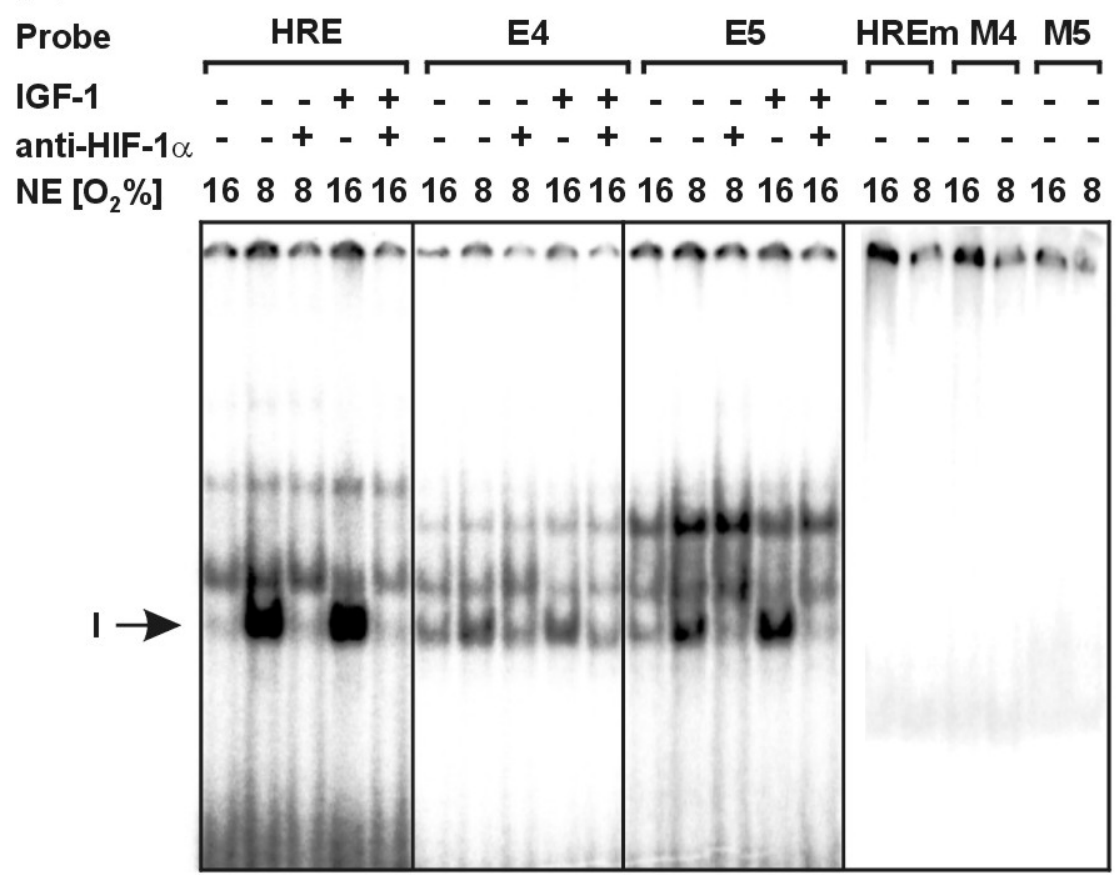

Figure 8. Induction of HIF-1 binding to the HRE, E4 and E5 boxes of the human PAI-1 promoter. (A) The HIF-1 consensus sequence BACGTSSK with $\mathrm{B}=\mathrm{G} / \mathrm{C} / \mathrm{T}, \mathrm{S}=\mathrm{G} / \mathrm{C}$ and $\mathrm{K}=\mathrm{G} / \mathrm{T}$; oligonucleotides spanning HRE, E-box 4 and E-box 5 were used as probes and bases matching the consensus sequence are underlined, mutated bases within HRE, E-box 4 and E-box 5 are indicated by lower case letters.

(B) Nuclear extracts were prepared from confluent HepG2 cells cultured under either normoxia $\left(16 \% \mathrm{O}_{2}\right)$ or hypoxia $\left(8 \% \mathrm{O}_{2}\right)$ for $4 \mathrm{~h}$ or in the presence of IGF-1 under normoxia for $4 \mathrm{~h}$. Electrophoretic mobility shift assays (EMSAs): the respective ${ }^{32} \mathrm{P}$-labelled human PAI-1 HRE, E4 and E5 oligonucleotides were incubated with $7 \mu \mathrm{g}$ nuclear extracts from HepG2 cells. In supershift experiments the nuclear extracts were pre-incubated on ice for 45 min with $0,5 \mu \mathrm{g} \mathrm{HIF-1} \alpha$ antibody before adding the labeled probes. The DNA-protein complexes were separated by electrophoresis on $5 \%$ native polyacrylamide gels and visualized by phosphoimaging. The same nuclear extracts were incubated with radioactively labeled oligonucleotides containing mutations within the boxes. I, induced HIF-1 complex. 


\subsubsection{Regulation of the human PAI-1 promoter Luc gene constructs in HepG2 cells by IGF-1 and insulin}

Since it was hypothesized that hypoxia-responsive elements (HREs) and E-boxes are commonly involved in mediating the effect of insulin and IGF-1 on gene transcription (Zelzer et al., 1998), we investigated the involvement of the HRE and the classical E-boxes E4 and E5 in the IGF-1-dependent and insulin-dependent human PAI-1 expression. For the purpose of analyses the -806 bp wild-type human PAl-1 promoter Luc construct (pGI3hPAl-806/+19) and its derivates, mutated in HRE as well as in the classical E-boxes were transfected into HepG2 cells which were then cultured in the presence of IGF-1 or insulin under normoxia and hypoxia.

\subsubsection{IGF-1-activated hPAI-1 promoter Luc gene expression in HepG2 cells}

After transfection of the wild-type human PAI-1 promoter Luc construct and exposure of the cells to hypoxia, Luc activity was enhanced by about 2-fold, in line with previous findings. When the wild-type PAI-1 promoter construct-transfected cells were exposed to IGF-1, Luc activity increased by about 3-fold under normoxia and by about 4-fold under hypoxia. In cells transfected with the construct containing a mutated HRE, pGI3hPAI-HREm, the hypoxiamediated induction of Luc activity was completely abolished and the IGF-1-dependent induction of Luc activity was decreased by about $50 \%$ each under normoxia and hypoxia. Mutation of the E4 and E5 boxes in the PAl-1 promoter constructs pGl3hPAl-M4 and pGl3hPAl-M5 reduced induction of Luc activity under hypoxia but did not affect the IGF-1-dependent induction of Luc activity under normoxia (Fig. 9). By contrast, mutation of either E4 or E5 abolished the additive effect of IGF-1 on the hypoxia-mediated response. After transfection of the PAI-1 construct pGI3hPAI-HREmM45 with mutations in HRE, E-box 4 and E-box 5, induction of Luc activity was nearly abolished after treatment with IGF-1, while no induction was detectable under hypoxia (Fig. 9). These results indicate that the HRE and the classical E-boxes can contribute to the hypoxia-mediated response of the PAI-1 gene in HepG2 cells and that IGF-1 might induce human PAI-1 expression via HIF-1.

\subsubsection{Insulin-activated hPAI-1 promoter Luc gene expression in HepG2 cells}

The wild-type human PAI-1 promoter construct can be activated not only by hypoxia but also by insulin as detected by a luciferase reporter assay. Mutation of HRE in pGI3hPAI-HREm construct abolished the insulin- and hypoxia-dependent activation of the hPAl-1 promoter (Fig.10). Mutation of the E-box 4 and 5 in the human PAI-1 promoter constructs pGI3hPAI-M4 and pGI3hPAI-M5 abolished the induction by insulin under normoxia whereas the hypoxia response was enhanced. The triple mutant (pGI3hPAI-HREmM45) construct responded neither to insulin nor to hypoxia, thus indicating again the involvement of HRE in the stimulation of human PAI by insulin and hypoxia (Fig. 10). This data suggests that the effect of insulin on the 
hPAl-1 promoter is mediated mostly by HRE and HIF-1; however, this does not exclude the possibility of other insulin responsive elements in the hPAI-1 promoter.

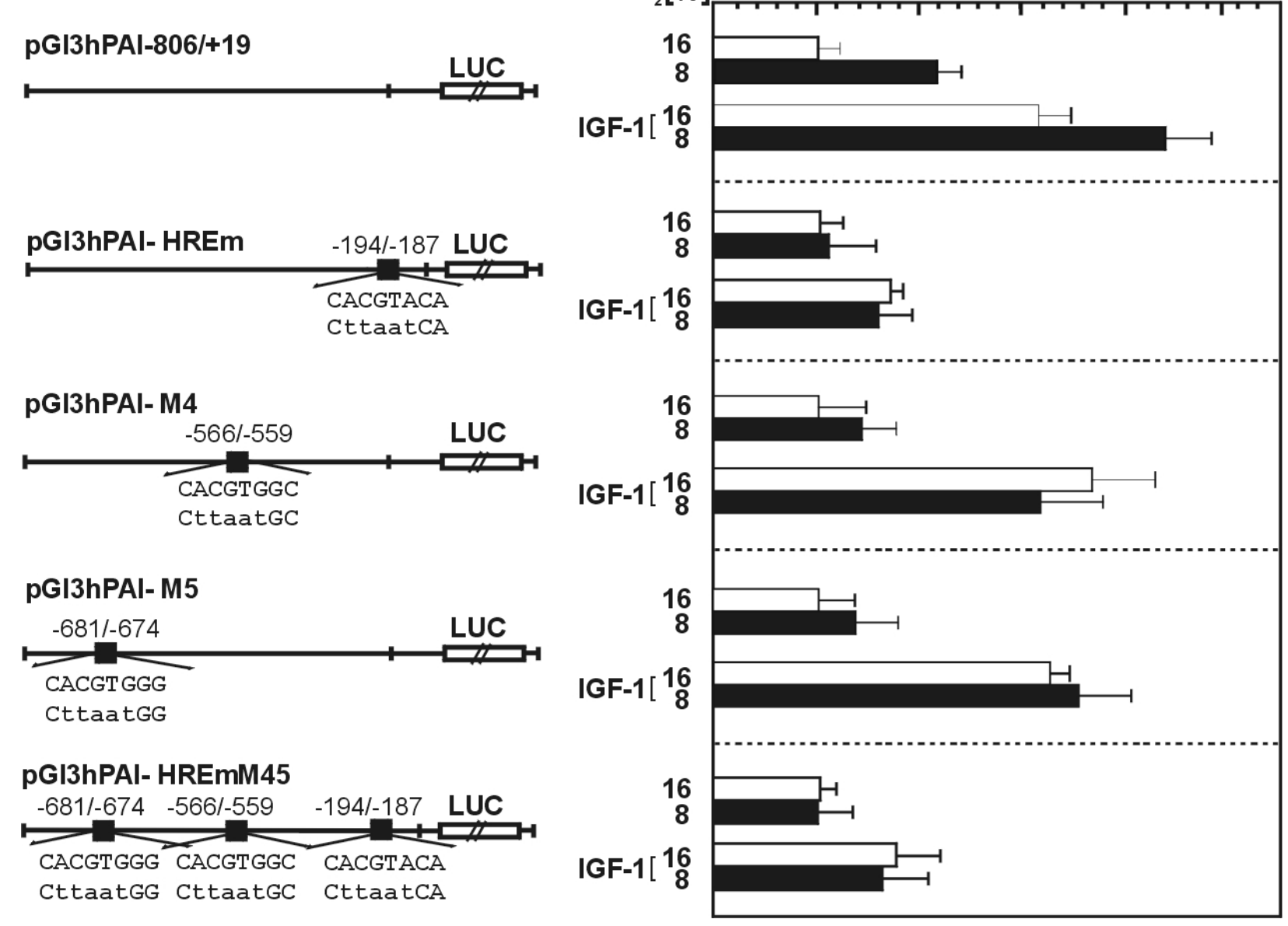

Figure 9. Induction of human PAI-1 promoter constructs by IGF-1 in HepG2 cells. HepG2 cells were transfected with Luc gene constructs driven by the wild-type human PAI promoter (pGI3hPAl-806/+19) or the human PAI-1 promoter, mutated at HRE, E-box 4 or E-box 5 . The wild-type sequences are shown on the upper strand; mutations are indicated on the lower strand by lower case letters. After transfection, cells were cultured in serum-free culture medium for additional $16 \mathrm{~h}$ under normoxia, then were stimulated with IGF-1 $(100 \mathrm{nM})$ and further cultured under normoxia $\left(16 \% \mathrm{O}_{2}\right)$ or hypoxia $\left(8 \% \mathrm{O}_{2}\right)$ for the next $24 \mathrm{~h}$. In each experiment the Luc activity was expressed as a fold induction compared to the Luc activity, measured in the respective controls. Values represent means \pm SEM of three independent experiments, each performed in duplicate. 

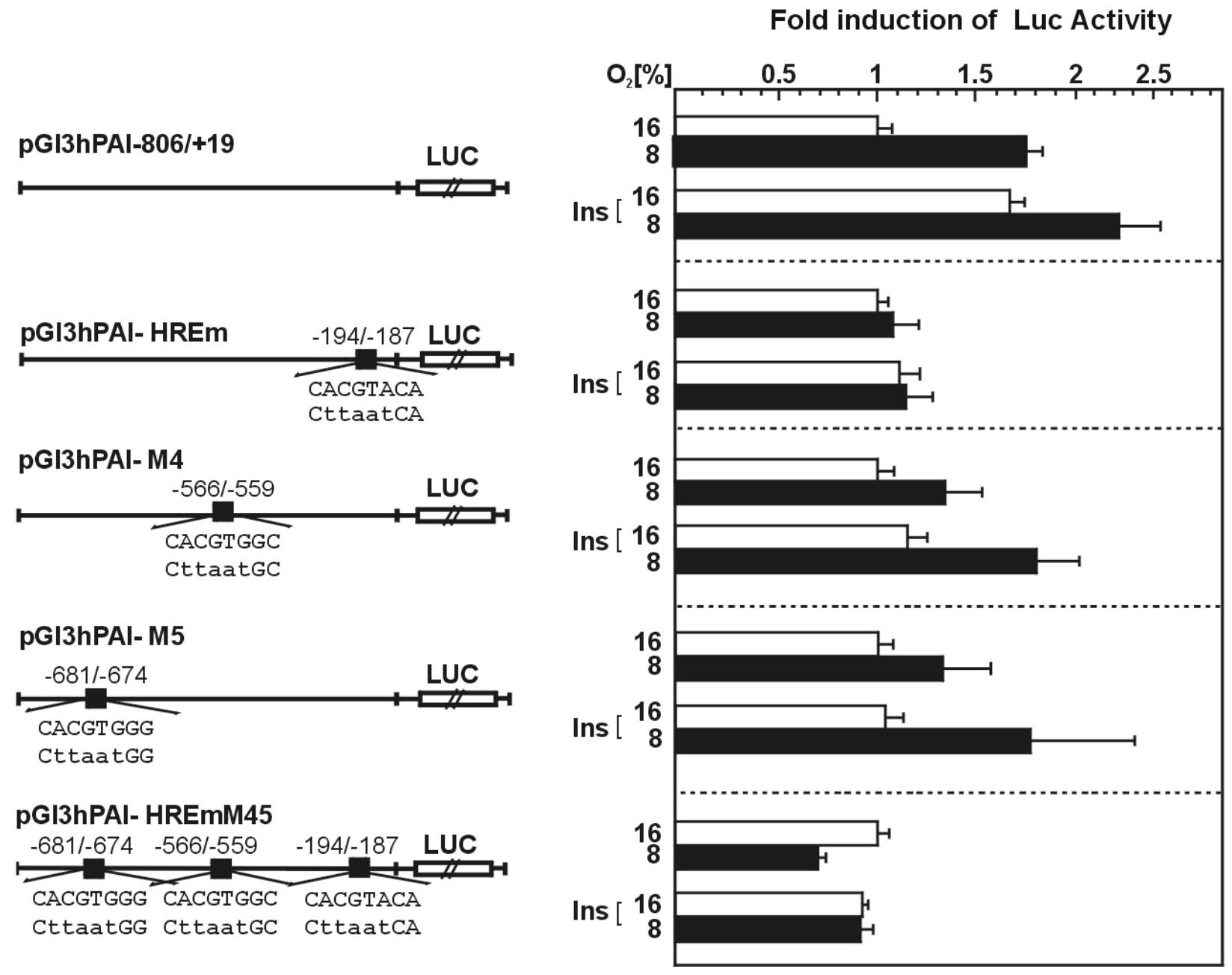

Figure 10. Induction of human PAI-1 promoter constructs by insulin in HepG2 cells. HepG2 cells were transfected with Luc gene constructs driven by the wild-type human PAl promoter (pGL3hPAl806/+19) or the human PAI-1 promoter, mutated at HRE, E-box 4 or E-box 5. The wild-type sequences are shown on the upper strand; mutations are indicated on the lower strand by lower case letters. After transfection, cells were cultured in serum-free culture medium for additional $16 \mathrm{~h}$ under normoxia, then were stimulated with insulin $(500 \mathrm{nM})$ and further cultured under normoxia $\left(16 \% \mathrm{O}_{2}\right)$ or hypoxia $\left(8 \% \mathrm{O}_{2}\right)$ for the next $24 \mathrm{~h}$. The Luc activity was expressed as a fold induction compared to the Luc activity, measured in the respective controls. Values represent means \pm SEM of five independent experiments, each performed in duplicate. 


\subsubsection{Reduction of insulin-dependent PAI-1 promoter activity under normoxia by mutation of the possible FKHR binding site}

In contrast to our results suggesting that insulin acts on human PAI-1 gene activation via HRE and HIF-1, it was proposed that an insulin responsive element in human PAI-1 promoter is more likely located between positions $-53 /-43$ containing a putative forkhead-related response element (TTATTT) (Vulin \& Stanley, 2003).

To test that, two constructs were created, one was only mutated in the putative binding site for FKHR, and the other contained both the HRE and the FKHR mutation. They were transfected into HepG2 cells and the mutation in the position -53/-43 in the pGI3hPAI-FKHRm construct resulted in loss of the inducing effect of insulin under normoxia, whereas the induction was preserved under hypoxia. In case of the double mutated construct, the induction of Luc activity by insulin was abolished both under normoxia and hypoxia (Fig. 11). These results indicate that the $-53 /-43$ region of the hPAl-1 promoter might contribute to the insulin-dependent induction, but only under normoxia.
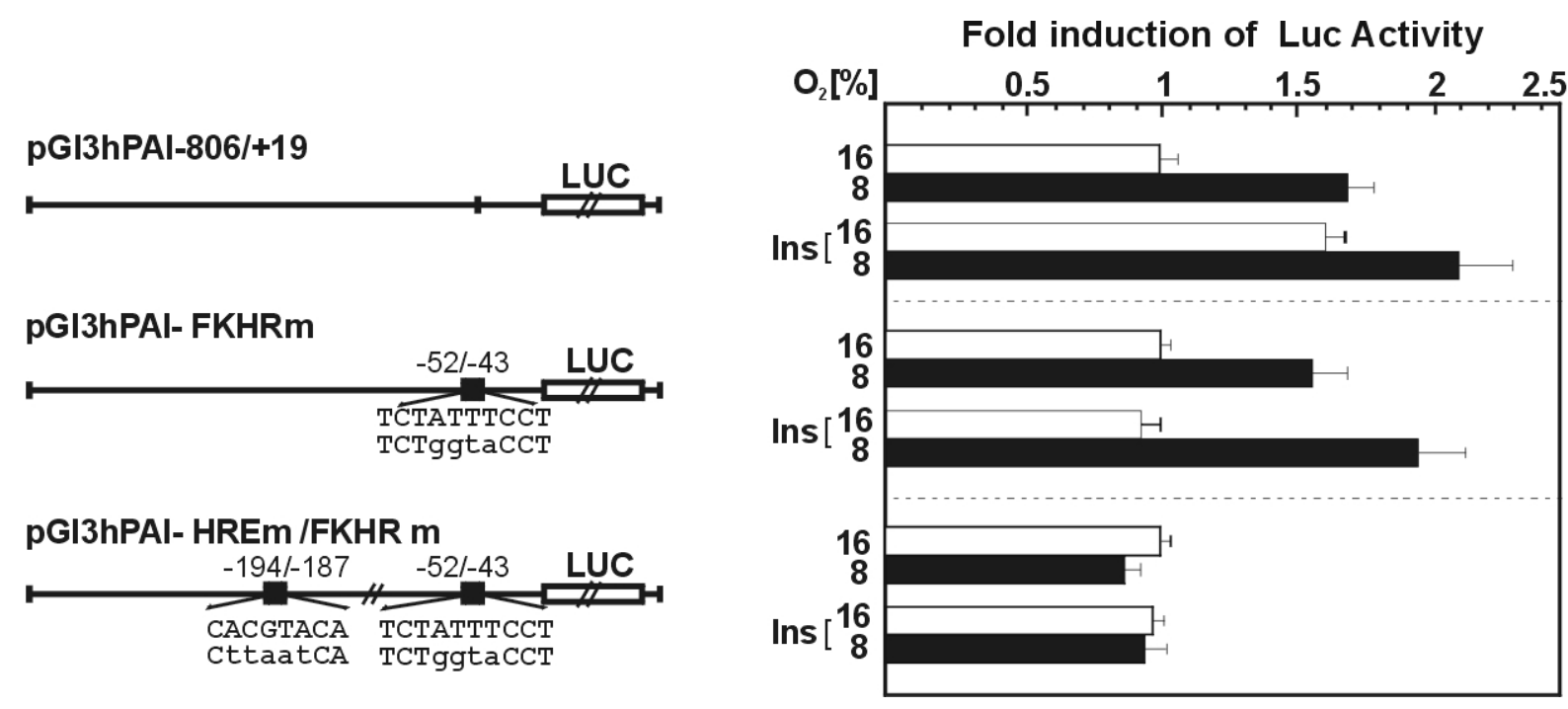

Figure 11. Mutation within the putative FKHR binding site abolished induction of human PAI-1 promoter activity by insulin under normoxia. HepG2 cells were transfected with Luc gene constructs driven by the wild-type human PAI promoter (pGL3hPAI-806/+19) or the human PAI-1 promoter, mutated at the putative FKHR binding site as well as at both FKHR and HRE. The wild-type sequences are shown on the upper strand; mutations are indicated on the lower strand by lower case letters. After transfection, cells were cultured in serum-free culture medium for additional $16 \mathrm{~h}$ under normoxia, and then they were stimulated with insulin and further cultured under normoxia $\left(16 \% \mathrm{O}_{2}\right)$ or hypoxia $\left(8 \% \mathrm{O}_{2}\right)$ for the next $24 \mathrm{~h}$. In each experiment the Luc activity was expressed as a fold induction compared to the Luc activity, measured in the respective controls. Values represent means \pm SEM of three independent experiments, each performed in duplicate. 


\subsubsection{Reduction of the hypoxia-dependent human PAI-1 promoter activity by FKHR proteins in HepG2 cells}

Since the $-53 /-43$ site in the human PAI-1 promoter seems to contain a Forkhead binding element-like sequence we examined whether FKHR can activate the promoter. We used FKHR and FKHR variant AAA, which contains three alanine residues at the three PKB phosphorylation sites, Thr24, Ser253 and Ser316. This variant is resistant to phosphorylation by PKB, thus resulting in nuclear retention of FKHR.

When HepG2 cells were cotransfected with the wild type human PAI promoter construct and the FKHR or FKHR AAA expression vectors, FKHR or FHKR AAA expression abolished the hypoxia-mediated response of the PAI-1 promoter but caused no change in promoter activity under normoxia. Surprisingly, no difference was observed when either wild type or mutated FKHR were used; furthermore, no significant change in PAI-1 promoter activity was observed with the construct pGI3hPAI-HREm after cotransfection of the FKHR expression vectors.

Interestingly, when the pGI3hPAI-FKHRm construct containing a mutation within the Forkhead binding element-like sequence was cotransfected together with the FKHR expression vector Luc activity was decreased compared to controls. Similarly, overexpression of the mutant FKHR AAA also resulted in decreased Luc activity (Fig. 12). After cotransfection of the pGl3hPAlHREm/FKHRm construct containing both mutated HRE and FKHR with the FKHR expression vector Luc activity was also reduced, but overexpression of FKHR AAA restored and even slightly induced Luc activity. Taken together these results suggest that rather than stimulating; FKHR down-regulates the hypoxia-dependent response of the human PAI-1 promoter activity in HepG2 cells.

\subsubsection{Effect of FKHR and FKHR AAA on insulin-dependent PAI-1 promoter activity}

The possible effect of FKHR on the insulin-dependent PAI-1 promoter activity was investigated next by Luc reporter assay. HepG2 cells were cotransfected with pGl3hPAl-806/+19 together with the expression vectors for FKHR and FKHR AAA, and then treated with insulin under normoxia and hypoxia for $24 \mathrm{~h}$. As mentioned before, the wild type promoter construct can be activated by hypoxia and insulin and overexpression of the FKHR and FKHR AAA decreased PAI-1 promoter activity under hypoxia, but not under normoxia. Treatment of the cotransfected cells with insulin neither increased nor decreased the Luc activity (Fig. 13). Thus, it appeared that FKHR does not contribute to the insulin-dependent PAI-1 promoter activation in HepG2 cells. 


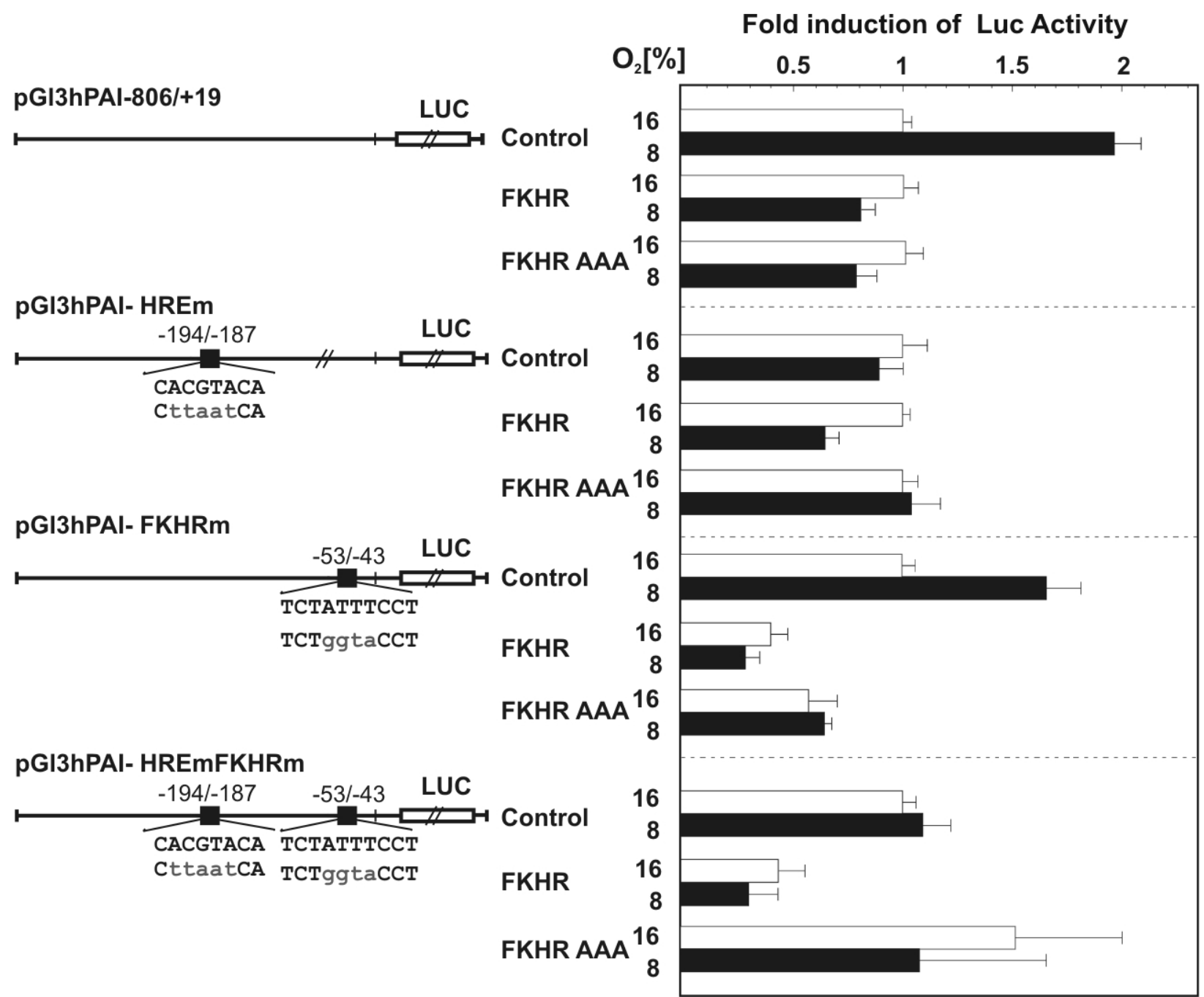

Figure 12. Reduction of the hypoxia-mediated induction of the PAI-1 promoter by Forkhead transcription factor. HepG2 cells were cotransfected with either wild type or mutated FKHR expression vectors or empty control vector and Luc gene constructs driven by the wild-type human PAI-1 promoter (pGl3hPAl-806/+19) or hPAl-1 promoter mutated in HRE and the putative FKHR binding site. The wildtype sequences are shown on the upper strand; mutations are indicated on the lower strand by lower case letters. $24 \mathrm{~h}$ before harvesting, the transfected cells were cultured under normoxia $\left(16 \% \mathrm{O}_{2}\right)$ or hypoxia $\left(8 \% \mathrm{O}_{2}\right)$. The Luc activity was expressed as a fold induction compared to the Luc activity, measured in the respective controls. Values represent means \pm SEM of three independent experiments, each performed in duplicate. 


\subsubsection{Modulation of PAI-1 and HIF-1 $\alpha$ mRNA and protein expression by FKHR and FKHR} AAA under normoxia and hypoxia in HepG2 cells

An interesting aspect from the previous results was the observation that overexpression of FKHR and FKHR AAA in reporter luciferase assays resulted in suppression of the hypoxiamediated response of the human PAI-1 promoter. Therefore, we were interested to explore the possible interrelation between PAI-1 mRNA, HIF-1 $\alpha$ mRNA and protein levels after overexpression of FKHR and FKHR AAA. For this purpose $5 \mu \mathrm{g}$ of the wild type or the mutant FKHR expression constructs or an empty vector in the controls were transfected into HepG2 cells. In HepG2 cells transfected with the empty vector hypoxia enhanced PAI-1 mRNA levels by about 2,5-fold (Fig. 14). Transfection of either FKHR or FKHR AAA expression vectors did not affect the human PAI-1 mRNA levels under normoxia and hypoxia. Both FKHR and FKHR AAA did not mediate an increase in human PAI-1 protein levels. In addition, overexpression of FKHR and FKHR AAA did not influence HIF-1 $\alpha$ mRNA and protein levels (Fig. 14). Thus, the collected data is not sufficient to speculate about an involvement of FKHR in human PAI-1 gene regulation by hypoxia and such a possible interrelation between FKHR and HIF-1 needs to be further elucidated.

Fold induction of Luc Activity

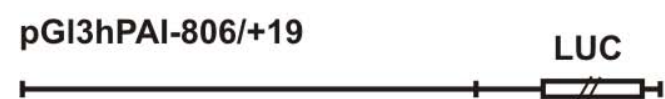

$\begin{array}{llllll}\mathrm{O}_{2}[\%] & 0.5 & 1 & 1.5 & 2 & 2.5\end{array}$

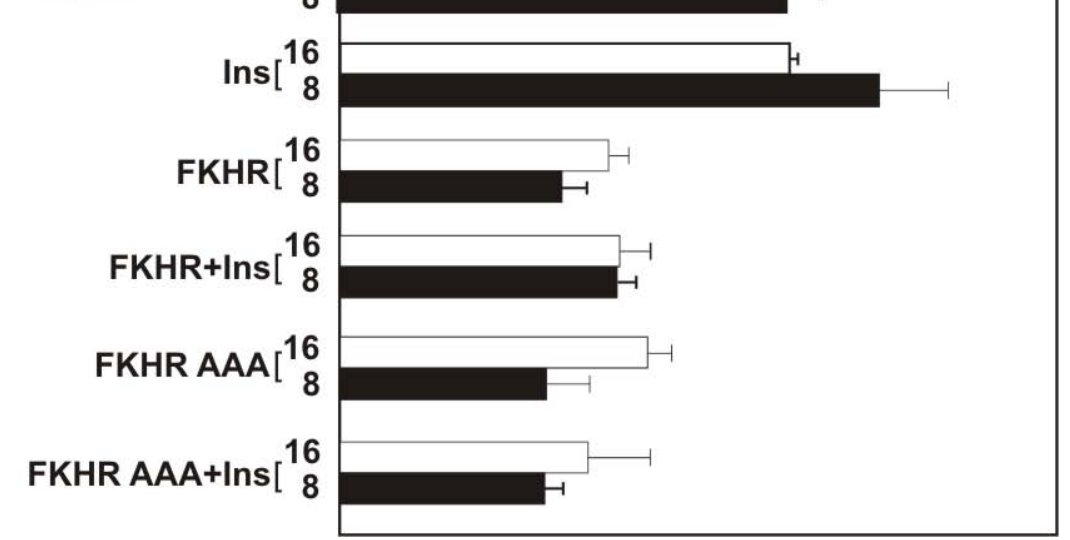

Figure 13. Effect of FKHR and FKHR AAA on insulin-dependent PAI-1 promoter activity. HepG2 cells were cotransfected with the FKHR or FKHR AAA expression vectors and the Luc gene construct driven by the wild-type human PAI promoter (pGL3hPAI-806/+19). After transfection, cells were cultured in serum-free culture medium for additional $16 \mathrm{~h}$ under normoxia, and then they were stimulated with insulin and further cultured under normoxia $\left(16 \% \mathrm{O}_{2}\right)$ or hypoxia $\left(8 \% \mathrm{O}_{2}\right)$ for the next $24 \mathrm{~h}$. In each experiment the Luc activity was expressed as a fold induction compared to the Luc activity, measured in the respective controls. Values represent means \pm SEM of three independent experiments, each performed in duplicate. 
(A)

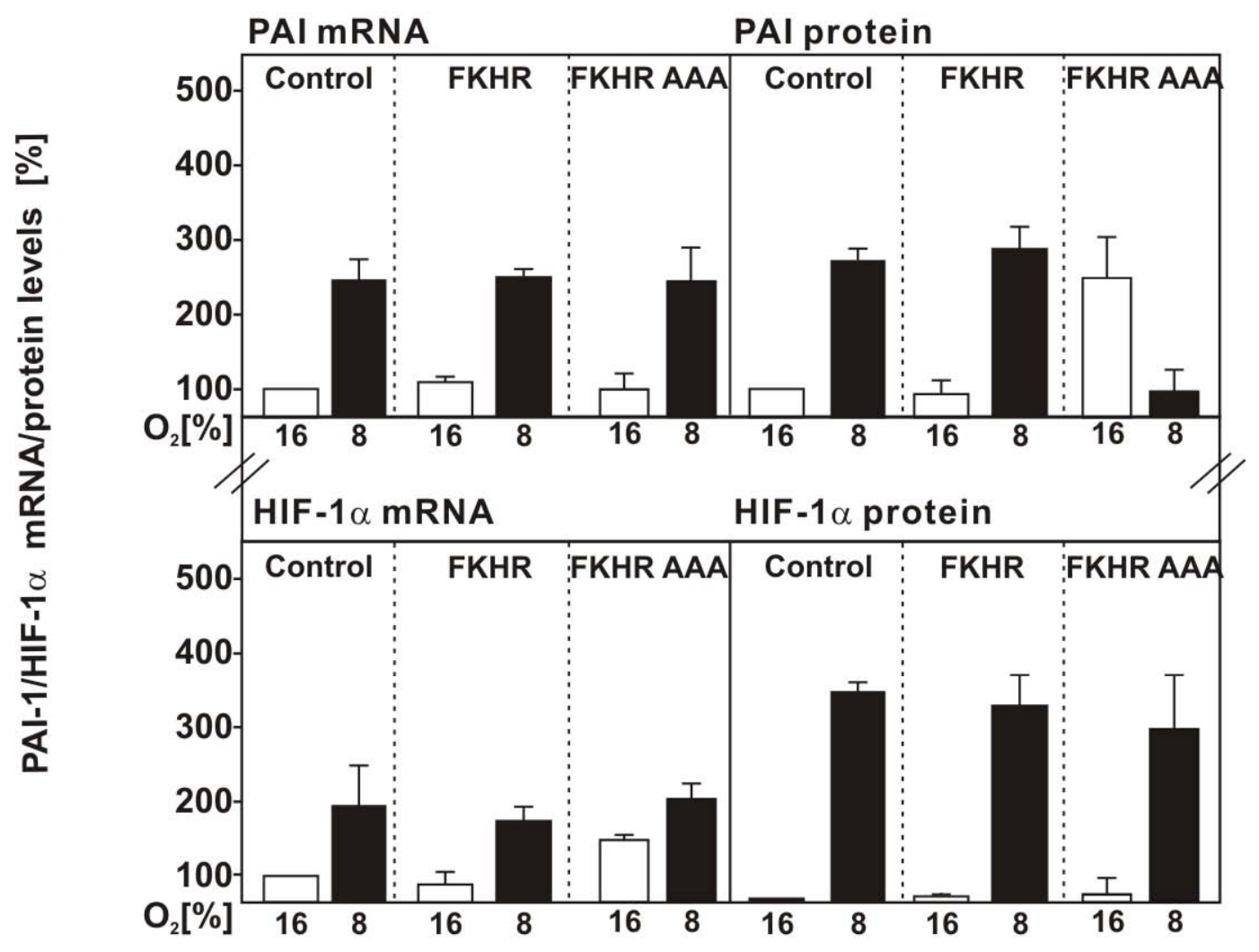

(B)

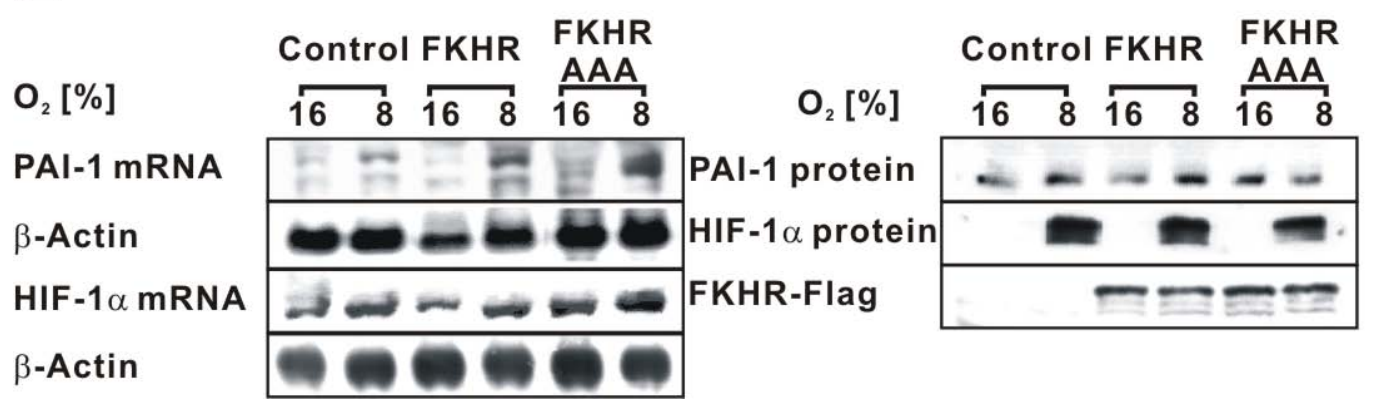

Figure 14. Modulation of PAI-1 and HIF- $1 \alpha$ mRNA and protein levels by FKHR and FKHR AAA. HepG2 cells were cultured under normoxia $\left(16 \% \mathrm{O}_{2}\right)$ for $24 \mathrm{~h}$ and then transfected with a Flag-tagged FKHR, Flag-tagged FKHR AAA expression vector or an empty control vector. The transfected cells were cultured for the next $24 \mathrm{~h}$ under normoxic $\left(16 \% \mathrm{O}_{2}\right)$ or hypoxic $\left(8 \% \mathrm{O}_{2}\right)$ conditions. In case of the HIF-1 $\alpha$ Western blot, transfected cells were cultured under normoxic conditions for $24 \mathrm{~h}$ and then cultured for $4 \mathrm{~h}$ under normoxia or hypoxia. (A) The statistical summary of PAI-1 mRNA and protein levels as well as HIF$1 \alpha$ mRNA and protein levels are shown. The mRNA or protein expression under normoxia was set to $100 \%$. (B) Representative Northern and Western blot. $20 \mu \mathrm{g}$ of total RNA was hybridized with DIGlabeled PAI-1, HIF-1 $\alpha$ or $\beta$-actin antisense RNA probes. For Western blot, $100 \mu \mathrm{g}$ of proteins from HepG2 culture medium or cell lysates were analysed with PAI-1, HIF-1 $\alpha$ or Flag antibody, respectively. Autoradiographic signals were detected by chemiluminescence and quantified by videodensitometry. 


\subsection{Signaling cascades involved in modulation of HIF-1 $\alpha$ protein levels by IGF-1 and} insulin

\subsubsection{Time-course of HIF-1 $\alpha$ protein expression under hypoxia and after treatment with IGF-1 and insulin}

The time-course experiments investigating HIF-1 $\alpha$ protein expression under hypoxia, IGF-1 and insulin were performed by co-workers in our laboratory and the data is not shown in the present study. Briefly, HIF-1 $\alpha$ protein levels remained at a very low level under normoxia whereas it was induced by hypoxia already within $2 \mathrm{~h}$, reached a maximum after $4 \mathrm{~h}$ and decreased at $24 \mathrm{~h}$. Both IGF-1 and insulin increased HIF-1 $\alpha$ protein levels maximally after $4 \mathrm{~h}$ under normoxia and hypoxia. Therefore, in the following experiments cells were cultured under hypoxia or treated with IGF-1 or insulin for about $4 \mathrm{~h}$ unless otherwise indicated.

\subsubsection{ERK but not PKB mediates enhancement of HIF-1 $\alpha$ levels by IGF-1}

Following the binding of IGF-1 to the IGF-1 receptor, two major downstream signalling pathways, the phosphatidylinositol 3-kinase $(\mathrm{PI}(3) \mathrm{K})$ and mitogen-activated protein (MAP) kinase pathways can be activated. To examine whether the $\mathrm{PI}(3) \mathrm{K}$ and/or ERK signalling pathways are involved in the IGF-1-dependent increase of HIF-1 $\alpha$ protein levels we performed inhibitor-studies using the PI(3)-kinase inhibitor LY294002 and the MEK inhibitor U0126. HepG2 cells were cultured under standard conditions for $24 \mathrm{~h}$ and the inhibitors LY294002 and U0126 diluted in DMSO were used in a final concentration of $10 \mu \mathrm{M}$ for $30 \mathrm{~min}$. Then, the cells were treated with IGF-1 and cultured under normoxia or hypoxia for $4 \mathrm{~h}$.

While hypoxia enhanced HIF-1 $\alpha$ levels by about 4-fold, incubation with IGF-1 increased the amount of HIF-1 $\alpha$ protein by about 3-fold under normoxia and about 7-fold under hypoxia. Treatment of HepG2 cells with the PI(3)-kinase inhibitor, LY294002, decreased HIF-1 $\alpha$ under mild hypoxia, in line with previous findings (Kietzmann et al., 2003). Further, LY294002 blocked the induction of HIF-1 $\alpha$ by IGF-1 under normoxia and hypoxia. Incubation with the MEK inhibitor U0126 resulted in a decrease of both hypoxia-induced and IGF-1-induced HIF-1 $\alpha$ protein levels. When both inhibitors were used together neither hypoxia nor IGF-1 mediated an increase in HIF-1 $\alpha$ proteins (Fig. 15 A, B). Moreover, we found that hypoxia and IGF-1 activated both PKB and ERK1/2 (Fig. 16 B, C). Interestingly, LY294002 was able to reduce ERK activation by IGF-1 thus pointing that $\mathrm{PI}(3) \mathrm{K}$ may act upstream of ERK. Together, these results suggest involvement of the PI(3)-kinase and the MAPK pathway in the activation of HIF-1 $\alpha$ by IGF-1.

To further investigate the downstream signaling from $\mathrm{PI}(3) \mathrm{K}$ to PKB we transfected cells with vectors for dominant-negative PDK1 and for TRB3, a tribbles homolog that inhibits AKt/PKB activation (Du et al., 2003). Overexpression of dominant-negative PDK1 decreased HIF-1 $\alpha$ protein level under normoxia and hypoxia, however, in the presence of IGF-1 the increase of the 
HIF-1 $\alpha$ protein levels was not inhibited. Similarly, overexpression of TRB3 decreased the basal HIF-1 $\alpha$ protein levels under normoxia and hypoxia; however, when cells were transfected with TRB3 and exposed to IGF-1, HIF-1 $\alpha$ protein levels were still increased (Fig. 16 A, B). To study the role of the MAPK pathway, we transfected cells with a kinase-deficient dominant-negative form of Raf-1.. We found that its overexpression prevented both the IGF-1-dependent phosphorylation of Erk1/2 and the increase in HIF-1 $\alpha$ protein levels. Together this data suggests that $\mathrm{PI}(3) \mathrm{K}$ and the ERK, but not PDK1 and PKB mediate the IGF-1-dependent increase of HIF-1 $\alpha$ in HepG2 cells (Fig. 16).

\subsubsection{Involvement of the MAPK pathway in the enhancement of HIF-1 $\alpha$ levels by insulin}

In this study, hypoxia enhanced HIF-1 $\alpha$ levels by about 4-fold and stimulation with insulin increased the HIF-1 $\alpha$ protein levels by about 3-fold under normoxia and about 8-fold under hypoxia. Consistent with previous findings (Kietzmann et al., 2003) treatment of HepG2 cells with the PI(3)-kinase inhibitor, LY294002, decreased HIF-1 $\alpha$ under mild hypoxia and we observed a decrease about 2-fold. Furthermore, LY294002 blocked the induction of HIF-1 $\alpha$ protein expression by insulin under normoxia, but did not affect it so strong under hypoxia (Fig. 17). After pre-treatment with LY294002 and subsequent stimulation with insulin HIF1 $\alpha$ protein levels were increased to the same extend as under hypoxia alone. Pre-treatment with the MEK inhibitor U0126 almost abolished both hypoxia-induced and insulin-induced HIF-1 $\alpha$ protein levels (Fig. 17). Together, these results suggest involvement of the MAPK pathway in the activation of HIF-1 $\alpha$ by insulin. Again, overexpression of dominant-negative PDK1 decreased HIF-1 $\alpha$ protein levels under normoxia and hypoxia. Treatment of dominant-negative PDK1 transfected HepG2 cells with insulin did not result in inhibition of HIF-1 $\alpha$ protein levels. Similarly, overexpression of TRB3 decreased the basal HIF-1 $\alpha$ protein levels under normoxia and hypoxia. However, in the presence of insulin, HIF-1 $\alpha$ protein levels were still increased (Fig. 18 A, B). Thus, together this data suggests that the MAPK pathway, but not PDK1 and PKB mediate the insulin-dependent increase of HIF-1 $\alpha$ and subsequently PAI-1 levels in HepG2 cells. 


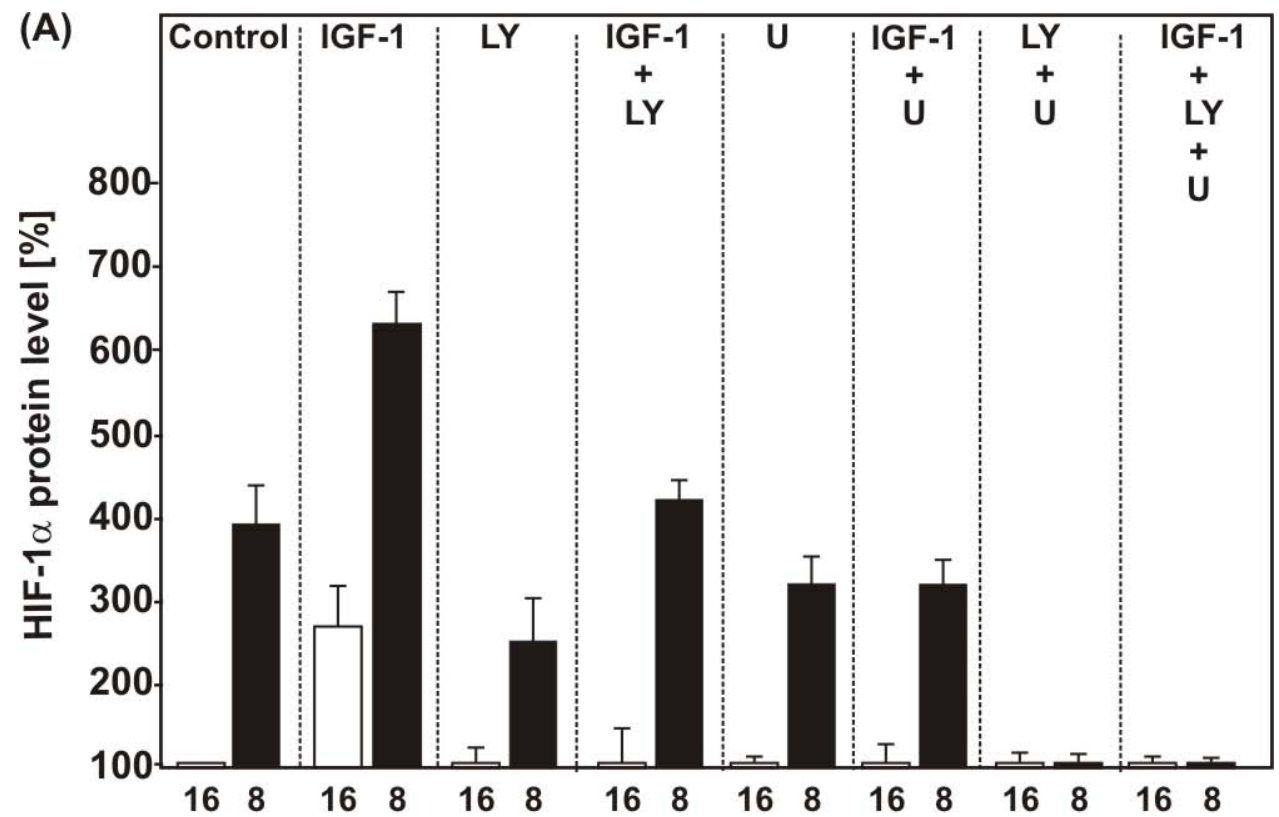

(B)

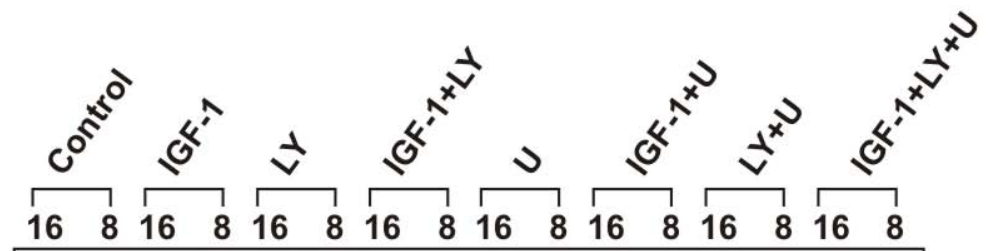

HIF-1 $\alpha$

$\beta$-Actin

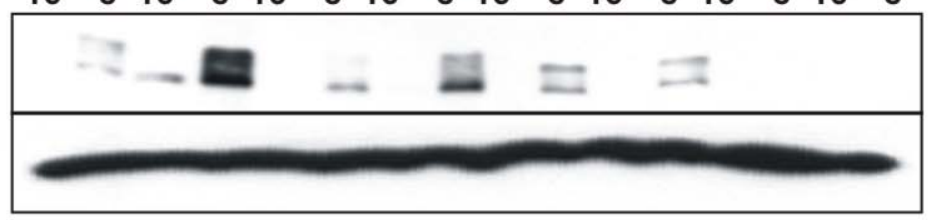

(C)

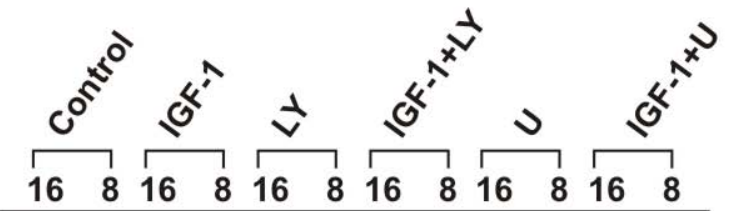

phospho-ERK

$\beta$-Actin

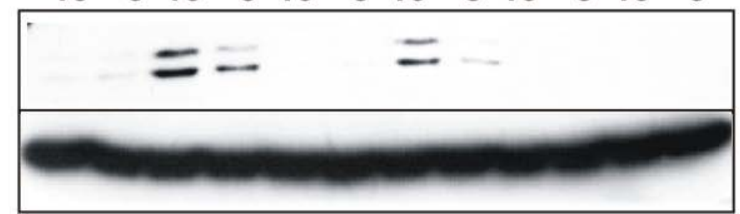

Figure 15. Inhibition of the IGF-1-mediated HIF-1 $\alpha$ induction by the PI(3)-kinase inhibitor LY294002 and the MEK inhibitor U0126. Serum-starved HepG2 cells were pre-treated with $10 \mu \mathrm{M} L Y 294002,10$ $\mu \mathrm{M}$ U0126 or both either with or without 100 nM IGF-1 and exposed to normoxia or hypoxia for $4 \mathrm{~h}$. (A) Statistical analyses of the HIF-1 $\alpha$ levels. The HIF-1 $\alpha$ protein levels under normoxia $\left(16 \% \mathrm{O}_{2}\right)$ were set to $100 \%$. Values represent means \pm SEM of at least three independent experiments. (B) Representative HIF-1 $\alpha$ Western blots. $100 \mu \mathrm{g}$ of protein from HepG2 cell lysates were analysed by Western Blotting with antibodies against HIF-1 $\alpha$, or as in (C) against phospho-ERK1/2 where HepG2 cells were stimulated for 15 min with IGF-1. 


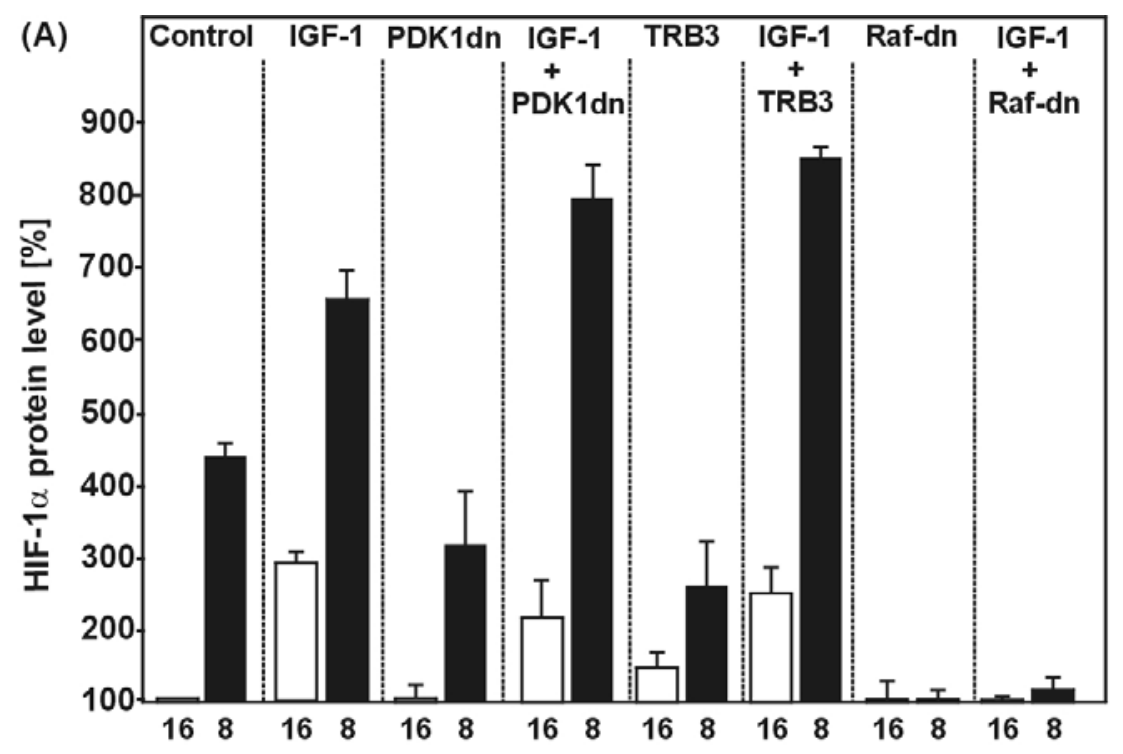

(B)

HIF-1 $\alpha$

PDK1dn-Myc

TRB3-Flag

phospho-PKB

$\beta$-Actin

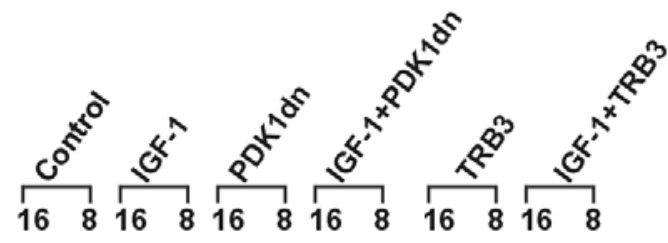

(C)

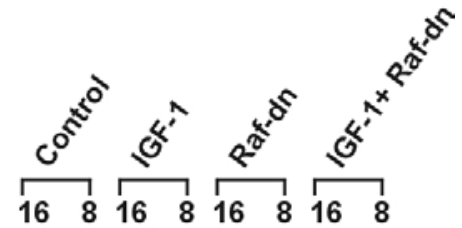

HIF-1 $\alpha$

phospho-ERK

Raf-dn-Flag

$\beta$-Actin

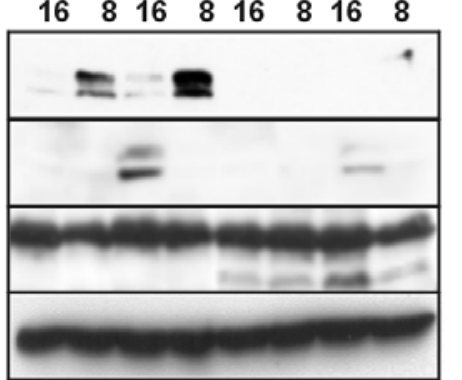

Figure 16. Regulation of IGF-1-dependent HIF-1 $\alpha$ induction by dominant-negative PDK1, the PKB inhibitor TRB3 and dominant negative Raf. HepG2 cells were cultured under normoxia $\left(16 \% \mathrm{O}_{2}\right)$ for $24 \mathrm{~h}$ and then transfected with either expression vectors for dominant-negative PDK1, the PKB inhibitor TRB3, kinase-deficient Raf or empty control vector. Then, $24 \mathrm{~h}$ after transfection serum-starved HepG2 cells were exposed either with or without $100 \mathrm{nM} \mathrm{IGF-1} \mathrm{to} \mathrm{normoxia}\left(16 \% \mathrm{O}_{2}\right)$ or hypoxia $\left(8 \% \mathrm{O}_{2}\right)$ for $4 \mathrm{~h}$ (A) Statistical analyses of HIF-1 $\alpha$ levels. The HIF-1 $\alpha$ protein levels under normoxia $\left(16 \% \mathrm{O}_{2}\right)$ were set to $100 \%$. Values represent means \pm SEM of at least three independent experiments. (B) Representative HIF-1 $\alpha$ Western blot and expression levels of dominant-negative PDK1 and TRB3. $100 \mu \mathrm{g}$ of protein from HepG2 cells were analysed by Western blotting with antibodies against HIF-1 $\alpha$ the Myc-Tag or Flag-Tag, respectively (C) Representative HIF-1 $\alpha$ and phospho-Erk1/2 Western blots. 


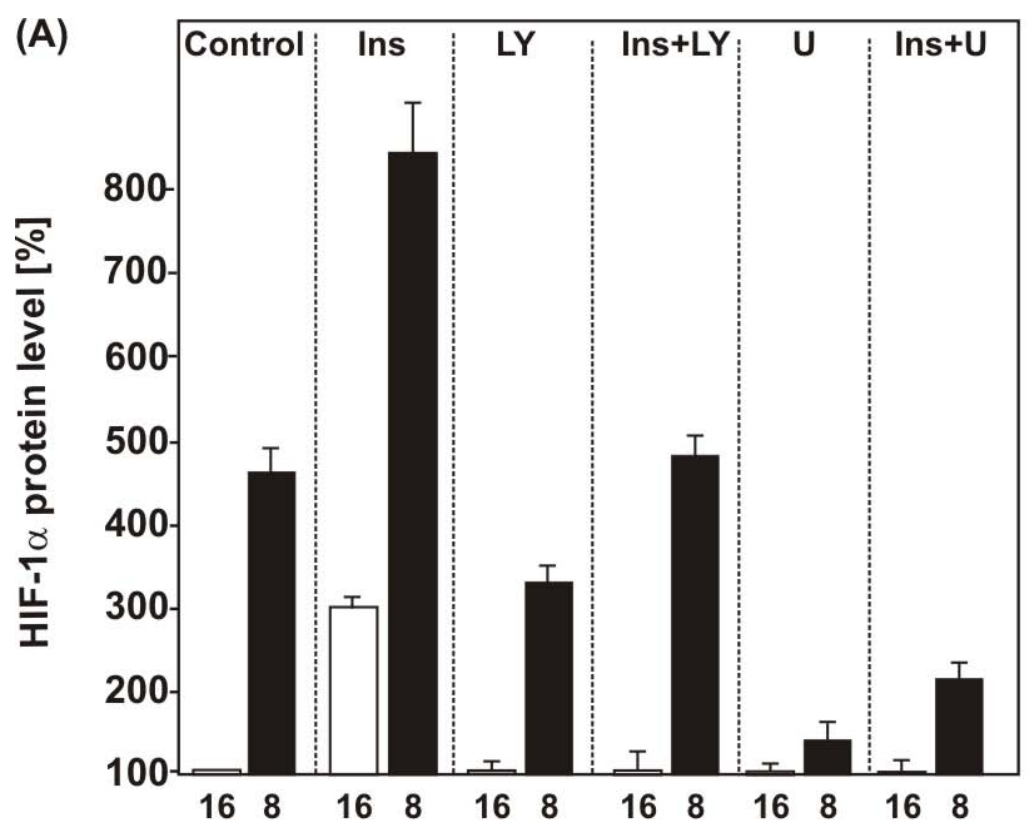

(B)

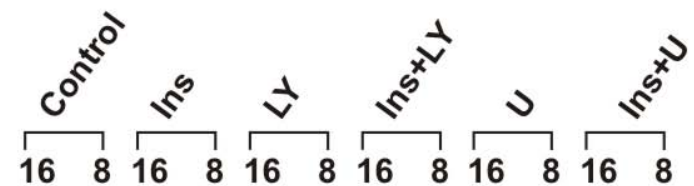

HIF-1 $\alpha$

$\beta$-Actin

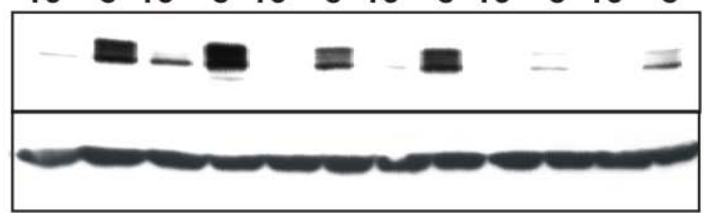

Figure 17. Modulation of the insulin-mediated HIF-1 $\alpha$ induction by the PI(3)-kinase inhibitor LY294002 and the MEK inhibitor U0126. Serum-starved HepG2 cells were pre-treated with $10 \mu \mathrm{M}$ LY294002, $10 \mu \mathrm{M}$ U0126 or both, either with or without $500 \mathrm{nM}$ insulin and exposed to normoxia (16\% $\left.\mathrm{O}_{2}\right)$ or hypoxia $\left(8 \% \mathrm{O}_{2}\right)$ for $4 \mathrm{~h}$. (A) Statistical analyses of the HIF-1 $\alpha$ levels. The HIF-1 $\alpha$ protein levels under normoxia $\left(16 \% \mathrm{O}_{2}\right)$ were set to $100 \%$. Values represent means \pm SEM of at least three independent experiments. (B) Representative HIF-1 $\alpha$ Western blots. $100 \mu \mathrm{g}$ of protein from HepG2 cell Iysates were analysed by Western blotting with an antibody against HIF-1 $\alpha$. 


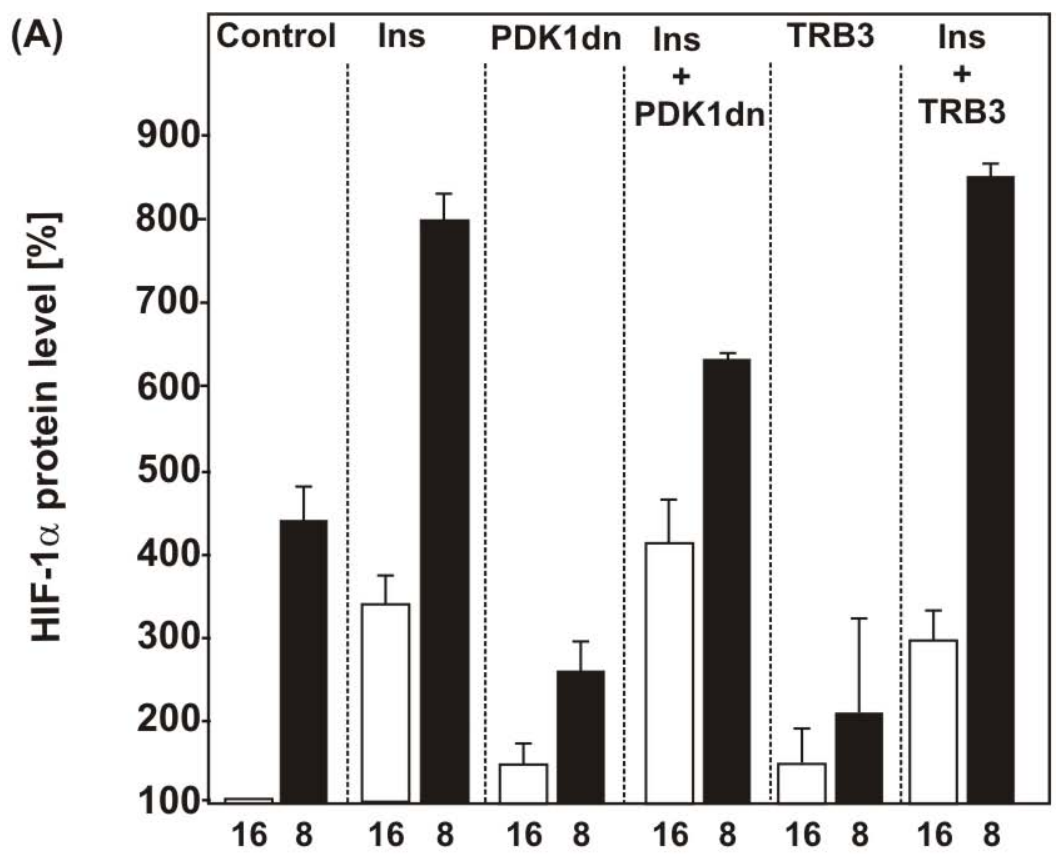

(B)
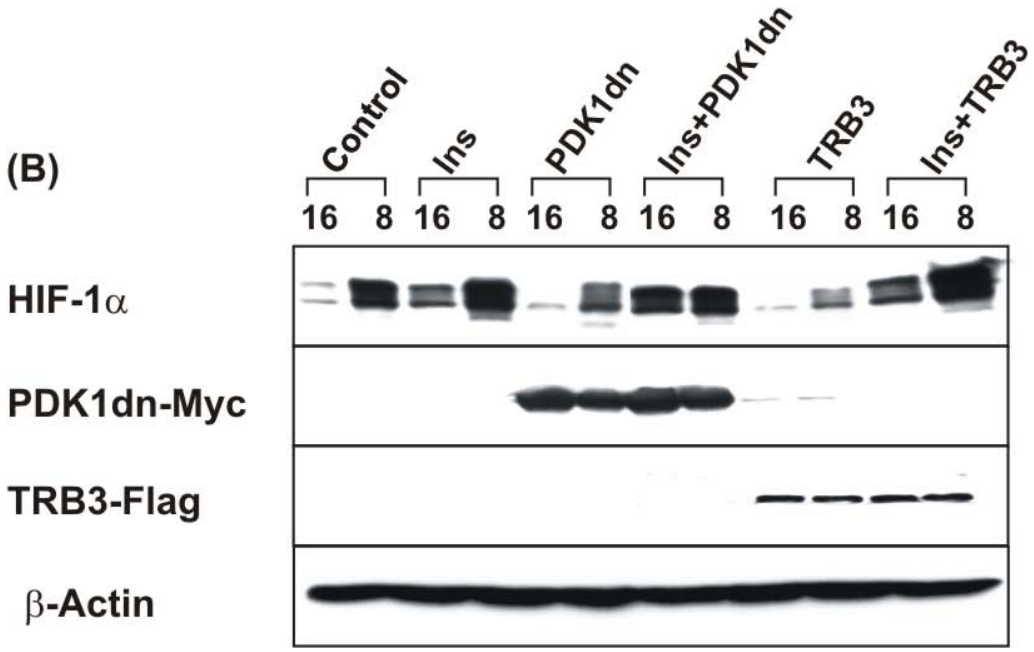

Figure 18. Regulation of insulin-dependent HIF-1 $\alpha$ induction by dominant-negative PDK1 and the PKB inhibitor TRB3. HepG2 cells were cultured under normoxia $\left(16 \% \mathrm{O}_{2}\right)$ for $24 \mathrm{~h}$ and then transfected with either expression vectors for dominant-negative PDK1, the PKB inhibitor TRB3, or empty control vector. Then, $24 \mathrm{~h}$ after transfection serum-starved HepG2 cells were exposed either with or without 500 $\mathrm{nM}$ insulin to normoxia $\left(16 \% \mathrm{O}_{2}\right)$ or hypoxia $\left(8 \% \mathrm{O}_{2}\right)$ for $4 \mathrm{~h}$. (A) Statistical analyses of HIF-1 $\alpha$ levels. The HIF-1 $\alpha$ protein levels under normoxia $\left(16 \% \mathrm{O}_{2}\right)$ were set to $100 \%$. Values represent means \pm SEM of at least three independent experiments. (B) Representative HIF-1 $\alpha$ Western blot and expression levels of dominant-negative PDK1 and TRB3. $100 \mu \mathrm{g}$ of protein from HepG2 cells were analysed by Western blotting with antibodies against HIF-1 $\alpha$ the Myc-Tag or Flag-Tag, respectively. 


\subsubsection{Involvement of the transcription factor USF-2 in insulin-dependent PAI-1 gene expression in HepG2 cells}

Since it had been shown that USF could bind the fatty acid synthase promoter and thus might have a role in insulin signalling to this gene (Sul \& Wang, 1995, 1997) we were interested to investigate whether USF-2 is involved in the positive regulation of human PAI-1 gene transcription by insulin. This hypothesis was tested by cotransfection of the PAI-1 promoter construct with the expression vector encoding USF-2. The wild-type PAI-1 promoter can be activated by hypoxia and insulin. Cotransfection of the wild-type PAI-1 promoter with the USF-2 expression vector resulted in a significant increase of Luc activity by about 20 -fold under normoxia and hypoxia. Treatment with insulin appeared to have no effect since the increase of Luc activity caused by USF-2 was preserved and not changed (Fig. 19). Interestingly, the mutation of the HRE abolished not only the hypoxia-dependent and insulin-dependent, but also the USF-dependent increase of Luc activity. Insulin treatment of cells cotransfected with pGI3hPAI-HREm and USF-2 again did not cause further changes in Luc activity. Taken together, these results suggest that USF-2 is not involved in the insulin-dependent PAI-1 gene expression.
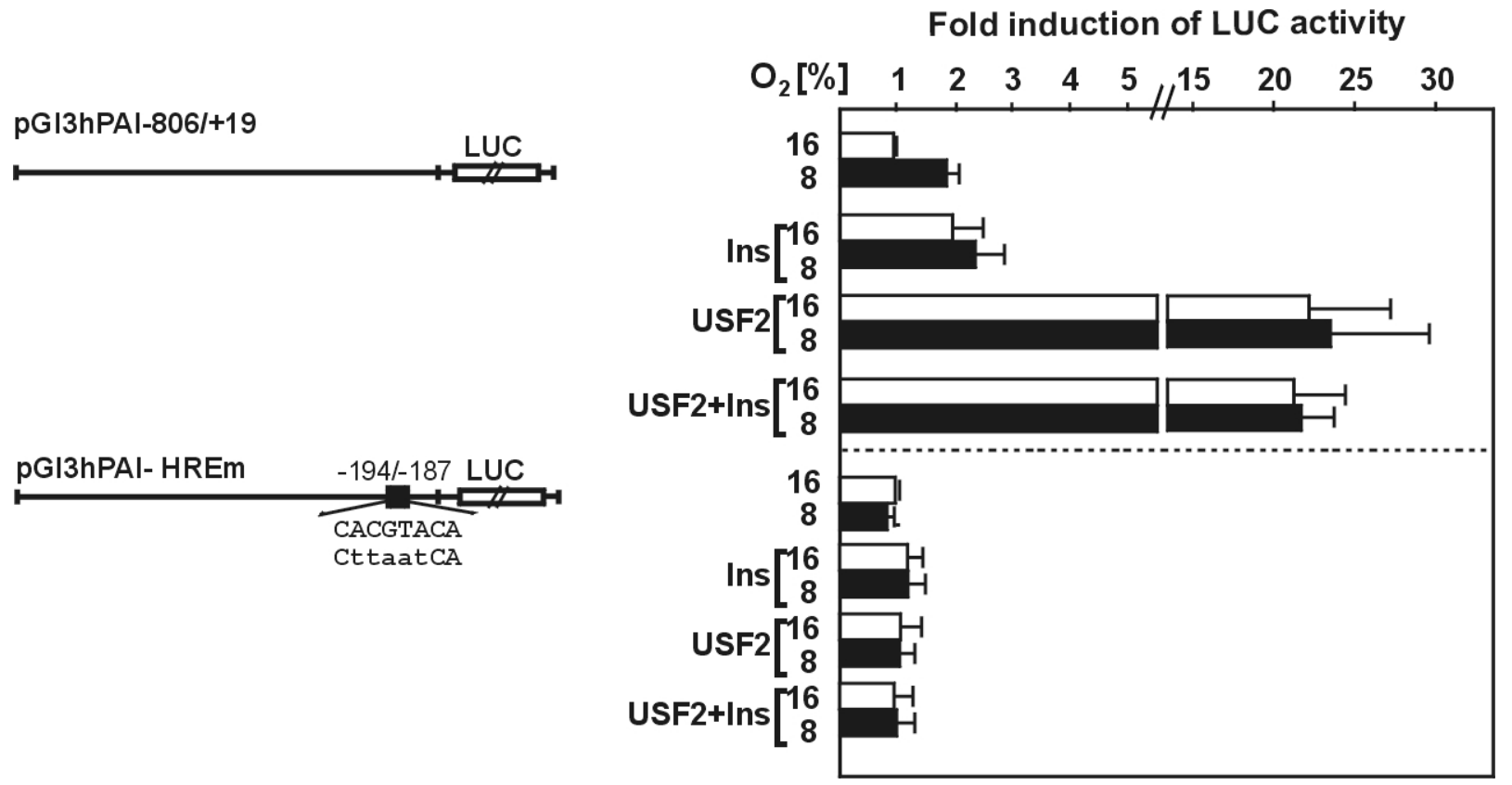

Figure 19. Induction of PAI-1 promoter activity by insulin and USF-2 in HepG2 cells. HepG2 cells were cotransfected with either the USF-2 expression vectors or empty control vector and Luc gene constructs driven by the wild-type human PAl promoter (pGl3hPAl-806) or hPAl-1 promoter mutated in HRE. The wild-type sequences are shown on the upper strand; mutations are indicated on the lower strand by lower case letters. After transfection, cells were cultured for additional $24 \mathrm{~h}$ under normoxia $\left(16 \% \mathrm{O}_{2}\right)$, and then they were stimulated with insulin $(500 \mathrm{nM})$ and further cultured under normoxia (16\% $\left.\mathrm{O}_{2}\right)$ or hypoxia $\left(8 \% \mathrm{O}_{2}\right)$ for the next $24 \mathrm{~h}$. The Luc activity was expressed as a fold induction compared to the Luc activity, measured in the respective controls. Values represent means \pm SEM of three independent experiments, each performed in duplicate. 


\subsection{Regulation of the human PAI-1 gene expression by USF-2}

\subsubsection{Induction of human PAI-1 mRNA and protein expression by USF-2 under normoxia and hypoxia in HepG2 cells}

The expression of the human PAI-1 gene was studied at both mRNA and protein levels. In HepG2 cells transfected with the empty control vector hypoxia enhanced PAI-1 mRNA by about 3,5-fold. Transfection of the USF-2 expression vector induced human PAI-1 mRNA by about 6,5-fold under normoxia and hypoxia (Fig. 20). The USF-mediated increase of human PAI-1 mRNA was followed by an increase of human PAI-1 protein levels. Overexpression of USF-2 enhanced PAI-1 protein levels by about 4-fold under normoxia and hypoxia (Fig. 20).

\subsubsection{USF-2 activated human PAI-1 promoter Luc gene constructs in HepG2 cells}

In the present study we have found that IGF-1 partially and insulin entirely exercise their effects through HRE which in addition can also be bound by USF-2. Further, sequence analyses of the human PAI-1 promoter revealed 5 E-box-like sequences of which only 4 and 5 are classical Eboxes. To investigate the involvement of HRE as well as E4 and E5 in the USF-2-dependent induction of human PAI-1 gene expression, the -806 bp wild-type human PAI-1 promoter Luc construct (pGl3hPAl-1-806/+19) and its derivates, mutated in HRE as well as in the classical Eboxes were cotransfected with the USF-2 expression vector or the empty control vector into HepG2 cells.

When the wild type PAI-1 promoter construct was cotransfected with the empty vector, hypoxia enhanced Luc activity by about 2-fold. Cotransfection of the wild-type human PAI-1 promoter Luc construct together with the USF-2 vector resulted in an about 20-fold increase of Luc activity both under normoxia and hypoxia. The construct pGI3hPAI-HREm containing the mutated HRE responded neither to USF-2 nor to hypoxia. Mutation of E-boxes E4 and E5 in the constructs pGI3hPAI-M4 and pGI3hPAI-M5 reduced induction under hypoxia and significantly decreased the USF-2-mediated induction of Luc activity to about 4-fold and 3-fold, respectively, compared to the control (Fig. 21).

Double mutation of E5 and E4 in pGI3hPAI-M45 also diminished induction of Luc activity by USF-2 to about 2-fold. Thus, this data indicates an involvement of HRE as well as E4 and E5 in the hypoxia- and USF-2-dependent PAI-1 expression (Fig. 21). 
(A)

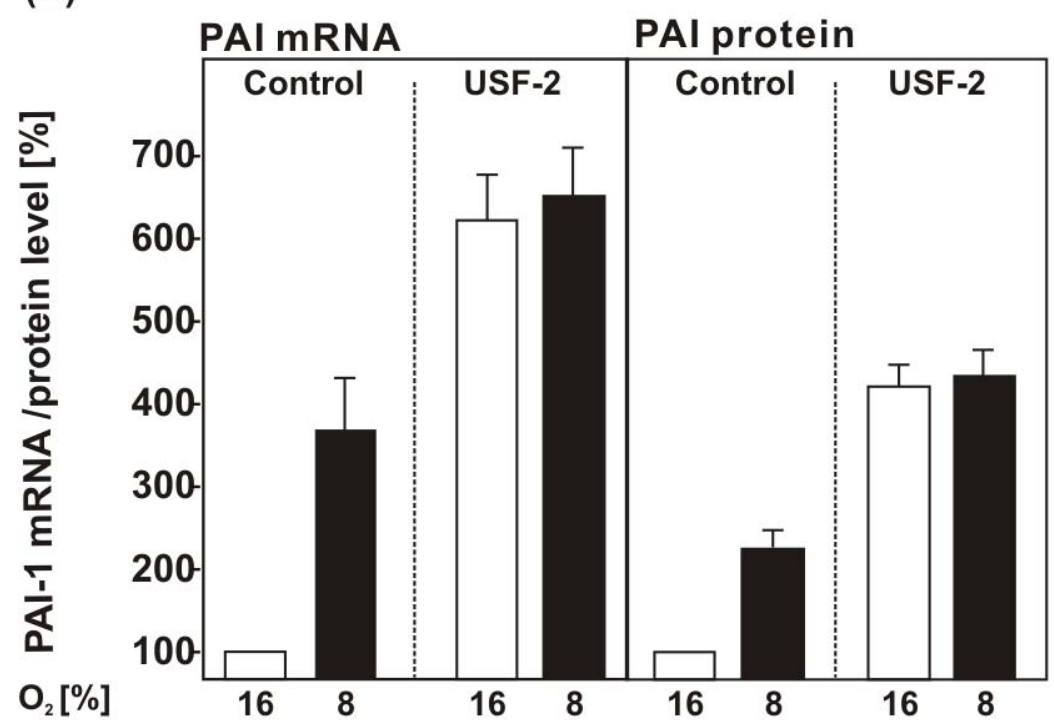

(B)

$\mathrm{O}_{2}[\%]$

Control USF-2

Control USF-2

PAI-1 mRNA

$\begin{array}{llll}16 & 8 & 16 & 8\end{array}$

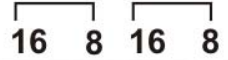

B-Actin mRNA

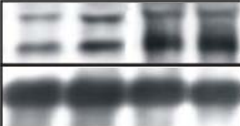

PAl-1 protein

Ponseau S

USF-HA

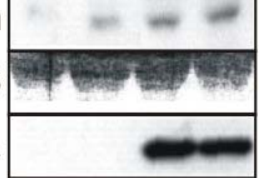

Figure 20. USF-dependent increase of human PAI-1 mRNA and protein levels in HepG2 cells. HepG2 cells were cultured under normoxia $\left(16 \% \mathrm{O}_{2}\right)$ for $24 \mathrm{~h}$ and then transfected with either an USF-2 expression vector or an empty control vector. After changing the medium, the cells were further cultured for $24 \mathrm{~h}$ under normoxic $\left(16 \% \mathrm{O}_{2}\right)$ or hypoxic $\left(8 \% \mathrm{O}_{2}\right)$ conditions. (A) The PAl-1 mRNA and protein levels were measured by Northern and Western blots respectively. The hPAI-1 mRNA and protein levels under normoxia $\left(16 \% \mathrm{O}_{2}\right)$ were set to $100 \%$. Values were presented as means \pm SEM of at least three independent experiments. (B) Representative Northern and Western blot. $20 \mu \mathrm{g}$ of total RNA isolated from cultured HepG2 cells were subjected to Northern blot analyses and hybridized with DIG-labeled PAI1 and $\beta$-actin antisense RNA probes. $100 \mu \mathrm{g}$ of protein from the HepG2 cell culture medium or cell lysates were subjected to Western blot analyses with hPAI-1 or USF-2-HA-tag antibodies, respectively. Autoradiographic signals were detected by chemiluminescence and quantified by videodensitometry. 

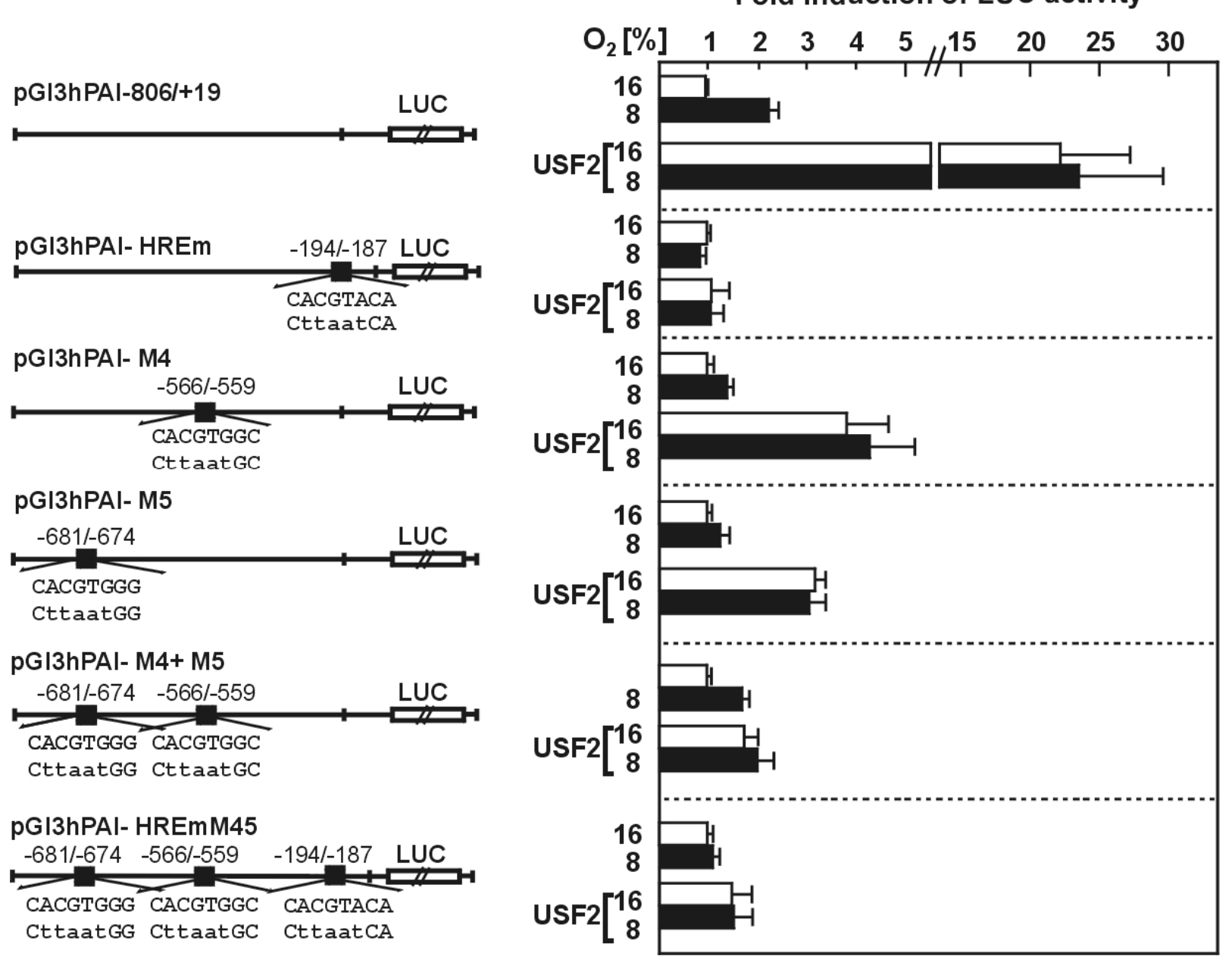

Figure 21. USF-activated human PAI-1 promoter constructs in HepG2 cells. HepG2 cells were cotransfected with either the USF-2 expression vectors or empty control vector and Luc gene constructs driven by the wild-type human PAI promoter (pGl3hPAl-806/+19) or hPAl-1 promoter derivates, mutated in the classical E-boxes as well as in HRE. The wild-type sequences are shown on the upper strand; mutations are indicated on the lower strand by lower case letters. After transfection, cells were cultured in fresh culture medium for additional $18 \mathrm{~h}$ under normoxia $\left(16 \% \mathrm{O}_{2}\right)$, then grouped, and further cultured under normoxia $\left(16 \% \mathrm{O}_{2}\right)$ or hypoxia $\left(8 \% \mathrm{O}_{2}\right)$ for the next $24 \mathrm{~h}$. The Luc activity was indicated as fold induction compared to the Luc activity, measured in the respective controls. Values represent means \pm SEM of three independent experiments, each performed in duplicate. 


\subsubsection{Binding of USF to E-box sequences in the human PAI-1 promoter}

In order to confirm the conclusion from the transfection experiments that USF-2 interacts with HRE, E4 and E5 within the human PAI-1 promoter, binding of nuclear proteins to oligonucleotides spanning HRE, E4 and E5 was examined by electrophoretic mobility shift assay (EMSA).

When the labeled oligonucleotide spanning HRE was incubated with HepG2 nuclear extracts, three major DNA-protein complexes were detected, but the mobility of these complexes was not affected by incubation with antibodies against USF-1 and USF-2. The oligonucleotides spanning E4 and E5 bound also three major DNA-protein complexes (Fig. 22). Addition of either USF-1 or USF-2 antibody supershifted the intermediate DNA-protein complexes bound to E4 and E5, confirming that this complex contains both USF-1 and USF-2. Since it is known that proteins of the ATF/CREB family bind constitutively to HREs (Kvietikova et al., 1995) it was tested whether the complexes formed with the HRE oligonucleotide contain ATF proteins. Addition of the ATF/CREB antibody to the reaction mixture resulted in a supershift not only with HRE but also with E4 and E5 showing that the major DNA-protein complex contains ATF/CREB proteins. To exclude the possibility that other members of the bHLH family were also binding these oligonucleotides, a Myc and Max antibody was present in the binding reaction but this did not result in a supershift or in an inhibition of the constitutive complex (Fig. 22). Thus, this data indicates that USFs can interact with E4 and E5 but not with HRE in the human PAI-1 promoter.

\subsection{Regulation of human and rat PAI-1 promoter Luc gene constructs by wild type and mutant USF-2 in different cell lines}

In order to ascertain which domains of USF-2 were involved in the different regulation of human and rat PAl-1 gene expression wild-type human PAl-1 promoter pGI3hPAl-806 and rat PAI-1 promoter pGI3rPAI-766 Luc constructs together with plasmids expressing USF-2 as well as various USF-2 mutants were cotransfected in human (HepG2) and rat (H4IIE) hepatoma cells as well as in primary rat hepatocytes. These mutants included the U2 $\triangle U S R$ protein $(\triangle A A 208$ 230) lacking the USF-specific region (USR), the U2 $\triangle E 5$ protein, which does not contain some of the amino acids encoded by exon 5 of the transactivation domain ( $\triangle \mathrm{AA}$ 144-188) and the $\triangle T D U 2$ protein ( $\triangle A A$ 1-198) lacking the transactivation domain but containing USR. 
(A)

USF consensus

$\begin{array}{ll}\text { HRE } & -199 /-181 \\ \text { E4 } & -571 /-552 \\ \text { E5 } & -689 /-670\end{array}$

CACGTG

TCTTACACACGTACACACA

ACAATCACGTGGCTGGCT AGTCTGGACACGTGGGGA

(B)

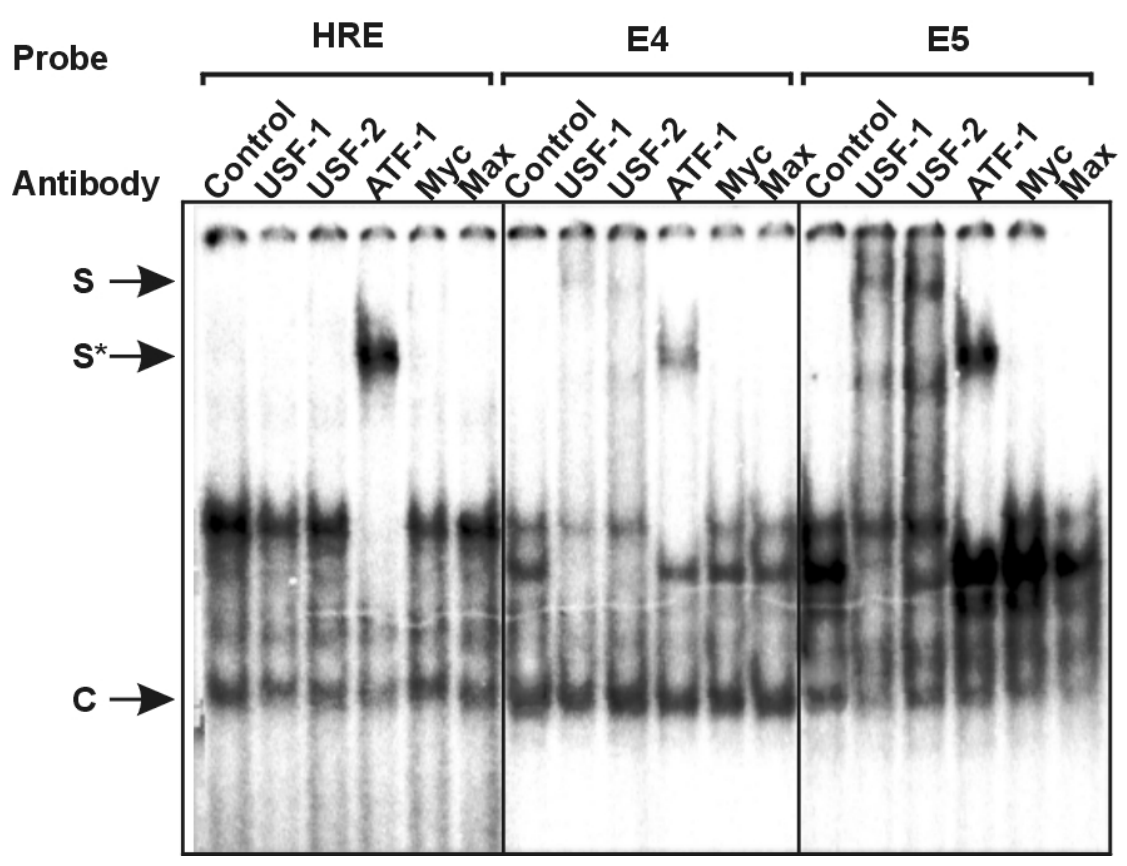

Figure 22. Binding of USF to the E-boxes of the human PAI-1 promoter. (A) The USF consensus sequence and oligonucleotides spanning HRE, E-box 4 and E-box 5 used as probes are shown; bases matching the consensus sequence are underlined; (B) Nuclear extracts used in these studies were prepared from confluent HepG2 cells cultured under normoxia $\left(16 \% \mathrm{O}_{2}\right)$. The ${ }^{32} \mathrm{P}$-labelled human PAI-1 HRE, E4 and E5 oligonucleotides were incubated with $7 \mu \mathrm{g}$ nuclear extracts from HepG2 cells. In EMSAs with antibody, the nuclear extracts were pre-incubated on ice for 45 min with $0,4 \mu \mathrm{g}$ USF-1, USF-2, ATF1/CREB cross-reactive, Myc or Max antibodies before adding the labeled probes. The DNA-protein interaction complexes were separated by electrophoresis on $5 \%$ native polyacrylamide gels and visualized by phosphoimaging; $S$ indicates supershifted USF complex; $S^{*}$, supershifted ATF-1/CREB complex; C, constitutive complex. 
In HepG2 cells cotransfected either with the human promoter construct pGI3hPAI-806/+19 and USF-2 or with the rat promoter construct pGI3rPAI-766 and USF-2, Luc activity was increased and the hypoxia-dependent response of both human and the rat promoters was abolished (Fig 23). Cotransfection of both promoter constructs pGI3hPAI-806/+19 and pGI3rPAl-766 together with U2 $\triangle$ USR no longer enhanced the Luc activity in HepG2 cells (Fig. 23). When the human PAI-1 promoter construct was used together with U2 $\Delta \mathrm{E} 5$ or $\Delta \mathrm{TDU} 2$ expression vectors LuC activity was decreased compared to USF-2 transfected HepG2 cells (Fig.23). Similarly, in HepG2 cells cotransfected with the rat PAI-1 promoter construct and U2 $\Delta \mathrm{E} 5$ or $\triangle \mathrm{TDU} 2$ Luc activity was only slightly increased compared to the control (Fig. 23).

In H4IIE cells cotransfection of the human promoter construct pGI3hPAI-806 or the rat promoter construct pGI3rPAI-766 with USF-2 again increased Luc activity whereas cotransfection with U2 $\triangle$ USR did not show an inducible effect (Fig 24). After cotransfection of H4IIE cells with pGI3hPAI-806/+19 and U2 $\Delta \mathrm{E} 5$ or $\Delta \mathrm{TDU} 2$ vectors, Luc activity did not change compared to the controls. By contrast, in H4IIE cells cotransfected with the rat PAI-1 promoter construct and the U2 $\triangle E 5$ vector, Luc activity was increased (Fig. 24). The transfection of $\Delta$ TDU2 together with pGI3rPAI-766 in H4IIE cells did not induce Luc activity (Fig. 24).

Since we already reported that USF-2 exhibited an inhibitory action on rat PAI-1 gene expression in primary rat hepatocytes we were interested to find out whether USR or the part of the transactivation domain encoded by exon 5 are crucial for that effect.

\subsubsection{Regulation of human and rat PAI-1 promoter Luc gene constructs by wild type and mutant USF-2 in primary hepatocytes}

In primary rat hepatocytes, USF-2 did not influence the human PAI-1 promoter-driven Luc activity under normoxia and slightly repressed it under hypoxia. Similarly, when primary rat hepatocytes were cotransfected with pGI3hPAI-806/+19 and U2AUSR, Luc activity was not changed under normoxia but it was slightly reduced under hypoxia. The rat PAI-1 promoter construct was repressed by USF-2 both under normoxia and hypoxia (Fig. 25). In addition, Luc activity was not repressed when primary rat hepatocytes were cotransfected with pGI3rPAI-766 and U2 $\triangle \mathrm{USR}$. (Fig. 25). However, transfection of both promoters with the U2 $\Delta \mathrm{E} 5$ vector again reduced Luc activity (data not shown for rat PAI promoter since it was not obtained during the course of this work). Together, this data supports that the USF-dependent induction or repression of the human and rat PAI-1 promoter requires mainly USR and appears to be celltype specific. 
(A)

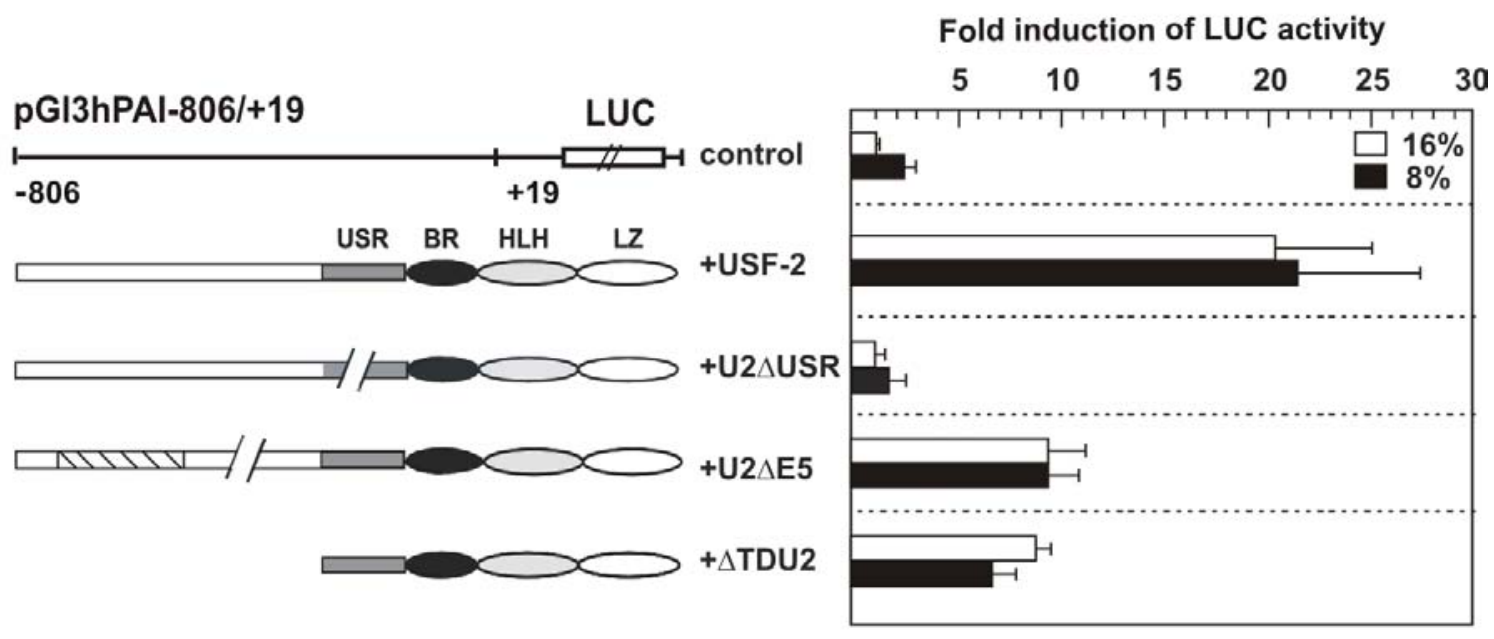

(B)

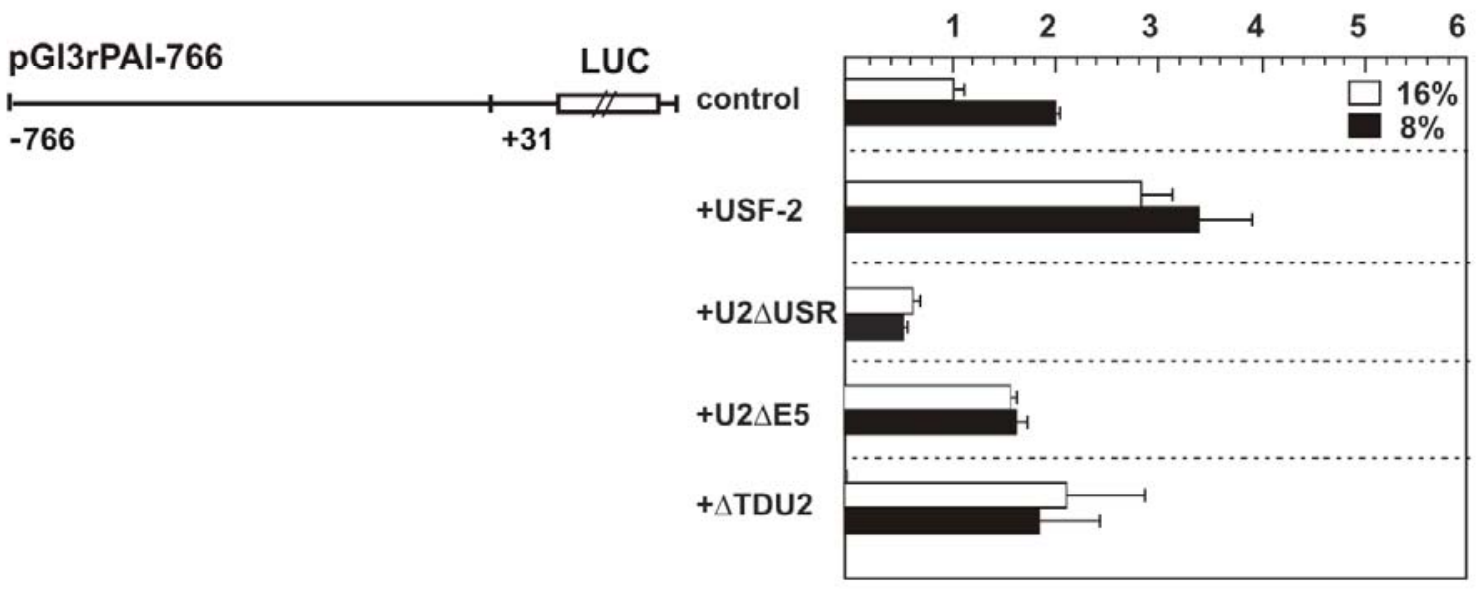

(C)

USF2-C-terminus

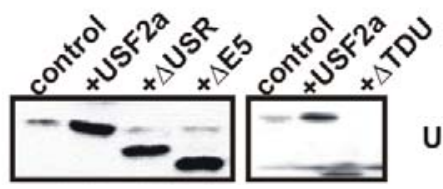

USF-2-N-terminus

Figure 23. Identification of the USF functional domain(s) responsible for the regulation of human and rat PAI-1 gene expression in HepG2 cells. (A, B) The human and rat PAI-1 promoter constructs (pGl3hPAI-806/+19 or pGI3rPAI-766 Luc) were cotransfected either with a backbone vector or with expression vectors encoding USF-2a, U2 $\Delta$ USR, U2 $\triangle E 5$ and $\triangle T D U 2$ into HepG2 cells. After transfection, cells were cultured in fresh culture medium for additional $18 \mathrm{~h}$ under normoxia $\left(16 \mathrm{O}_{2}\right)$. Then, they were cultured under normoxia $\left(16 \% \mathrm{O}_{2}\right)$ or hypoxia $\left(8 \% \mathrm{O}_{2}\right)$ for the next $24 \mathrm{~h}$. The Luc activity was expressed as fold induction compared to the Luc activity measured in the respective controls. Values represent means \pm SEM of four independent experiments, each performed in duplicate. (C) Expression levels of USF-2 and its mutant forms. $100 \mu \mathrm{g}$ of cell lysate proteins from the Luc assays (A) were analyzed by Western blotting with antibodies against the USF-2-C-terminus or USF-2-N-terminus, respectively. 
(A)

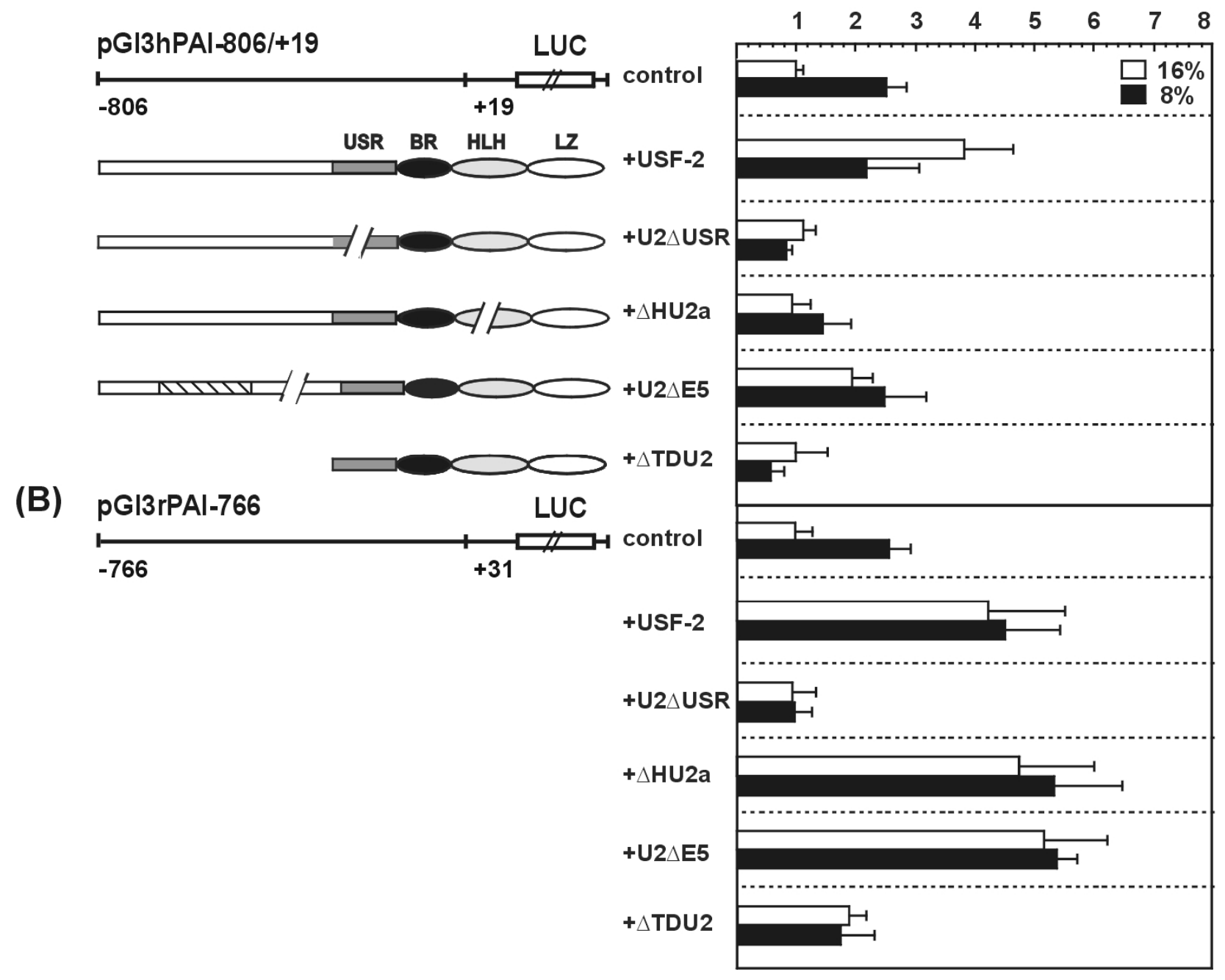

Figure 24. Transcriptional activation of the human and rat PAI-1 promoter constructs by USF in the rat hepatoma cell line H4IIE. (A, B) The human or rat PAl-1 promoter constructs (pGI3hPAl-806/+19 or pGI3rPAI-766 Luc) were cotransfected either with a backbone vector or with expression vectors encoding U2 $\triangle \mathrm{USR}, \mathrm{U} 2 \Delta \mathrm{E} 5$ or $\triangle \mathrm{TDU} 2$ into H4IIE cells. After transfection, cells were cultured in fresh culture medium for additional $18 \mathrm{~h}$ under normoxia. Then they were cultured under normoxia $\left(16 \% \mathrm{O}_{2}\right)$ or hypoxia $\left(8 \% \mathrm{O}_{2}\right)$ for the next $24 \mathrm{~h}$. The Luc activity was estimated as fold induction compared to the Luc activity, measured in the respective controls. Values represent means \pm SEM of four independent experiments, each performed in duplicate. 
(A)

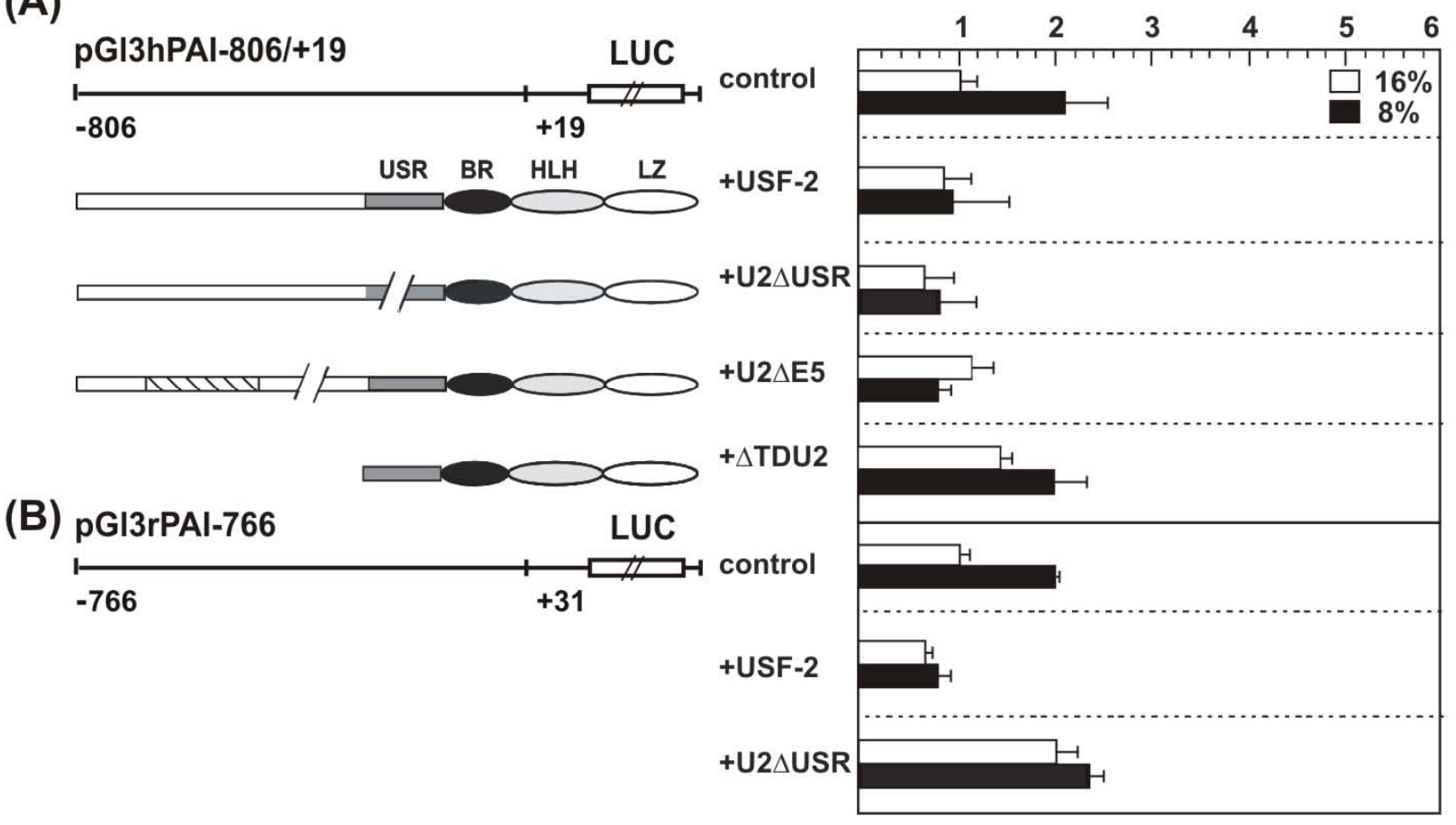

Figure 25. Inhibition of the human and rat PAI-1 promoter constructs by USF in primary rat hepatocytes. (A, B) The human PAl-1 promoter construct pGl3hPAl-806/+19 was cotransfected either with a backbone vector or with expression vectors encoding USF-2a, U2 $\Delta \mathrm{USR}, \mathrm{U} 2 \Delta \mathrm{E} 5$ and $\Delta \mathrm{TDU} 2$ into primary rat hepatocytes. The rat PAI-1 promoter construct pGI3rPAI-766 was cotransfected either with a backbone vector or with expression vectors encoding USF-2a and $\triangle$ USR. After transfection, cells were cultured in fresh culture medium for additional $18 \mathrm{~h}$ under normoxia $\left(16 \% \mathrm{O}_{2}\right)$. Then they were cultured under normoxia $\left(16 \% \mathrm{O}_{2}\right)$ or hypoxia $\left(8 \% \mathrm{O}_{2}\right)$ for the next $24 \mathrm{~h}$. The Luc activity was expressed as fold induction compared to the Luc activity, measured in the respective controls. Values represent means \pm SEM of four independent experiments, each performed in duplicate. 


\section{Discussion}

Plasminogen activator inhibitor (PAI-1), a serine protease inhibitor, inhibits the conversion of the inactive proenzyme plasminogen to the active fibrin-degrading protease plasmin by binding and inactivating both tissue-type and urokinase-type plasminogen activators. (Lijnen \& Collen, 1988, review by Kohler \& Grant, 2000). In addition to its inhibitory effect on fibrinolysis, PAI-1 appears to be a multifunctional protein modulating proteolytic processes associated with pathophysiological conditions e.g. prethrombic events, hemorrhage and thrombus formation which are positively correlated with increased PAI-1 plasma levels and hypoxic conditions. Furthermore, insulin-resistant states, associated hyperinsulinemia, obesity, hypertension and diabetes type 2, are characterized by enhanced PAI-1 levels (reviewed by Eddy, 2002). The molecular mechanisms of these effects have not been yet fully elucidated althought insulin and IGF-1 increase human PAI-1 production in several experimental systems.

Therefore, we investigated in this study the signaling mechanisms and the transcription factors possibly involved in the IGF-1 and insulin-dependent induction of human PAI-1 expression in human hepatoma HepG2 cells.

The present study showed that IGF-1 and insulin induced human PAI-1 gene expression in the HepG2 cell line via activation of the PI(3)-kinase and MAPK signalling cascades, indicating a molecular cross talk between these two pathways. In case of insulin, activation of PAI-1 expression occurred mainly via the MAPK pathway. Further, it was demonstrated that PAI-1 induction occured via a transcriptional mechanism involving HIF-1 $\alpha$ instead of USF-2. However, we have demonstrated that the human PAI-1 promoter is regulated by USF-2 via the E4, E5 and the HRE motifs. Thereby, the different regulation of the PAI-1 promoter occurred in a cell-typedependent manner where the USR domain of USF plays a crucial role, implicating an interaction with a yet unknown cofactor.

\subsection{Regulation of PAI-1 expression by IGF-1 and insulin}

\subsubsection{Transcriptional and post-transcriptional regulation of PAI-1 expression by IGF-1 and insulin}

IGF-1 and insulin were previously reported to enhance PAI-1 mRNA levels and protein secretion in primary human hepatocytes and HepG2 cells (Alessi et al., 1988; Kooistra et al., 1989; Anfosso et al., 1990; Schneider \& Sobel, 1991; Padayatty et al., 1993; Kietzmann et al., 2003) and the results of this study correlate well with these findings. IGF-1 and insulin have been shown to regulate expression of human PAI-1 at a post-transcriptional level by mRNA stabilization, since nuclear run-on experiments showed that the rate of transcription was not 
affected (Fattal et al., 1992). However, there was significant evidence that insulin influenced PAl-1 transcription (Banfi et al., 2001, Vulin \& Stanley, 2002, Kietmann et al., 2003) whereas information concerning a transcriptional regulation by IGF-1 was not available. The PAI-1 promoter luciferase assays in this study showed for the first time that IGF-1 influenced positively PAI-1 transcription in HepG2 cells. Using a reporter gene approach, we localized three IGF-1responsive elements within the human PAI-1 promoter namely the HRE, E4 and E5. Mutation of the HRE abolished the hypoxia-dependent induction and nearly all the IGF-1-dependent induction of the PAI-1 promoter. Interestingly, mutation of either E4 or E5 decreased the IGF-1dependent PAI-1 promoter activation only under hypoxia (Fig. 9). However, when all three elements were mutated IGF-1 was still able to exert a small but significant about 1,6-fold induction of the PAI-1 promoter implicating that an additional motif of the promoter might be involved in the regulation by IGF-1. While IGF-1 operates via the HRE, E4 and E5 it appeared that insulin acted only via the HRE since mutation of the HRE motif (-194/-187) abolished hypoxia- and insulin-dependent activation of the human PAI-1 promoter in HepG2 cells (Fig. 10). Further, mutation in E4 or E5 did not affect PAI-1 promoter induction by insulin but diminished the hypoxia-mediated response indicating that the insulin effects are mediated mostly by the HRE. These data are in line with the data available for the rat PAI-1 promoter where insulin effects were also mediated through HRE in primary rat hepatocytes (Kietzmann et al., 2003). However, other groups searched also for insulin responsive elements in the human PAI-1 promoter using different model systems but the obtained results were so far contradictory. The insulin responsive element within the human PAI-1 promoter was first suggested to be in the regions -93/-62, -157/-128, and -777/-741 when HepG2 cells were used (Banfi et al., 2001). In addition, a mutation at $-52 /-45$ also abolished the insulin responsiveness of the human PAI-1 promoter in GH4 cells (Vulin and Stanley, 2002). Interestingly, the present study also showed that the element at -52/-45 might be involved in the insulin response; however, mutation of this site only abolished insulin-dependent induction under normoxia (Fig. 11). Thus, it might be that different factors mediate the insulin response under normoxia and hypoxia.

Together, these data suggest a major involvement of the HRE in the IGF-1-dependent and insulin-dependent transcriptional regulation of the PAI-1 gene. In addition, the classical E-boxes 4 and 5 seem to have a supportive role in the IGF-1- and the hypoxia-dependent, but not in the insulin-dependent transcriptional regulation of the PAI-1 gene, which leads to the suggestion that IGF-1 and insulin signaling pathways in HepG2 cells might diverge at some point.

\subsubsection{Enhancement of HIF-1 $\alpha$ and PAI-1 by IGF-1 and insulin}

An IGF-1 responsive element in the PAI-1 promoter has not been shown previously, but IGF-1 shares many signalling components and cellular responses with insulin (Blakesley, et al, 1996). 
In this context, the location of the insulin responsive element of the human PAI-1 promoter has been suggested to be bound by a member of the forkhead/winged helix transcription factors family (Vulin \& Stanley, 2002). In addition, it has been shown by performing electrophoretic mobility shift assays (EMSAs) with nuclear extracts from primary rat hepatocytes that insulin enhanced HIF-1 $\alpha$ protein levels and HIF-1 DNA binding (Kietzmann et al., 2003). Thus, the insulin-dependent activation of the rat PAI-1 gene expression is assumed to be mediated via the transcription factor HIF-1 binding to the HRE in the rat PAI-1 gene promoter in primary rat hepatocytes (Kietzmann et al., 2003). Activation of HIF-1 by IGF-1 and insulin as in the present study correlates with previous studies showing that IGF-1, IGF-2 and insulin can enhance HIF$1 \alpha$ protein levels (Zelzer et al, 1998; Feldser et al., 1999; Fukuda et al, 2002; Burroughs et al., 2003). Both IGF-1 and insulin can exert their stimulating effects via MAPK and PI(3)K/PKB pathways. In colon cancer cells IGF-1 was shown to mediate an enhancement of HIF-1 $\alpha$ via the MAPK and $\mathrm{PI}(3) \mathrm{K} / \mathrm{PKB}$ pathway (Fukuda et al., 2002). The $\mathrm{PI}(3) \mathrm{K} / \mathrm{PKB}$ pathway is also involved in the NO-dependent (Sandau et al., 2000), thrombin-dependent (Gorlach et al., 2001), heregulin-dependent (Laughner et al., 2001) and insulin-dependent (Treins et al., 2002; Kietzmann et al., 2003) activation of HIF-1 $\alpha$ under normoxia. Thereby, it appeared that like heregulin, IGF-1 acted via a translation-dependent pathway (Laughner et al., 2001; Fukuda et al., 2002) whereas insulin seemed to act on both HIF-1 $\alpha$ stabilization (Zundel et al., 2000;) and translation (Treins et al., 2003).

\subsubsection{Enhancement of HIF-1 $\alpha$ and PAI-1 by IGF-1 via ERK but not PKB}

In our study, the PI(3)K inhibitor, LY294002, could abrogate the IGF-1-dependent increase of HIF-1 $\alpha$ (Fig. 15). This is in line with experiments in human colon cancer cells in which inhibition of $\mathrm{PI}(3) \mathrm{K}$ by wortmannin prevented induction of HIF-1 $\alpha$ (Fukuda et al., 2002). While in this study inhibition of $\mathrm{PI}(3) \mathrm{K}$ and subsequently PKB contributed to the regulation of HIF-1 $\alpha$ levels, this was only partially the case in our experimental data. Indeed, in correlation with previous observations (Alvarez-Tejado et al., 2002; Kietzmann et al., 2003; Hirota et al., 2004) we found that the inhibition of PI(3)K by LY294002 downregulated HIF-1 $\alpha$ levels after IGF-1 treatment. However, this effect was not due to further inhibition of PDK1 or PKB since neither the kinasedeficient PDK1 nor the direct PKB inhibitor TRB-3 abolished IGF-1-dependent induction of HIF$1 \alpha$ (Fig. 16). By contrast, LY294002, the kinase-deficient PDK1 and TRB-3 reduced the hypoxia-dependent enhancement of HIF-1 $\alpha$ in agreement with models which propose a role of the PKB pathway in $\mathrm{O}_{2}$-signalling (Zhong\& Simons, 2001; Kietzmann et al., 2003 a,b). Similar to the data obtained from human colon cancer cells (Fukuda et al., 2002) we also found that the MAPK pathway was involved in the HIF-1 $\alpha$ regulation by IGF-1 since the MEK $1 / 2$ inhibitor, U0126, and a kinase-deficient Raf-1 inhibited the IGF-1-mediated upregulation of HIF-1 $\alpha$. 
Remarkably, the $\mathrm{PI}(3) \mathrm{K}$ inhibitor LY294002 reduced the levels of phospho-ERK1/2 upon treatment with IGF-1 suggesting that the ERK pathway appears to be regulated in some way by $\mathrm{PI}(3) \mathrm{K}$. This is in conformity with a study showing that in primary human erythroid progenitors $\mathrm{PI}(3) \mathrm{K}$ inhibitors blocked ERK activation by EPO (Schmidt et al., 2004). In addition, the PI(3)K inhibitors LY294002 and wortmannin abolished the angiotensin-II-stimulated ERK phosphorylation in human MCF-7 breast cancer cells (Muscella et al., 2003) thus also supporting the idea that $\mathrm{PI}(3) \mathrm{K}$ probably acts upstream of ERK. Furthermore, we detected an inhibition of the HIF-1 $\alpha$ protein levels when the dominant-negative form of Raf-1 was overexpressed, confirming again the involvement of the ERK pathway in IGF-1-mediated induction of HIF-1 $\alpha$. Together, all these findings suggest that in different tumor cells IGF-1 appears to regulate HIF-1 $\alpha$ induction via slightly different signalling pathways in which $\mathrm{PI}(3) \mathrm{K}$ and ERK1/2 are critical players.

\subsubsection{Enhancement of HIF-1 $\alpha$ and PAI-1 by insulin via MAP kinase}

In our study, the insulin-induced enhancement of HIF-1 $\alpha$ protein levels by specific $\mathrm{PI}(3) \mathrm{K}$ inhibitors such as LY294002 was inhibited under normoxia and only slightly reduced under hypoxia and thus the role of $\mathrm{PI}(3) \mathrm{K}$ in that process remained uncertain. In addition, the insulindependent increase of HIF-1 $\alpha$ was completely abolished by MEK inhibitors such as U0126 (Fig. 17). These unexpected results implicated a major involvement of the MAPK pathway whereas studies performed in prostate carcinoma-derived cell lines (Jiang et al., 2001), the arising retinal pigment epithelia cell line-19 (ARPE-19) (Treins et al., 2002) and primary rat hepatocytes (Kietzmann et al., 2003) showed the involvement of a $\mathrm{PI}(3) \mathrm{K}$-dependent pathway in insulininduced enhancement of HIF-1 $\alpha$ protein levels. Additionally, the overexpression of dominant negative PDK1 as well as the tribbles homolog TRB3 which inhibits Akt/PKB activation (Du et al., 2003) reduced the basal HIF-1 $\alpha$ protein levels but did not influence the insulin-induced HIF$1 \alpha$ protein levels, thus indicating again the possible involvement of the MAPK pathway.

Altogether, we have found that the insulin effect on HIF-1 $\alpha$ expression is dependent on the MAPK pathway in HepG2 cells. In contrast, in the same cell line the $\mathrm{PI}(3) \mathrm{K}$ pathway does not appear to be required for insulin action on HIF-1 $\alpha$. To our knowledge, these studies provide the first report that insulin activates HIF-1 $\alpha$ via the MAPK pathway in HepG2 cells. Interestingly, another study showed transcriptional activation of PAI-1 by insulin due to $\mathrm{PI}(3) \mathrm{K}$ activation, followed by protein kinase C and ERK2 phosphorylation in HepG2 cells (Banfi et al., 2001). Thus, further investigations are necessary to elucidate the detailed role of $\mathrm{PI}(3) \mathrm{K}$ under hypoxia and in the presence of insulin as well as to determine all the components in the signaling pathway from insulin to HIF-1 in HepG2 cells. 
The evidence from our experimental data that IGF-1 and insulin use different pathways to induce PAI-1 transcription via HIF-1 in HepG2 cells raises an interesting question concerning the involvement of the E-boxes in the PAI-1 promoter in IGF-1- but not in insulin-dependent PAI1 expression. It has been reported that the high-affinity DNA-binding form of HIF-1 was only generated when HIF-1 $\alpha$ forms a pair with variants of HIF-1 $\beta$ which are capable to elicit an allosteric change in the conformation of the dimer (Kallio et al., 1997). Thus, if the HIF-1 $\alpha$ dimerization partner might be differentially modified, HIF-1 would respond in a different manner. Although it has been suggested that HIF-1 $\alpha$ heterodimerizes only with HIF-1 $\beta$ (Jiang et al., 1996), a heterodimer consisting of MOP3 and HIF-1 $\alpha$ which can drive transcription in response to cellular hypoxia has been reported (Hogenesch et al., 1998). In this context, one possible explanation of our observations could be that upon IGF-1 and insulin treatment, HIF-1 itself or the cofactors such as p300/CBP which are critical for HIF-1 activity are modified in different manner. Also, additional yet unknown mechanisms might be involved and this might result in a different affinity of HIF-1 to the binding elements within the PAI-1 promoter.

\subsection{Regulation of PAI-1 promoter activity by Forkhead transcription factor}

Members of the forkhead transcription factor (FKHR) family are thought to play an important role in development and cell differentiation. FKHR has been reported to be regulated by insulin in several cell lines of hepatic origin such as rat hepatomas (Tomizawa et al., 2000), SV40transformed murine hepatocytes (Nakae, et al., 1999) and human HepG2 hepatoma cells (Guo et al., 1999). FKHR factors are regulated by several signal transduction cascades. However, the main regulator is the $\mathrm{PI}(3) \mathrm{K} / \mathrm{PKB}$ pathway whereas FKHR function is "fine-tuned" by the protein kinase CK1 (formerly known as casein kinase 1 ) and the dual-specificity regulated kinase $1 \mathrm{~A}$ (DYRK1A) (reviewed by Van der Heide et al., 2004). Thus, phosphorylation of FKHR by PKB on Thr24, Ser 256 and Ser319 was reported to attenuate its nuclear import by binding of FKHR to 14-3-3 proteins (Brunet et al., 1999; Cahill et al., 2001; Brownawell et al., 2001). In addition, mutation of FKHR Thr/Ser residues abolished both PKB-mediated phosphorylation and the nuclear export (Biggs et al., 1999; Tang et al., 1999). Thus, it was expected that FKHR contributes to the effect of insulin also in HepG2 cells. This was, indeed, only partially the case in our study.

The human PAI-1 promoter seems to contain a forkhead binding-like element which resembles that one found in genes negatively regulated by insulin such as PEPCK (O`Brien et al., 1991) and IGFBP-1 (Suwanichkul et al., 1990). Our observation indicated that FKHR did not augment the basal activity of the PAI-1 promoter or the insulin-dependent PAI-1 promoter activity. This is based on three lines of evidence. First, expression of either FKHR or FKHR AAA, which is a PKB unresponsive variant did not contribute to the transcriptional activity of the PAI-1 promoter 
under normoxia but, interestingly, abolished the hypoxia-mediated response in HepG2 cells (Fig. 12). Second, the mutation in the putative FHKR binding site abolished insulin-dependent PAl-1 promoter activity under normoxia but not under hypoxia. Third, treatment of cells cotransfected with wild-type PAI-1 promoter construct and FKHR as well as with FKHR AAA vectors with insulin did not show a difference between the cells transfected with wild-type FKHR and the PKB resistant FKHR AAA. Further, if the FKHR would play a dominant role in regulating PAI-1 promoter activity by insulin, transfection of the FKHR should downregulate PAI-1 promoter activity and treatment with insulin should derepress this effect. This was not the case and thus we consider that FKHR is not the major regulator of PAI-1 expresiion in response to insulin.

\subsection{Transcriptional regulation of PAI-1 by USF-2}

\subsubsection{Involvement of USF-2 in transcriptional regulation of PAI-1 by insulin}

It was proposed that USFs binding to the CATGTG E-box element in the fatty acid synthase promoter could have a role in insulin-dependent regulation of the fatty acid synthase gene expression. The observations from the present study showing that IGF-1 and insulin induced PAI-1 gene transcription thought HRE, E4 and E5 raised the question of whether USF-2 was involved in the positive regulation of human PAI-1 gene transcription by insulin. For that purpose, luciferase assays were performed and the data obtained from them (Fig. 19) showed that probably USF-2 is not involved in insulin-dependent PAI-1 gene expression. This is in correlation with a study showing that the transcription factor HIF-1 mediated the induction of PAl-1 gene expression by insulin in primary rat hepatocytes (Kietzmann et al., 2003). However, it has been reported that USF-2 repressed PAI-1 by competing with HIF-1 for HRE binding within the rat PAI-1 promoter (Samoylenko et al., 2003). By contrast, the present study showed that USF-2 had an inducing effect on human PAI-1 promoter activity in HepG2 cells. The reason might be that USFs can function either as repressor or activators.

\subsubsection{USF modulates PAI-1 expression via binding to E-box motifs}

USF was originally identified as a transcription factor activating the adenovirus major late promoter (Sawadogo \& Roeder, 1985). USFs mainly functions through classical E-box core sequences but an ability to bind non-canonical E-boxes (Coulson et al., 2003; Virolle et al., 2002, Harris et al., 2000) as well as pyridine-rich initiator (Inr) sites (Roy et al., 1991) has been reported. In our study, USF-2 activated the human PAI-1 promoter in HepG2 cells via the HRE, which contains a non-canonical E-box sequence and the classical E-boxes, E4 and E5 (Fig. 22). Mutations of E4, E5 or both decreased the activation of the PAI-1 promoter by USF-2 while the mutation of the HRE alone completely abolished it. In addition, in this study and in our previous 
one, we observed that the hypoxia-mediated response of the PAI-1 gene was abolished not only by the mutation of the HRE but also after transfection with USF-2. Mutations of E4 and E5 also diminished the response of the PAI-1 promoter to hypoxia. Thus, all these sites are significant for the action of USF and thus a possible competitive action between USF and HIF-1 as shown for the rat PAI-1 promoter (Samoylenko et al., 2001) seems to be valid also for the human PAI-1 promoter. These observations implicated that the HRE is the major USF binding site in PAI-1 promoter. Interestingly, electrophoretic mobility-shift analyses demonstrated that E4 (-566/-559) and E5 (-681/-674) bind USFs but although the HRE (-194/-187) contributed to the USF-dependent regulation of the human PAI-1 gene, it did not bind USFS (Fig. 22). Thus, these results again emphasize the role of the HRE, E4 and E5 in the USF-2-dependent PAI-1 gene transcription and suggest a cooperative interaction among these elements within the promoter possibly via a yet unknown cofactor. Since we detected that a transcription factor from the ATF-1/CREB family binds constitutively to the HRE it is tempting to speculate that CREBbinding protein (CBP) is involved as a cofactor suggesting that it interacts via USR with the USF proteins bound to E4 and E5, and then this complex of transcription factors cooperates with the general transcriptional machinery. This seems to be likely since USF is related to the basal transcription factor TFII-I and both of them have been implicated in the recruitment of the general transcriptional complexes to TATA-less promoters and in stabilization of the general transcriptional machinery in TATA-box-containing promoters (Roy et al.,1991; Du, et al., 1993; Bungert et al., 1992). The PAI-1 promoter contains a TATA box and the USF action might be due to interaction with the basal machinery rather than with its stabilization since luciferase assays showed that only mutation of the HRE is sufficient to completely abolish the USF effect (Fig. 21). Further, the cooperative mode is supported by a study showing that USF can act through both an E-box and a noncanonical E-box as both enhancer and initiator in the regulation of the vasopressin promoter (Coulson et al., 2003) However, up to now it is not known whether and to what extend USF, CBP and the general transcriptional machinery interact and this remains to be clarified in future studies.

\subsubsection{USFs act as activators and inhibitors}

Among the USF-induced genes are those involved in cellular proliferation such as p53 (Reisman \& Rotter, 1993), cyclin B1 (Cogswell et al., 1995) and transforming growth factor $\beta 2$ (Scholtz et al., 1996) as well as glucose controlled genes such as fatty acid synthase (Wang \& Sul, 1995), L-type pyruvate kinase (Lefrancois-Martinez et al., 1995) and hormone sensitive lipase (Smih et al., 2002). The inhibitory role of USF was reported for the immunoglobulin heavy chain enhancer gene (Carter et al., 1997), aortic preferentially expressed gene-1 (APEG-1) (Chen et al., 2001), the CYP1A1 gene (Takahashi et al., 1997) and CYP19 gene (Jiang \& Mendelson, 2003). 
The experimental evidence from the present study indicating that USF-2 acts as an inducer of human PAI-1 expression appears to be contradictory to our previous findings from studying the rat PAI-1 gene where USF-2 has been characterised to act as an inhibitor. First, we thought that these differences might be due to sequence variabilities within the promoter since sequence analysis of the human and rat PAI-1 promoter revealed a number of differences. While a complete conservation of the HRE in human and rat PAI-1 promoters was found, the two classical E-boxes E4 and E5 were found only in the human but not in the rat PAI-1 promoter. In addition, the USF-2-binding site in the rat promoter (Samoylenko et al., 2001) is absent from the human PAI-1 promoter. However, our transfection experiments with wild-type human PAI-1 promoter pGI3hPAI-806/+19 or rat PAI-1 promoter pGI3rPAI-766 Luc gene constructs together with a USF-2 expression vector in human (HepG2), and rat (H4IIE) cells as well as in primary rat hepatocytes showed that USF-2 induced both the human and the rat PAI-1 promoter constructs in either the human or the rat hepatoma cell lines (Fig. 23, 24). In addition, we found that USF-2 repressed both promoters in primary rat hepatocytes (Fig. 25). Thus, these results give direct evidence that the action of USF as activator or repressor of human or rat PAI-1 expression depends on the cell-type rather than on differences between the promoters.

\subsubsection{The USR domain as critical part within USF-2}

Several functional domains of the USF-2 protein such as the USF specific region (USR) and especially the part of the transactivation domain which is encoded by exon 5 of the USF gene have been proposed to be important for USF activity (Luo, Sawadogo, 1996, Qyang, Luo, Sawadogo, 1999). The USR has been shown to be necessary and sufficient for transcriptional activation by USF-2 of promoters containing both a TATA-box and an initiator (Inr) element whereas the exon 5 is required together with USR for transcriptional activation of promoters containing only the TATA-box but no Ihr-element (Luo \& Sawadogo, 1996; Qyang et al., 1999). In this work, we showed that in hepatoma cells the USR domain appears to contribute predominantly to the activity of USF-2 regulating the PAI-1 promoter which contains E-box motifs, TATA-box but no Inr-element. In addition, we obtained data indicating that the USR is also required for PAI-1 gene repression by USF-2 in primary rat hepatocytes (Fig. 25). Furthermore, when the sequence corresponding to exon 5 was deleted from USF-2 no effects on transcriptional activity of USF-2 were observed with one exception; enhanced transcriptional activity with the rat PAI-1 promoter in H4IIE cells (Fig. 24). This suggests that this part can inhibit the activity of USF-2 only in H4IIE cells i.e. in a cell-type-specific manner. Thus, our findings are in line with a study in which the transcriptional activity of USF proteins appeared also to be controlled by an unknown factor recognizing the USR (Qyang et al., 1999) which might be either differently expressed or modified in a cell-type-specific manner. 


\subsection{Regulation of human PAI-1 gene expression by IGF-1, insulin and USF-2}

The IGF-1 and insulin activated PAI-1 expression in HepG2 cells appears to occur through signaling cascades involving the $\mathrm{PI}(3) \mathrm{K}$ and MAPK-ERK pathway. Within this regulation the transcription factor HIF-1 plays a major role. Under normoxic unstimulated conditions the PAI-1 promoter is bound by USF protein and ATF/CREB. This complex is probably stabilized by a coactivator like CBP/p300. Under hypoxia inhibition of prolyl hydroxylases (PHDs) will stabilize HIF-1 $\alpha$. Further, upon treatment with IGF-1 and insulin HIF-1 $\alpha$ levels are induced. Enhancement of HIF-1 $\alpha$ protein levels and subsequently HIF-1 levels replaces USF-proteins which are normally bound to the E-boxes E4 and E5 as well as ATF/CREB bound to the HRE. Replacement of the USF/cofactor complex by HIF-1 enables then profound and strong induction of PAI-1 expression.
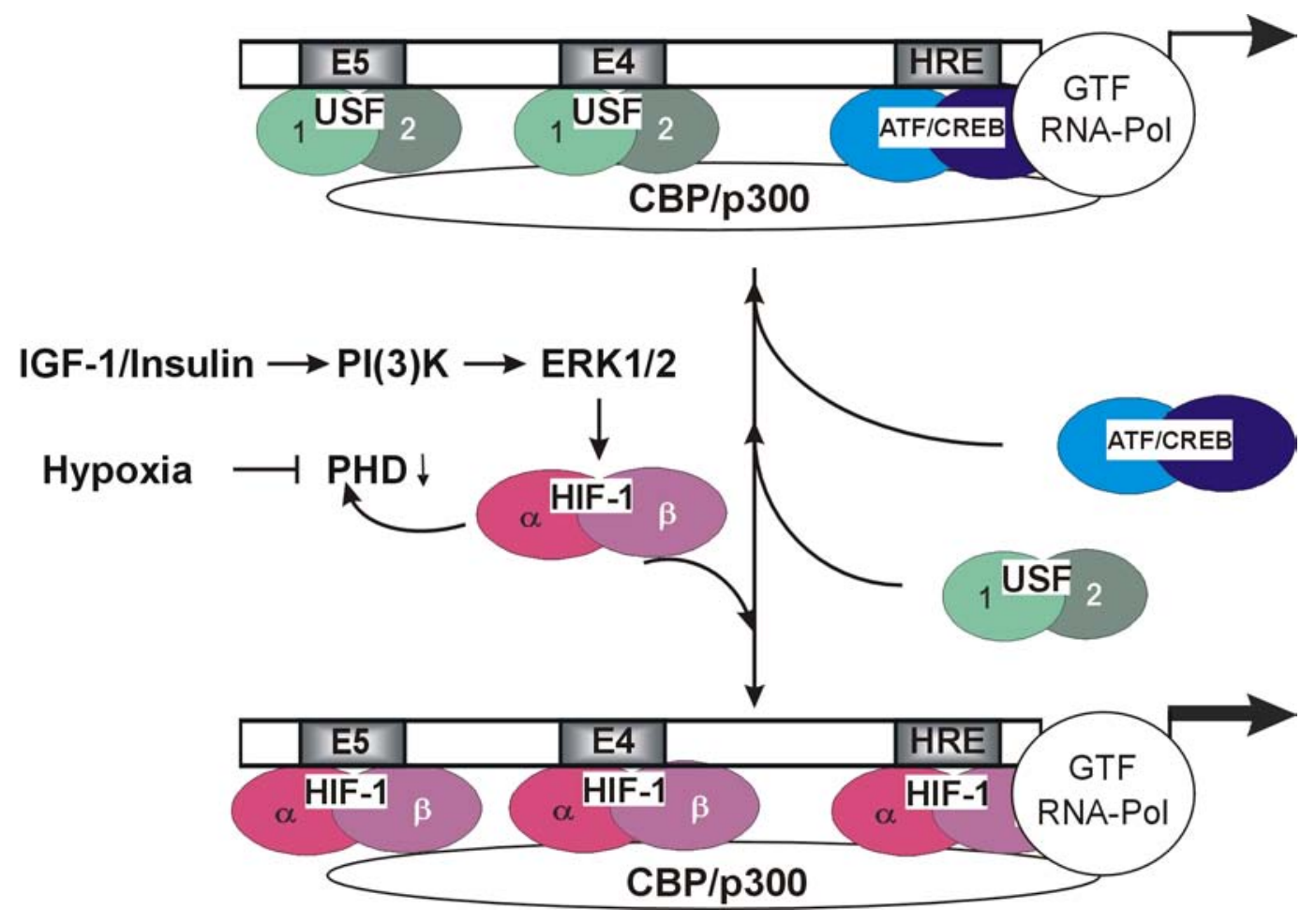

Figure 26. Model of human PAI-1 gene regulation by IGF-1, insulin and USF-2 under normoxia and hypoxia. see text for explanation; PHD; prolyl hydroxylases; GTF, general transcription factors; RNA-Pol, RNA polymerase II; CBP, CREB-binding protein; 


\section{REFERENCES}

Ahn JD, Morishita R, Kaneda Y, Lee KU, Park JY, Jeon YJ, Song HS, Lee IK (2001). Transcription factor decoy for activator protein-1 (AP-1) inhibits high glucose- and angiotensin II-induced type 1 plasminogen activator inhibitor (PAI-1) gene expression in cultured human vascular smooth muscle cells. Diabetologia 44:713-20

Agrenius V, Chmielewska J, Widstrom O, Blomback M (1989). Pleural fibrinolytic activity is decreased in inflammation as demonstrated in quinacrine pleurodesis treatment of malignant pleural effusion. Am Rev Respir Dis. 140:1381-5

Alemany J, Borras T, de Pablo F (1990). Transcriptional stimulation of the delta 1-crystallin gene by insulin-like growth factor I and insulin requires DNA cis elements in chicken. Proc Natl Acad Sci USA 87:3353-7

Alessi DR, Cohen P (1998). Mechanism of activation and function of protein kinase B. Curr Opin Genet Dev 8:55-62

Alexander-Bridges M, Mukhopadhyay NK, Jhala U, Denaro M, Kong X F, Avruch J, and Maller J (1992). Growth factor-activated kinases phosphorylate IRE-AB. Biochem Soc Trans 20:691-3

Alessi MC, Juhan-Vague I, Kooistra T, Declerck PJ, Collen D (1988). Insulin stimulates the synthesis of plasminogen activator inhibitor 1 by the human hepatocellular cell line Hep G2. Thromb Haemost. 60:491-4

Al-Nedawi KN, Czyz M, Bednarek R, Szemraj J, Swiatkowska M, Cierniewska-Cieslak A, Wyczolkowska J, Cierniewski CS (2004). Thymosin beta 4 induces the synthesis of plasminogen activator inhibitor 1 in cultured endothelial cells and increases its extracellular expression. Blood 103:1319-24

Alvarez-Tejado M, Alfranca A, Aragones J, Vara A, Landazuri MO, del Peso L (2002). Lack of evidence for the involvement of the phosphoinositide 3-kinase/Akt pathway in the activation of hypoxiainducible factors by low oxygen tension. J Biol Chem. 277:13508-17

Anfosso F, Alessi MC, Nalbone G, Chomiki N, Henry M, Juhan-Vague I (1990). Up-regulated expression of plasminogen activator inhibitor-1 in Hep G2 cells: interrelationship between insulin and insulin-like growth factor 1. Thromb Haemost. 73:268-74

Aperlo C, Boulukos KE, Sage J, Cuzin F, Pognonec P (1996). Complete sequencing of the murine USF gene and comparison of its genomic organization to that of mFIP/USF2. Genomics 37:337-44

Ayala JE, Streeper RS, Desgrosellier JS, Durham SK, Suwanichkul A, Svitek CA, Goldman JK, Barr FG, Powell DR, O'Brien RM (1999). Conservation of an insulin response unit between mouse and human glucose-6-phosphatase catalytic subunit gene promoters: transcription factor FKHR binds the insulin response sequence. Diabetes 48:1885-9

Balaram SK, Agrawal DK, Edwards JD (1999). Insulin like growth factor-1 activates nuclear factorkappa B and increases transcription of the intercellular adhesion molecule-1 gene in endothelial cells. Cardiovasc Surg. 7:91-7

Banfi C, Eriksson P, Giandomenico G, Mussoni L, Sironi L, Hamsten A, Tremoli E (2001). Transcriptional regulation of plasminogen activator inhibitor type 1 gene by insulin: insights into the signaling pathway. Diabetes 50:1522-30

Barroso I, Santisteban P (1999). Insulin-induced early growth response gene (Egr-1) mediates a short term repression of rat malic enzyme gene ranscription. J Biol Chem 274:17997-18004

Berry MN, Friend DS (1969). High-yield preparation of isolated rat liver parenchymal cells - A biochemical and fine structural study. Journal of Cell Biology 43: 506-520 
Bertrand L, Alessi DR, Deprez J, Deak M, Viaene E, Rider MH, Hue L (1999). Heart 6-phosphofructo2-kinase activation by insulin results from Ser-466 and Ser-483 phosphorylation and requires 3phosphoinositide-dependent kinase-1, but not protein kinase B. J Biol Chem. 274:30927-33

Biggs WH 3rd, Meisenhelder J, Hunter T, Cavenee WK, Arden KC (1999). Protein kinase B/Aktmediated phosphorylation promotes nuclear exclusion of the winged helix transcription factor FKHR1. Proc Natl Acad Sci USA 96:7421-6

Binder BR, Christ G, Gruber F, Grubic N, Hufnagl P, Krebs M, Mihaly J, Prager GW (2002). Plasminogen activator inhibitor 1: physiological and pathophysiological roles. News Physiol Sci. 17:56-61

Blakesley VA, Scrimgeour A, Esposito D, Le Roith D (1996). Signaling via the insulin-like growth factor-I receptor: does it differ from insulin receptor signaling? Cytokine Growth Factor Rev. 7:153-9

Boffa MB, Wang W, Bajzar L, Nesheim ME (1998). Plasma and recombinant thrombin-activable fibrinolysis inhibitor (TAFI) and activated TAFI compared with respect to glycosylation, thrombin/thrombomodulin-dependent activation, thermal stability, and enzymatic properties. J Biol Chem. 273:2127-35

Bosma PJ, van den Berg EA, Kooistra T, Siemieniak DR, Slightom JL (1988). Human plasminogen activator inhibitor-1 gene. Promoter and structural gene nucleotide sequences. J Biol Chem. 263:9129-41

Bradford MM (1976). A rapid and sensitive method for the quantitation of microgram quantities of protein utilizing the principle of protein-dye binding. Anal Biochem. 72:248-54

Brownawell AM, Kops GJ, Macara IG, Burgering BM (2001). Inhibition of nuclear import by protein kinase $B$ (Akt) regulates the subcellular distribution and activity of the forkhead transcription factor AFX. Mol Cell Biol. 21:3534-46

Bruick RK, McKnight SL (2001). A conserved family of prolyl-4-hydroxylases that modify HIF. Science 294:1337-40

Brunet A, Bonni A, Zigmond MJ, Lin MZ, Juo PJ, Hu LS, Anderson MJ, Arden K, Blenis CJ and Greenberg ME (1999). Akt promotes cell survival by phosphorylating and inhibiting a Forkhead transcription factor. Cell 96:857-68

Bruzdzinski CJ, Riordan-Johnson M, Nordby EC, Suter SM, Gelehrter TD (1990). Isolation and characterization of the rat PAI-1 gene. J Biol Chem. 265:2078-85

Bullock WO, Fernandez JM and Short JM (1987). XL1-Blue: A high efficiency plasmid transforming recA-E. coli strain with $\beta$-galactosidase selection. Biotechniques 5, 376-379

Bungert J, Kober I, During F, Seifart KH (1992). Transcription factor eUSF is an essential component of isolated transcription complexes on the duck histone $\mathrm{H} 5$ gene and it mediates the interaction of TFIID with a TATA-deficient promoter. J Mol Biol. 223:885-98

Burroughs KD, Oh J, Barrett JC, DiAugustine RP (2003). Phosphatidylinositol 3-kinase and mek1/2 are necessary for insulin-like growth factor-I-induced vascular endothelial growth factor synthesis in prostate epithelial cells: a role for hypoxia-inducible factor-1? Mol Cancer Res. 1:312-22

Busso N, Nicodeme E, Chesne C, Guillouzo A, Belin D, Hyafil F (1994). Urokinase and type I plasminogen activator inhibitor production by normal human hepatocytes: modulation by inflammatory agents. Hepatology 20:186-90

Cahill CM, Tzivion G, Nasrin N, Ogg S, Dore J, Ruvkun G, Alexander-Bridges M (2001). Phosphatidylinositol 3-kinase signaling inhibits DAF-16 DNA binding and function via 14-3-3-dependent and 14-3-3-independent pathways. J Biol Chem. 276:13402-10

Carmeliet P, Kieckens L, Schoonjans L, Ream B, van Nuffelen A, Prendergast G, Cole M, Bronson R, Collen D, Mulligan RC (1993). PAI-1 gene-deficient mice. I. Generation by homologous recombination and characterization. J Clin Invest. 92:2746-55 
Carrero P, Okamoto K, Coumailleau P, O'Brien S, Tanaka H, Poellinger L (2000). Redox-regulated recruitment of the transcriptional coactivators CREB-binding protein and SRC-1 to hypoxia-inducible factor 1alpha. Mol Cell Biol. 20:402-15

Carter RS, Ordentlich P, Kadesch T (1997). Selective utilization of basic helix-loop-helix-leucine zipper proteins at the immunoglobulin heavy-chain enhancer. Mol Cell Biol. 17:18-23

Chapman SC, Ayala JE, Streeper RS, Culbert AA, Eaton EM, Svitek CA, Goldman J K, Tavaré JM and O'Brien RM (1999). Multiple promoter elements are required for the stimulatory effect of insulin on human collagenase-1 gene transcription Selective effects on activator protein-1 expression may explain the quantitative difference in insulin and phorbol ester action. J Biol Chem 274:18625-34

Cheatham B, Kahn CR (1995). Insulin action and the insulin signaling network. Endocr Rev. 16:117-42

Chen YH, Layne MD, Watanabe M, Yet SF, Perrella MA (2001). Upstream stimulatory factors regulate aortic preferentially expressed gene-1 expression in vascular smooth muscle cells. $\mathrm{J}$ Biol Chem. 276:47658-63

Chen C., Okayama H (1987). High-efficiency transformation of mammalian-cells by plasmid DNA. Molecular and cellular biology 7: 2745-2752

Chen C., Okayama H (1988). Calcium phosphate-mediated gene-transfer - a highly efficient transfection system for stably transforming cells with plasmid DNA. Biotechniques 6: 632-8

Chen YQ, Su M, Walia RR, Hao Q, Covington JW, Vaughan DE (1998). Sp1 sites mediate activation of the plasminogen activator inhibitor-1 promoter by glucose in vascular smooth muscle cells. J Biol Chem. 273:8225-31

Chmielewska J, Wiman B (1983). Determination of tissue plasminogen activator and its "fast" inhibitor in plasma. Clin Chem. 32:482-5

Clement S, Krause U, Desmedt F, Tanti JF, Behrends J, Pesesse X, Sasaki T, Penninger J, Doherty M, Malaisse W, Dumont JE, Le Marchand-Brustel Y, Erneux C, Hue L, Schurmans S (2001). The lipid phosphatase SHIP2 controls insulin sensitivity. Nature 409:92-7

Cohen P, Alessi DR, Cross DA (1997). PDK1, one of the missing links in insulin signal transduction? FEBS Lett. 23;410:3-10

Cogswell JP, Godlevski MM, Bonham M, Bisi J, Babiss L (1995). Upstream stimulatory factor regulates expression of the cell cycle-dependent cyclin B1 gene promoter. Mol Cell Biol. 15:2782-90

Coulson JM, Edgson JL, Marshall-Jones ZV, Mulgrew R, Quinn JP, Woll PJ (2003). Upstream stimulatory factor activates the vasopressin promoter via multiple motifs, including a non-canonical E-box. Biochem J. 369:549-61

Crews CM, Alessandrini A, Erikson RL (1992). The primary structure of MEK, a protein kinase that phosphorylates the ERK gene product. Science 258:478-80

Cross DA, Alessi DR, Cohen P, Andjelkovich M, Hemmings BA (1995). Inhibition of glycogen synthase kinase-3 by insulin mediated by protein kinase B. Nature 378:785-9

Damante G, Cox F, Rapoport B (1988). IGF-I increases C-fos expression in FRTL5 rat thyroid cells by activating the c-fos promoter. Biochem Biophys Res Commun. 151:1194-9

Datta SR, Brunet A and Greenberg ME (1999) Cellular survival : a play in three Akts. Genes Dev 13: 2905- 2927

Dent P, Reardon DB, Morrison DK, Sturgill TW (1995). Regulation of Raf-1 and Raf-1 mutants by Rasdependent and Ras-independent mechanisms in vitro. Mol Cell Biol. 15:4125-35

Dieval J, Nguyen G, Gross S, Delobel J, Kruithof EK (1991). A lifelong bleeding disorder associated with a deficiency of plasminogen activator inhibitor type 1. Blood 77:528-32 
Dijkers PF, Medema RH, Pals C, Banerji L, Thomas NS, Lam EW, Burgering BM, Raaijmakers JA, Lammers JW, Koenderman L, Coffer PJ (2000). Forkhead transcription factor FKHR-L1 modulates cytokine-dependent transcriptional regulation of p27(KIP1). Mol Cell Biol. 20:9138-48

Downward J (1998). Mechanisms and consequences of activation of protein kinase B/Akt. Curr Opin Cell Biol. 10:262-7

Du H, Roy AL, Roeder RG (1993). Human transcription factor USF stimulates transcription through the initiator elements of the HIV-1 and the Ad-ML promoters. EMBO J. 12:501-11

Du K, Herzig S, Kulkarni RN, Montminy M (2003). TRB3: a tribbles homolog that inhibits Akt/PKB activation by insulin in liver. Science 300:1574-7

Du K, Montminy M (1998). CREB is a regulatory target for the protein kinase Akt/PKB. J Biol Chem 273:32377-9.

Du XL, Edelstein D, Rossetti L, Fantus IG, Goldberg H, Ziyadeh F, Wu J, and Brownlee M (2000). Hyperglycemia-induced mitochondrial superoxide overproduction activates the hexosamine pathway and induces plasminogen activator inhibitor-1 expression by increasing Sp1 glycosylation. Proc Natl Acad Sci USA 97: 12222-12226

Durham SK, Suwanichkul A, Scheimann AO, Yee D, Jackson JG, Barr FG and Powell DR (1999). FKHR binds the insulin response element in the insulin-like growth factor binding protein-1 promoter. Endocrinology 140:3140-6

Eddy AA (2002). Plasminogen activator inhibitor-1 and the kidney.Am J Physiol Renal Physiol. 283:209-

Eddy AA, Giachelli CM (1995). Renal expression of genes that promote interstitial inflammation and fibrosis in rats with protein-overload proteinuria. Kidney Int. 47:1546-57

Efstratiadis A, Posakony JW, Maniatis T, Lawn RM, O'Connell C, Spritz RA, DeRiel JK, Forget BG, Weissman SM, Slightom JL, Blechl AE, Smithies O, Baralle FE, Shoulders CC, Proudfoot NJ (1980). The structure and evolution of the human beta-globin gene family. Cell 21:653-68

Ema M, Hirota K, Mimura J, Abe H, Yodoi J, Sogawa K, Poellinger L, Fujii-Kuriyama Y (1999). Molecular mechanisms of transcription activation by HLF and HIF1alpha in response to hypoxia: their stabilization and redox signal-induced interaction with CBP/p300. EMBO J. 18:1905-14

Ema M, Taya S, Yokotani N, Sogawa K, Matsuda Y, Fujii-Kuriyama Y (1997). A novel bHLH-PAS factor with close sequence similarity to hypoxia-inducible factor 1alpha regulates the VEGF expression and is potentially involved in lung and vascular development. Proc Natl Acad Sci USA. 94:4273-8

Erickson LA, Hekman CM, Loskutoff DJ. (1985). The primary plasminogen-activator inhibitors in endothelial cells, platelets, serum, and plasma are immunologically related. Proc Natl Acad Sci USA 82:8710-4

Fattal PG, Billadello JJ (1993). Species-specific differential cleavage and polyadenylation of plasminogen activator inhibitor type 1 hnRNA. Nucleic Acids Res. 21:1463-6

Fattal PG, Schneider DJ, Sobel BE, Billadello JJ (1992). Post-transcriptional regulation of expression of plasminogen activator inhibitor type $1 \mathrm{mRNA}$ by insulin and insulin-like growth factor 1 . $\mathrm{J} \mathrm{Biol} \mathrm{Chem.}$ 267:12412-5

Feldser D, Agani F, lyer NV, Pak B, Ferreira G, Semenza GL (1999). Reciprocal positive regulation of hypoxia-inducible factor 1alpha and insulin-like growth factor 2. Cancer Res. 59:3915-8

Fingar DC, Birnbaum MJ (1994). Characterization of the mitogen-activated protein kinase/90-kilodalton ribosomal protein S6 kinase signaling pathway in 3T3-L1 adipocytes and its role in insulin-stimulated glucose transport. Endocrinology 134:728-35

Fink T, Kazlauskas A, Poellinger L, Ebbesen P, Zachar V (2002). Identification of a tightly regulated hypoxia-response element in the promoter of human plasminogen activator inhibitor-1. Blood 99:2077-83 
Firth JD, Ebert BL, Pugh CW, Ratcliffe PJ (1994). Oxygen-regulated control elements in the phosphoglycerate kinase 1 and lactate dehydrogenase A genes: similarities with the erythropoietin $3^{\prime}$ enhancer. Proc Natl Acad Sci USA. 91:6496-500

Flamme I, Frohlich T, von Reutern M, Kappel A, Damert A, Risau W (1997). HRF, a putative basic helix-loop-helix-PAS-domain transcription factor is closely related to hypoxia-inducible factor-1 alpha and developmentally expressed in blood vessels. Mech Dev. 63:51-60

Forsythe JA, Jiang BH, lyer NV, Agani F, Leung SW, Koos RD, Semenza GL (1996). Activation of vascular endothelial growth factor gene transcription by hypoxia-inducible factor 1. Mol Cell Biol. 16:460413

Fukuda R, Hirota K, Fan F, Jung YD, Ellis LM, Semenza GL (2002). Insulin-like growth factor 1 induces hypoxia-inducible factor 1-mediated vascular endothelial growth factor expression, which is dependent on MAP kinase and phosphatidylinositol 3-kinase signaling in colon cancer cells. J Biol Chem. 277:38205-11

Furstenberger G, Morant R, Senn HJ (2003). Insulin-like growth factors and breast cancer. Onkologie 26:290-4

Gille H, Sharrocks AD, Shaw PE (1992). Phosphorylation of transcription factor p62TCF by MAP kinase stimulates ternary complex formation at c-fos promoter. Nature 358:414-7

Ginot F, Decaux JF, Cognet M, t. Berbar T, Levrat F, Kahn A, Weber A (1989). Transfection of hepatic genes into adult-rat hepatocytes in primary culture and their tissue-specific expression. European journal of biochemistry 180: 289-294

Goad DL, Rubin J, Wang H, Tashjian AH Jr, Patterson C (1996). Enhanced expression of vascular endothelial growth factor in human SaOS-2 osteoblast-like cells and murine osteoblasts induced by insulin-like growth factor I. Endocrinology 137:2262-8

Gorlach A, Diebold I, Schini-Kerth VB, Berchner-Pfannschmidt U, Roth U, Brandes RP, Kietzmann T, Busse R (2001). Thrombin activates the hypoxia-inducible factor-1 signaling pathway in vascular smooth muscle cells: Role of the p22(phox)-containing NADPH oxidase. Circ Res. 89:47-54

Graham FL., Vandereb AJ (1973). New technique for assay of infectivity of human adenovirus 5 DNA. Virology 52: 456-467

Gregor PD, Sawadogo M, Roeder RG (1990). The adenovirus major late transcription factor USF is a member of the helix-loop-helix group of regulatory proteins and binds to DNA as a dimer. Genes Dev 4:1730-40

Grinberg AV, Kerppola T (2003). Both Max and TFE3 cooperate with Smad proteins to bind the plasminogen activator inhibitor-1 promoter, but they have opposite effects on transcriptional activity. J Biol Chem. 278:11227-36

Gruber F, Hufnagl P, Hofer-Warbinek R, Schmid JA, Breuss JM, Huber-Beckmann R, Lucerna M, Papac N, Harant H, Lindley I, de Martin R, Binder BR (2003). Direct binding of Nur77/NAK-1 to the plasminogen activator inhibitor 1 (PAI-1) promoter regulates TNF alpha -induced PAI-1 expression. Blood 101:3042-8

Gu YZ, Moran SM, Hogenesch JB, Wartman L, Bradfield CA (1998). Molecular characterization and chromosomal localization of a third alpha-class hypoxia inducible factor subunit, HIF3alpha. Gene Expr. $7: 205-13$

Guo S, Rena G, Cichy S, He X, Cohen P, Unterman T (1999). Phosphorylation of serine 256 by protein kinase B disrupts transactivation by FKHR and mediates effects of insulin on insulin-like growth factorbinding protein-1 promoter activity through a conserved insulin response sequence. $\mathrm{J}$ Biol Chem. 274:17184-92

Gustafsson H, Tamm C, Forsby A (2004). Signalling pathways for insulin-like growth factor type 1mediated expression of uncoupling protein 3. J Neurochem. 88:462-8 
Hall RK, Yamasaki T, Kucera T, Waltner-Law M, O'Brien R, Granner DK (2000). Regulation of phosphoenolpyruvate carboxykinase and insulin-like growth factor-binding protein-1 gene expression by insulin. The role of winged helix/forkhead proteins. J Biol Chem. 275:30169-75

Hamsten A, de Faire U, Walldius G, Dahlen G, Szamosi A, Landou C, Blomback M, Wiman B (1987). Plasminogen activator inhibitor in plasma: risk factor for recurrent myocardial infarction. Lancet 2:3-9

Hanahan D (1983). Studies on transformation of E. coli with plasmids. J Mol Biol 166, 557-580

Harris VK, Coticchia CM, List HJ, Wellstein A, Riegel AT (2000). Mitogen-induced expression of the fibroblast growth factor-binding protein is transcriptionally repressed through a non-canonical E-box element. J Biol Chem. 275:28539-48

Hazel SJ, Nordqvist AC, Hall K, Nilsson M, Schalling M (1998). Differential expression of IGF-I and IGF-binding protein-1 and -2 in periportal and perivenous zones of rat liver. J Endocrinol:157:285-94

Heaton JH, Nebes VL, O'Dell LG, Morris SM Jr, Gelehrter TD (1989). Glucocorticoid and cyclic nucleotide regulation of plasminogen activator and plasminogen activator-inhibitor gene expression in primary cultures of rat hepatocytes. Mol Endocrinol. 3:185-92

Henrion AA, Martinez A, Mattei MG, Kahn A, Raymondjean M (1995). Structure, sequence, and chromosomal location of the gene for USF2 transcription factors in mouse. Genomics 25:36-43

Henrion AA, Vaulont S, Raymondjean M, Kahn A (1996). Mouse USF1 gene cloning: comparative organization within the c-myc gene family. Mamm Genome 7:803-9

Hirota K, Fukuda R, Takabuchi S, Kizaka-Kondoh S, Adachi T, Fukuda K, Semenza GL (2004). Induction of hypoxia-inducible factor 1 activity by muscarinic acetylcholine receptor signaling. $\mathrm{J}$ Biol Chem. 279:41521-8

Hogenesch JB, Gu YZ, Jain S, Bradfield CA (1998). The basic-helix-loop-helix-PAS orphan MOP3 forms transcriptionally active complexes with circadian and hypoxia factors. Proc Natl Acad Sci USA 95:5474-9

Hou B, Eren M, Painter CA, Covington JW, Dixon JD, Schoenhard JA, Vaughan DE (2004). Tumor necrosis factor alpha activates the human plasminogen activator inhibitor-1 gene through a distal nuclear factor kappaB site. J Biol Chem. 279:18127-36

Hu Q, Klippel A, Muslin AJ, Fantl WJ, Williams LT (1995). Ras-dependent induction of cellular responses by constitutively active phosphatidylinositol-3 kinase. Science 268:100-2

Hua X, Liu X, Ansari DO, Lodish HF (1998). Synergistic cooperation of TFE3 and smad proteins in TGF-beta-induced transcription of the plasminogen activator inhibitor-1 gene. Genes Dev. 12:3084-95

Huang LE, Arany Z, Livingston DM, Bunn HF (1996). Activation of hypoxia-inducible transcription factor depends primarily upon redox-sensitive stabilization of its alpha subunit. $\mathrm{J}$ Biol Chem. 271:32253-9

Jensen DE, Rich CB, Terpstra AJ, Farmer SR, Foster JA (1995). Transcriptional regulation of the elastin gene by insulin-like growth factor-I involves disruption of Sp1 binding. Evidence for the role of Rb in mediating Sp1 binding in aortic smooth muscle cells. J Biol Chem. 270:6555-63

Jiang B, Mendelson CR (2003). USF1 and USF2 mediate inhibition of human trophoblast differentiation and CYP19 gene expression by Mash-2 and hypoxia. Mol Cell Biol. 23:6117-28

Jiang BH, Jiang G, Zheng JZ, Lu Z, Hunter T, Vogt PK (2001). Phosphatidylinositol 3-kinase signaling controls levels of hypoxia-inducible factor 1. Cell Growth Differ. 12:363-9

Jiang BH, Rue E, Wang GL, Roe R, Semenza GL (1996). Dimerization, DNA binding, and transactivation properties of hypoxia-inducible factor 1. J Biol Chem. 271:17771-8

Jungermann K, Keitzmann T (1996). Zonation of parenchymal and nonparenchymal metabolism in liver. Annual Review of Nutrition 16:179-203 
Jungermann K, Kietzmann T. (2000). Oxygen: modulator of metabolic zonation and disease of the liver. Hepatology 31:255-60

Kallio PJ, Pongratz I, Gradin K, McGuire J, Poellinger L (1997). Activation of hypoxia-inducible factor 1alpha: posttranscriptional regulation and conformational change by recruitment of the Arnt transcription factor. Proc Natl Acad Sci USA 94:5667-72

Kellerer M, Lammers R, Haring HU (1999). Insulin signal transduction: possible mechanisms for insulin resistance. Exp Clin Endocrinol Diabetes 107:97-106

Kietzmann T, Roth U, Jungermann K (1999). Induction of the plasminogen activator inhibitor-1 gene expression by mild hypoxia via a hypoxia response element binding the hypoxia-inducible factor- 1 in rat hepatocytes. Blood 94:4177-85

Kietzmann T, Samoylenko A, Roth U, Jungermann K (2003). Hypoxia-inducible factor-1 and hypoxia response elements mediate the induction of plasminogen activator inhibitor-1 gene expression by insulin in primary rat hepatocytes. Blood 01:907-14

Kietzmann T, Jungermann K, Gorlach A (2003). Regulation of the hypoxia-dependent plasminogen activator inhibitor 1 expression by MAP kinases. Thromb Haemost. 89:666-73

Kohler HP, Grant PJ (2000). Plasminogen-activator inhibitor type 1 and coronary artery disease. N Engl J Med. 342:1792-801

Kooistra T, Bosma PJ, Tons HA, van den Berg AP, Meyer P, Princen HM (1989). Plasminogen activator inhibitor 1: biosynthesis and mRNA level are increased by insulin in cultured human hepatocytes. Thromb Haemost. 62:723-8

Kops GJ, de Ruiter ND, De Vries-Smits AM, Powell DR, Bos JL, Burgering BM (1999). Direct control of the Forkhead transcription factor AFX by protein kinase B. Nature 398:630-4

Klemm DJ, Roesler WJ, Boras T, Colton LA, Felder K, Reusch JE (1998). Insulin stimulates cAMPresponse element binding protein activity in HepG2 and 3T3-L1 cell lines. J Biol Chem. 273:917-23

Knudsen H, Olesen T, Riccio A, Ungaro P, Christensen L, Andreasen PA (1994). A common response element mediates differential effects of phorbol esters and forskolin on type-1 plasminogen activator inhibitor gene expression in human breast carcinoma cells. Eur J Biochem. 220:63-74

Krones A, Jungermann K, Kietzmann T (2001). Cross-talk between the signals hypoxia and glucose at the glucose response element of the L-type pyruvate kinase gene. Endocrinology 142:2707-18

Kuhne MR, Zhao Z, Rowles J, Lavan BE, Shen SH, Fischer EH, Lienhard GE (1994)

Dephosphorylation of insulin receptor substrate 1 by the tyrosine phosphatase PTP2C. J Biol

Chem. 269: 15833-15837

Kvietikova I, Wenger RH, Marti HH, Gassmann M (1995). The transcription factors ATF-1 and CREB-1 bind constitutively to the hypoxia-inducible factor-1 (HIF-1) DNA recognition site. Nucleic Acids Res. 23:4542-50

Lando D, Peet DJ, Gorman JJ, Whelan DA, Whitelaw ML, Bruick RK (2002). FIH-1 is an asparaginyl hydroxylase enzyme that regulates the transcriptional activity of hypoxia-inducible factor. Genes Dev. 16:1466-71

Laughner E, Taghavi P, Chiles K, Mahon PC, Semenza GL (2001). HER2 (neu) signaling increases the rate of hypoxia-inducible factor 1alpha (HIF-1alpha) synthesis: novel mechanism for HIF-1-mediated vascular endothelial growth factor expression. Mol Cell Biol. 21:3995-4004

Lawlor MA and Alessi DR (2001) PKB/Akt : a key mediator of cell proliferation, survival and insulin responses? J Cell Sci 114: 2903-2910

Lee MH, Vosburgh E, Anderson K, McDonagh J (1993). Deficiency of plasma plasminogen activator inhibitor 1 results in hyperfibrinolytic bleeding. Blood 81:2357-62 
Lefrancois-Martinez AM, Martinez A, Antoine B, Raymondjean M, Kahn A (1995). Upstream stimulatory factor proteins are major components of the glucose response complex of the L-type pyruvate kinase gene promoter. J Biol Chem. 270:2640-3

Li T, Chen YH, Liu TJ, Jia J, Hampson S, Shan YX, Kibler D, Wang PH (2003). Using DNA microarray to identify Sp1 as a transcriptional regulatory element of insulin-like growth factor 1 in cardiac muscle cells. Circ Res. 93:1202-9

Lijnen HR, Collen D (1988). Mechanisms of plasminogen activation by mammalian plasminogen activators. Enzyme 40:90-6

Lin Q, Luo X, Sawadogo M (1994). Archaic structure of the gene encoding transcription factor USF. J Biol Chem. 269:23894-903

Littlewood TD, Evan GI (1995). Transcription factors 2: helix-loop-helix. Protein Profile:621-702

Liu Y, Cox SR, Morita T, Kourembanas S (1995). Hypoxia regulates vascular endothelial growth factor gene expression in endothelial cells. Identification of a 5' enhancer. Circ Res. 77:638-43

Loskutoff DJ, Sawdey M, Mimuro J (1989). Type 1 plasminogen activator inhibitor. Prog Hemost Thromb. 9:87-115

Luo X, Sawadogo M (1996). Functional domains of the transcription factor USF2: atypical nuclear localization signals and context-dependent transcriptional activation domains. Mol Cell Biol. 16:1367-75

Luo X, Sawadogo M (1996). Antiproliferative properties of the USF family of helix-loop-helix transcription factors. Proc Natl Acad Sci USA 93:1308-13

Maniatis T, Goodbourn S, Fischer JA (1987). Regulation of inducible and tissue-specific gene expression. Science 236:1237-45

Marte BM, Rodriguez-Viciana P, Wennstrom S, Warne PH, Downward J (1997).R-Ras can activate the phosphoinositide 3-kinase but not the MAP kinase arm of the Ras effector pathways.Curr Biol.7:63-70

Maxwell PH, Wiesener MS, Chang GW, Clifford SC, Vaux EC, Cockman ME, Wykoff CC, Pugh CW, Maher ER, Ratcliffe PJ (1999). The tumour suppressor protein VHL targets hypoxia-inducible factors for oxygen-dependent proteolysis. Nature 399:271-5

Medema RH, Kops GJ, Bos JL, Burgering BM (2000). AFX-like Forkhead transcription factors mediate cell-cycle regulation by Ras and PKB through p27kip1. Nature 404:782-7

Medina-Acosta, E., and G. Cross. (1993). Rapid isolation of DNA from trypanosomatid protozoa using a simple 'mini-prep' procedure. Mol Biochem Parasitol 59:327-30

Mehrhof FB, Muller FU, Bergmann MW, Li P, Wang Y, Schmitz W, Dietz R, von Harsdorf R (2001). In cardiomyocyte hypoxia, insulin-like growth factor-I-induced antiapoptotic signaling requires phosphatidylinositol-3-OH-kinase-dependent and mitogen-activated protein kinase-dependent activation of the transcription factor cAMP response element-binding protein. Circulation. 104:2088-94

Millinder S., Clack B. Chemistry 555 Laboratory Manual. pp 6,10,13. Stephen F. Austin State University Biotechnology Division, TX

Motojima M, Ando T, Yoshioka T (2000). Sp1-like activity mediates angiotensin-II-induced plasminogen-activator inhibitor type-1 (PAI-1) gene expression in mesangial cells. Biochem J. 349:435-41

Mullis KB, Faloona FA (1987). Specific synthesis of DNA in vitro via a polymerase-catalyzed chain reaction. Methods Enzymol 155:335-350

Murre C, McCaw PS, Vaessin H, Caudy M, Jan LY, Jan YN, Cabrera CV, Buskin JN, Hauschka SD, Lassar AB (1989). Interactions between heterologous helix-loop-helix proteins generate complexes that bind specifically to a common DNA sequence. Cell 58:537-44 
Muscella A, Greco S, Elia MG, Storelli C, Marsigliante S (2003). PKC-zeta is required for angiotensin II-induced activation of ERK and synthesis of C-FOS in MCF-7 cells. J Cell Physiol. 197:61-8

Nakae J, Park BC, Accili D (1999). Insulin stimulates phosphorylation of the forkhead transcription factor FKHR on serine 253 through a Wortmannin-sensitive pathway. J Biol Chem. 274:15982-5

Nar H, Bauer M, Stassen JM, Lang D, Gils A, Declerck PJ (2000). Plasminogen activator inhibitor 1. Structure of the native serpin, comparison to its other conformers and implications for serpin inactivation. J Mol Biol. 297:683-95

O'Brien RM, Bonovich MT, Forest CD, Granner DK (1991). Signal transduction convergence: phorbol esters and insulin inhibit phosphoenolpyruvate carboxykinase gene transcription through the same 10base-pair sequence. Proc Natl Acad Sci USA 88:6580-4

O’Brien RM, Granner DK (1991). Regulation of gene expression by insulin. Biochem J 278:609-19

O'Brien RM, Granner DK (1996). Regulation of gene expression by insulin. Physiological Reviews 76:1109-60

O'Brien RM, Granner DK (2000). in Diabetes mellitus. A fundamental and clinical text (LeRoith, D., Taylor, S. I. and Olefsky, J. M., eds), pp.291-305, Lippincott-Raven, Philadelphia

O' Brien RM, Lucas PC, Forest CD, Magnuson MA and Granner DK (1990). Identification of a sequence in the PEPCK gene that mediates a negative effect of insulin on transcription. Science 249:533-537

O'Brien RM, Streeper RS, Ayala JE, Stadelmaier BT, Hornbuckle LA (2001). Insulin-regulated gene expression. Biochem Soc Trans. 29:552-8

Olman MA, Hagood JS, Simmons WL, Fuller GM, Vinson C, White KE (1999). Fibrin fragment induction of plasminogen activator inhibitor transcription is mediated by activator protein-1 through a highly conserved element. Blood 94(6):2029-38

Ortiz L, Aza-Blanc P, Zannini M, Cato ACB and Santisteban P (1999). The interaction between the forkhead thyroid transcription factor TTF-2 and the constitutive factor CTF/NF-1 is required for efficient hormonal regulation of the thyroperoxidase gene transcription. J Biol Chem 274:15213-21

Ouyang L, Jacob KK and Stanley FM (1996). GABP mediates insulin-increased prolactin gene transcription. J Biol Chem 271:10425-8

Padayatty SJ, Orme S, Zenobi PD, Stickland MH, Belchetz PE, Grant PJ (1993). The effects of insulin-like growth factor-1 on plasminogen activator inhibitor-1 synthesis and secretion: results from in vitro and in vivo studies. Thromb Haemost. 70:1009-13

Parker BA., Stark GR (1979). Regulation of simian-virus 40 transcription - sensitive analysis of the RNA species present early in infections by virus or viral-DNA.Journal of Virology 31:360-369

Pasco DS., Fagan JB (1989). Efficient DNA-mediated gene-transfer into primary cultures of adult-rat hepatocytes. Journal of Molecular and Cellular Biology 8: 535-541.

Pessara U, Koch $N$ (1990). Tumor necrosis factor alpha regulates expression of the major histocompatibility complex class II-associated invariant chain by binding of an NF-kappa B-like factor to a promoter element. Mol Cell Biol. 10:4146-54

Pronk GJ, Bos JL (1994). The role of p21ras in receptor tyrosine kinase signalling. Biochim Biophys Acta 1198:131-47

Qyang Y, Luo X, Lu T, Ismail PM, Krylov D, Vinson C, Sawadogo M (1999). Cell-type-dependent activity of the ubiquitous transcription factor USF in cellular proliferation and transcriptional activation. $\mathrm{Mol}$ Cell Biol. 19:1508-17 
Reilly CF, McFall RC (1991). Platelet-derived growth factor and transforming growth factor-beta regulate plasminogen activator inhibitor-1 synthesis in vascular smooth muscle cells. J Biol Chem. 266:9419-27

Reisman D, Rotter V (1993). The helix-loop-helix containing transcription factor USF binds to and transactivates the promoter of the p53 tumor suppressor gene.Nucleic Acids Res 21:345-50

Rena G, Guo S, Cichy SC, Unterman TG, Cohen P (1999). Phosphorylation of the transcription factor forkhead family member FKHR by protein kinase B. J Biol Chem. 274:17179-83

Richard DE, Berra E, Gothie E, Roux D, Pouyssegur J (1999). p42/p44 mitogen-activated protein kinases phosphorylate hypoxia-inducible factor 1alpha (HIF-1alpha) and enhance the transcriptional activity of HIF-1. J Biol Chem. 274:32631-7

Rippe RA., Brenner DA, Leffert HL (1990). DNA-mediated gene-transfer into adult-rat hepatocytes in primary culture. Molecular and Cellular Biology 10: 689-695

Rodriguez-Viciana P, Warne PH, Dhand R, Vanhaesebroeck B, Gout I, Fry MJ, Waterfield MD, Downward J (1994). Phosphatidylinositol-3-OH kinase as a direct target of Ras. Nature 370:527-32

Rodriguez-Viciana P, Warne PH, Vanhaesebroeck B, Waterfield MD, Downward J (1996). Activation of phosphoinositide 3-kinase by interaction with Ras and by point mutation. EMBO J. 15:2442-51

Roy AL, Meisterernst M, Pognonec P, Roeder RG (1991). Cooperative interaction of an initiatorbinding transcription initiation factor and the helix-loop-helix activator USF. Nature. 354:245-8

Sambrook J, Fritsch EF and Maniatis T (1989). Molecular cloning. A laboratory manual. 2- nd edition Cold Spring Harbor Laboratory

Samoylenko A, Roth U, Jungermann K, Kietzmann T (2001). The upstream stimulatory factor-2a inhibits plasminogen activator inhibitor- 1 gene expression by binding to a promoter element adjacent to the hypoxia-inducible factor-1 binding site. Blood 97:2657-66

Sandau KB, Faus HG, Brune B (2000). Induction of hypoxia-inducible-factor 1 by nitric oxide is mediated via the PI 3K pathway. Biochem Biophys Res Commun. 278:263-7

Sanger F, Nicklen S, Coulson AR (1977). DNA sequencing with chain-terminating inhibitors. Proc Natl Acad Sci USA 74:5463-7

Sato M, Tanaka T, Maemura K, Uchiyama T, Sato H, Maeno T, Suga T, Iso T, Ohyama $Y$, Arai M, Tamura J, Sakamoto H, Nagai R, Kurabayashi M (2004). The PAl-1 gene as a direct target of endothelial PAS domain protein-1 in adenocarcinoma A549 cells. Am J Respir Cell Mol Biol. 31:209-15

Sawadogo M (1988). Multiple forms of the human gene-specific transcription factor USF. II. DNA binding properties and transcriptional activity of the purified HeLa USF. J Biol Chem. 263:11994-2001

Sawadogo M, Roeder RG (1985). Interaction of a gene-specific transcription factor with the adenovirus major late promoter upstream of the TATA box region. Cell 43:165-75

Schmidt EK, Fichelson S, Feller SM (2004). PI3 kinase is important for Ras, MEK and Erk activation of Epo-stimulated human erythroid progenitors. BMC Biol. 2:7

Schmoll D, Walker KS, Alessi DR, Grempler R, Burchell A, Guo S, Walther R, Unterman TG (2000). Regulation of glucose-6-phosphatase gene expression by protein kinase Balpha and the forkhead transcription factor FKHR. Evidence for insulin response unit-dependent and -independent effects of insulin on promoter activity. J Biol Chem.275:36324-33

Schneider DJ, Sobel BE (1991). Augmentation of synthesis of plasminogen activator inhibitor type 1 by insulin and insulin-like growth factor type I: implications for vascular disease in hyperinsulinemic states. Proc Natl Acad Sci U S A. 88:9959-63 
Schoenhard JA, Smith LH, Painter CA, Eren M, Johnson CH, Vaughan DE (2003). Regulation of the PAI-1 promoter by circadian clock components: differential activation by BMAL1 and BMAL2. J Mol Cell Cardiol. 35:473-81

Scholtz B, Lamb K, Rosfjord E, Kingsley M, Rizzino A (1996). Appearance of nuclear protease activity after embryonal carcinoma cells undergo differentiation. Dev Biol. 173:420-7

Seely BL, Staubs PA, Reichart DR, Berhanu P, Milarski KL, Saltiel AR, Kusari J, Olefsky JM (1996). Protein tyrosine phosphatase 1B interacts with the activated insulin receptor. Diabetes 45:1379-85

Sirito M, Lin Q, Maity T, Sawadogo M (1994). Ubiquitous expression of the 43- and 44-kDa forms of transcription factor USF in mammalian cells. Nucleic Acids Res. 22:427-33

Sirito M, Lin Q, Deng JM, Behringer RR, Sawadogo M (1998). Overlapping roles and asymmetrical cross-regulation of the USF proteins in mice. Proc Natl Acad Sci USA 95:3758-63

Skolnik EY, Batzer A, Li N, Lee CH, Lowenstein E, Mohammadi M, Margolis B, Schlessinger J (1993). The function of GRB2 in linking the insulin receptor to Ras signaling pathways. Science 260(5116):1953-5

Skolnik EY, Lee CH, Batzer A, Vicentini LM, Zhou M, Daly R, Myers MJ Jr, Backer JM, Ullrich A, White MF, et al. (1993). The SH2/SH3 domain-containing protein GRB2 interacts with tyrosinephosphorylated IRS1 and Shc: implications for insulin control of ras signalling. EMBO J 12:1929-36

Smih F, Rouet P, Lucas S, Mairal A, Sengenes C, Lafontan M, Vaulont S, Casado M, Langin D (2002). Transcriptional regulation of adipocyte hormone-sensitive lipase by glucose. Diabetes.51:293-300

Song CZ, Siok TE, Gelehrter TD (1998). Smad4/DPC4 and Smad3 mediate transforming growth factorbeta (TGF-beta) signaling through direct binding to a novel TGF-beta-responsive element in the human plasminogen activator inhibitor-1 promoter. J Biol Chem. 273:29287-90

Streeper RS , Chapman SC, Ayala JE, Svitek CA, Goldmann JK, Cave A and O'Brien RM (1998). A phorbol ester-insensitive AP-1 motif mediates the stimulatory effect of insulin on rat malic enzyme gene transcription. Mol Endocrinol 12:1778-91

Suwanichkul A, Cubbage ML, Powell DR (1990). The promoter of the human gene for insulin-like growth factor binding protein-1. Basal promoter activity in HEP G2 cells depends upon liver factor B1. J Biol Chem. 265:21185-93

Suzuki M, Akimoto K, Hattori Y (2002). Glucose upregulates plasminogen activator inhibitor-1 gene expression in vascular smooth muscle cells. Life Sci. 72(1):59-66

Taha C, Klip A. (1999). The insulin signaling pathway. J Membr Biol. 169:1-12

Takaishi H, Konishi H, Matsuzaki H, Ono Y, Shirai Y, Saito N, Kitamura T, Ogawa W, Kasuga M, Kikkawa U, Nishizuka Y (1999). Regulation of nuclear translocation of forkhead transcription factor AFX by protein kinase B. Proc Natl Acad Sci USA 96:11836-41

Takahashi Y, Nakayama K, Itoh S, Kamataki T (1997). Upstream stimulatory factor 1 (USF1) suppresses induction of CYP1A1 mRNA by 3-methylcholanthrene (MC) in HepG2 cells. Biochem Biophys Res Commun. 240:293-7

Tang ED, Nunez G, Barr FG, Guan KL (1999). Negative regulation of the forkhead transcription factor FKHR by Akt. J Biol Chem. 274:16741-6

Thiebaud D, Ng KW, Findlay DM, Harker M, Martin TJ (1990). Insulin-like growth factor 1 regulates mRNA levels of osteonectin and pro-alpha $1(\mathrm{I})$-collagen in clonal preosteoblastic calvarial cells. $\mathrm{J}$ Bone Miner Res. 5:761-7

Thompson, M J, Roe, M W, Malik, R K, and Blackshear, P J (1994). Insulin and other growth factors induce binding of the ternary complex and a novel protein complex to the c-fos serum response element. J Biol Chem 269:21127-35 
Tian H, McKnight SL, Russell DW (1997). Endothelial PAS domain protein 1 (EPAS1), a transcription factor selectively expressed in endothelial cells. Genes Dev. 11:72-82

Toker A, Newton AC (2000). Cellular signaling: pivoting around PDK-1. Cell 13;103:185-8

Towbin H, Staehelin T, Gordon J (1979). Electrophoretic transfer of proteins from polyacrylamide gels to nitrocellulose sheets: procedure and some applications. Proc Natl Acad Sci USA 76:4350-4

Tomizawa M, Kumar A, Perrot V, Nakae J, Accili D, Rechler MM (2000). Insulin inhibits the activation of transcription by a C-terminal fragment of the forkhead transcription factor FKHR. A mechanism for insulin inhibition of insulin-like growth factor-binding protein-1 transcription. J Biol Chem. 275:7289-95

Treins C, Giorgetti-Peraldi S, Murdaca J, Semenza GL, Van Obberghen E (2002). Insulin stimulates hypoxia-inducible factor 1 through a phosphatidylinositol 3-kinase/target of rapamycin-dependent signaling pathway. J Biol Chem. 277:27975-81

Van Der Heide LP, Hoekman MF, Smidt MP (2004). The ins and outs of FoxO shuttling: mechanisms of FoxO translocation and transcriptional regulation. Biochem J. 380:297-309

Vanhaesebroeck B, Stein RC, Waterfield MD (1996). The study of phosphoinositide 3-kinase function. Cancer Surv. 27:249-70

Van Obberghen E, Ksauga M, Le Cam A, Hedo JA, Itin A, Harrison LC (1981). Biosynthetic labeling of insulin receptor: studies of subunits in cultured human IM-9 lymphocytes. Proc Natl Acad Sci U S A 78:1052-6

Viollet B, Lefrancois-Martinez AM, Henrion A, Kahn A, Raymondjean M, Martinez A (1996). Immunochemical characterization and transacting properties of upstream stimulatory factor isoforms. $J$ Biol Chem. 271:1405-15

Virolle T, Coraux C, Ferrigno O, Cailleteau L, Ortonne JP, Pognonec P, Aberdam D (2003). Binding of USF to a non-canonical E-box following stress results in a cell-specific derepression of the lama3 gene. Nucleic Acids Res. 30:1789-98

Vollenweider P, Clodi M, Martin SS, Imamura T, Kavanaugh WM, Olefsky JM (1999). An SH2 domain-containing 5' inositolphosphatase inhibits insulin-induced GLUT4 translocation and growth factorinduced actin filament rearrangement. Mol Cell Biol. 19:1081-91

Vulin AI, Stanley FM (2003). A Forkhead/winged helix-related transcription factor mediates insulinincreased plasminogen activator inhibitor-1 gene transcription. J Biol Chem. 277:20169-76

Wang GL, Jiang BH, Rue EA, Semenza GL (1995). Hypoxia-inducible factor 1 is a basic-helix-loophelix-PAS heterodimer regulated by cellular O2 tension. Proc Natl Acad Sci U S A. 92:5510-4

Wang GL, Semenza GL (1993). General involvement of hypoxia-inducible factor 1 in transcriptional response to hypoxia. Proc Natl Acad Sci U S A. 90:4304-8

Wang D, Sul HS (1995). Upstream stimulatory factors bind to insulin response sequence of the fatty acid synthase promoter. USF1 is regulated. J Biol Chem. 270:28716-22

Wang D, Sul HS (1997). Upstream stimulatory factor binding to the E-box at -65 is required for insulin regulation of the fatty acid synthase promoter. J Biol Chem. 272:26367-74

Warren RS, Yuan H, Matli MR, Ferrara N, Donner DB (1996). Induction of vascular endothelial growth factor by insulin-like growth factor 1 in colorectal carcinoma. J Biol Chem. 271:29483-8

Weigel D, Jurgens G, Kuttner F, Seifert E, Jackle H (1989). The homeotic gene fork head encodes a nuclear protein and is expressed in the terminal regions of the Drosophila embryo. Cell 57:645-58

Wenger RH (2002). Cellular adaptation to hypoxia: O2-sensing protein hydroxylases, hypoxia-inducible transcription factors, and O2-regulated gene expression. FASEB J. 16:1151-62 
White MF (1996). The IRS-signalling system in insulin and cytokine action. Philos Trans $R$ Soc Lond $B$ Biol Sci. 29;351:181-9.

White MF (1998). The IRS-signaling system: a network of docking proteins that mediate insulin and cytokine action. Recent Prog Horm Res. 53:119-38

Wiman B, Chmielewska J, Ranby M (1984). Inactivation of tissue plasminogen activator in plasma. Demonstration of a complex with a new rapid inhibitor. J Biol Chem. 259:3644-7

Yan S, Sloane BF (2004). Isolation of a novel USF2 isoform: repressor of cathepsin B expression. Gene 337:199-206.

Zelzer E, Levy Y, Kahana C, Shilo BZ, Rubinstein M, Cohen B (1998). Insulin induces transcription of target genes through the hypoxia-inducible factor HIF-1alpha/ARNT. EMBO J. 17:5085-94

Zhong H, Simons JW (2001). Activation of hypoxia-inducible factor 1 alpha by oxygen independent pathways. Exp Oncol 23:88-96

Zundel W, Schindler C, Haas-Kogan D, Koong A, Kaper F, Chen E, Gottschalk AR, Ryan HE, Johnson RS, Jefferson AB, Stokoe D, Giaccia AJ (2000). Loss of PTEN facilitates HIF-1-mediated gene expression. Genes Dev. 14:391-6 


\section{Thank you....}

Prof. Dr. Thomas Kietzmann, my enthusiastic supervisor being invaluable for me to understand a number of molecular biology matters; who has encouraged me and cared for me during these years and has really patiently tried to teach me some of what he knows not only about the science, but also about the human existence and psychology; and who to my great displeasure adores the Ariel font, black \& white presentations and the Alexander Graham Bell`s invention:;

Prof. Dr. K. Jungermann, who gave me the opportunity to work in his department otherwise this work probably would not have been at all; and who, unfortunately, did not live to see the end of the story;

Prof. Dr. G. Burckhardt, the speaker of GRK 335 for his active support during all these years I was a member of the Graduate College 335;

Daniela, Qing, Goutham, Tolja and Jacek, cool co-workers, for the friendly cooperation and for the nice attitude towards me;

Ulrike, Doreen and Katia, rulers of the lab, possessing the secret knowledge how to manage everything and everybody everywhere; my priceless teachers of German language and coffee co-drinkers who always readily shared with me their experience and knowledge;

All staff of the Department Biochemistry-I for the good collaboration and friendly working atmosphere;

Krassimir Slanchev, Frank Rhode, Nina Dobriczikowski, Petra Bauer, Bettina Scholtka and Frank Stümpel for helping me to stand on my own feet at the beginning of my stay in Germany;

Milica Stojakovich for being what she is and for many shared evenings of discussion about "Manolo" shoes, "Quelle" quality, some private staff of course and for the few lessons in Serbian;

All friends in Goettingen, especially Srebrena and Doroteya for the support, for many unforgettable evenings and discussions and for making my stay in Goettingen much easier and nicer;

My parents, who always made me aim higher than I would have and who still ask me what I will do with my life when I grow up;

Kaloian for his loving attitude and patience, for many fruitful (sometimes hurtful) discussions about Life, Universe, Science and Everything, for the Music and for the help during the preparation of this thesis especially with the language revision of it; Обичам те, Газу! 


\section{Curriculum Vitae}

\section{Personal Details}

Name

Year of birth

Nationality
Elitsa Yosifova Dimova

1973

Bulgarian

\section{Education and work history}

September 1980 - June 1988 130th Primary School - Sofia, Bulgaria

September 1988 - June 1992 Professional School for Industrial Chemistry and Biotechnology "Prof. Dr. As. Zlatarov" - Sofia, Bulgaria;

Specialization in Biotechnology

October 1992 - July 1997

M. Sc. in Ecology from the Sofia University "St. KI. Ohridski", Faculty of Biology, Department of Ecology and Environmental Protection - Sofia, Bulgaria;

Thesis: "Characteristics of the Microbial Community as a Corrosion Factor in Water-Circulation Cooling Systems"

May 1998 - March 2001

Research assistant in the Laboratory of Chemistry and Biotechnology of Proteins and Enzymes at the Institute of Organic Chemistry, Bulgarian Academy of Sciences - Sofia, Bulgaria;

Project: "Isolation and Characteristics of Keratinase Enzymes from Termophilic Actinomycetes"

April 2001 - November 2001

Postgraduate student at the Institute for Biochemistry I - GeorgAugust University - Goettingen, Germany;

Project: "Cloning, Sequencing and Characterization of the Enteroglucagon-37 Receptor"

December 2001 - May 2005

Postgraduate student at the Institute for Biochemistry I - GeorgAugust University - Goettingen, Germany;

preparation of the present Ph. D. thesis: "Transcriptional Regulation of human Plasminogen Activator Inhibitor-1 Gene Expression by Insulin-like Growth Factor-1, Insulin and Upstream Stimulatory Factor-2";

Member of the DFG postgraduate program No. 335 "Clinical, Cellular and Molecular Biology of Internal Organs" 